Review

\title{
Calcium Orthophosphates in Nature, Biology and Medicine
}

\author{
Sergey V. Dorozhkin \\ Kudrinskaja sq. 1-155, Moscow 123242, Russia; E-Mail: sedorozhkin@yandex.ru; \\ Tel. +7-499-255-4460
}

Received: 24 February 2009; in revised form: 9 April 2009 / Accepted: 20 April 2009 /

Published: 20 April 2009

\begin{abstract}
The present overview is intended to point the readers' attention to the important subject of calcium orthophosphates. These materials are of the special significance because they represent the inorganic part of major normal (bones, teeth and dear antlers) and pathological (i.e. those appearing due to various diseases) calcified tissues of mammals. Due to a great chemical similarity with the biological calcified tissues, many calcium orthophosphates possess remarkable biocompatibility and bioactivity. Materials scientists use this property extensively to construct artificial bone grafts that are either entirely made of or only surface-coated with the biologically relevant calcium orthophosphates. For example, self-setting hydraulic cements made of calcium orthophosphates are helpful in bone repair, while titanium substitutes covered by a surface layer of calcium orthophosphates are used for hip joint endoprostheses and as tooth substitutes. Porous scaffolds made of calcium orthophosphates are very promising tools for tissue engineering applications. In addition, technical grade calcium orthophosphates are very popular mineral fertilizers. Thus ere calcium orthophosphates are of great significance for humankind and, in this paper, an overview on the current knowledge on this subject is provided.
\end{abstract}

Keywords: Calcium orthophosphates, antlers, biological apatite, biomaterials, bioceramics, biomimetics, biomineralization, bone grafts, bones, calcified tissues, fluorapatite, hydroxyapatite, materials chemistry, pathological calcification, teeth, tissue engineering.

\section{Introduction}

Calcium orthophosphates are chemical compounds of special interest in many interdisciplinary fields of science, including geology, chemistry, biology and medicine. According to the literature, the 
initial attempts to establish their chemical composition were performed by J. Berzelius in the middle of the $19^{\text {th }}$ century [1]. However, the first systematic studies were performed by F. K. Cameron and coworkers [2-5] and H. Bassett [6-9] at the beginning of the $20^{\text {th }}$ century. Both researchers already worked with individual chemical compounds of various calcium orthophosphates, which had been called apatites [10] until then [11].

By definition, all calcium orthophosphates consist of three major chemical elements: calcium (oxidation state +2 ), phosphorus (oxidation state +5 ) and oxygen (reduction state -2 ), as a part of orthophosphate anions. These three chemical elements are present in abundance on the surface of our planet: oxygen is the most widespread chemical element of the Earth's surface ( 47 mass \%), calcium occupies the fifth place $(\sim 3.3-3.4$ mass $\%)$ and phosphorus $(\sim 0.08-0.12$ mass $\%)$ is among the first twenty chemical elements most widespread on our planet [12]. In addition, the chemical composition of many calcium orthophosphates includes hydrogen, either as part of an acidic orthophosphate anion (for example, $\mathrm{HPO}_{4}{ }^{2-}$ or $\mathrm{H}_{2} \mathrm{PO}_{4}{ }^{-}$), hydroxide (for example, $\mathrm{Ca}_{10}\left(\mathrm{PO}_{4}\right)_{6}(\mathrm{OH})_{2}$ ) and/or incorporated water (for example, $\mathrm{CaHPO}_{4} \cdot 2 \mathrm{H}_{2} \mathrm{O}$ ). Diverse combinations of $\mathrm{CaO}$ and $\mathrm{P}_{2} \mathrm{O}_{5}$ (both in the presence of water and without it) provide a large variety of calcium phosphates, which are distinguished by the type of the phosphate anion: ortho- $\left(\mathrm{PO}_{4}{ }^{3-}\right)$, meta- $\left(\mathrm{PO}_{3}{ }^{-}\right)$, pyro- $\left(\mathrm{P}_{2} \mathrm{O}_{7}{ }^{4-}\right)$ and poly- $\left(\left(\mathrm{PO}_{3}\right)_{\mathrm{n}}{ }^{\mathrm{n}}\right)$. In the case of multi-charged anions (orthophosphates and pyrophosphates), calcium phosphates are also differentiated by the number of hydrogen ions attached to the anion. Examples include mono$\left(\mathrm{Ca}\left(\mathrm{H}_{2} \mathrm{PO}_{4}\right)_{2}\right)$, di- $\left(\mathrm{CaHPO}_{4}\right)$, tri- $\left(\mathrm{Ca}_{3}\left(\mathrm{PO}_{4}\right)_{2}\right)$ and tetra- $\left(\mathrm{Ca}_{2} \mathrm{P}_{2} \mathrm{O}_{7}\right)$ calcium phosphates [13-15]. However, only the various calcium orthophosphates will be reviewed in this paper.

The atomic arrangement of calcium orthophosphates is built up around a network of orthophosphate $\left(\mathrm{PO}_{4}\right)$ groups, which provides stability to the entire structure. The majority of calcium orthophosphates are sparingly soluble in water and insoluble in alkaline solutions, but all of them are easily soluble in acids. All chemically pure calcium orthophosphates are white colored crystals of moderate hardness, whereas natural calcium orthophosphates minerals are always colored due to the presence of different impurities, the most widespread of which are ions of Fe, Mn and rare earth elements [16,17]. Biologically formed calcium orthophosphates are the major component of all mammalian calcified tissues [8], while the natural ones are the major raw materials used to produce phosphorus-containing fertilizers [19-22].

\section{Geological and Biological Ooccurrence of Calcium Orthophosphates}

Calcium orthophosphates are abundant in both nature and living organisms. Geologically, natural calcium orthophosphates are found in different regions, mostly as deposits of apatites (whch belong to the igneous rocks), mainly as natural fluorapatite (FA, chemical formula $\mathrm{Ca}_{10}\left(\mathrm{PO}_{4}\right)_{6} \mathrm{~F}_{2}$ ) or phosphorites (a sedimentary rock) $[20,23]$. Some types of sedimentary rocks can be formed by weathering of igneous rocks into smaller particles. Other types of sedimentary rocks can be composed of minerals precipitated from the dissolution products of igneous rocks or minerals produced by biomineralization. Thus, due to a sedimentary origin, both a general appearance and a chemical composition of natural phosphorites vary a lot. It is a common practice to consider francolite (or carbonatehydroxyfluorapatite regarded as its synonym) as the basic phosphorite mineral [23-28]. A cryptocrystalline (almost amorphous) variety of francolite (partly of a biological origin) is called 
collophane (synonyms: collophanit, collophanita, collophanite, grodnolite, kollophan) [29,30]. It occurs in natural phosphorites predominantly as fossil bones and phosphatized microbial pseudomorphs: phosphatic crusts of chasmolithic biofilms (or microstromatolites) and globular clusters with intra-particular porosities [31,32]. Natural phosphorites (therefore, francolite and collophane as well) occur in various forms, such as nodules, crystals, or masses. Occasionally, other types of natural calcium orthophosphates are found as minerals, for example clinohydroxylapatite [33] and staffelite (synonyms: staffelit, staffelita) belonging to carbonate-rich fluorapatites (chemical formula: $\left.\mathrm{Ca}_{5}\left[(\mathrm{~F}, \mathrm{O})\left(\mathrm{PO}_{4}, \mathrm{CO}_{3}\right)_{3}\right]\right)$ [34], as well as $\mathrm{CaHPO}_{4} \cdot 2 \mathrm{H}_{2} \mathrm{O}$ [35]. Furthermore, calcium orthophosphates have been found in meteorite stones [36]. The world deposits of natural calcium orthophosphates are estimated to exceed 150 billion tons, of which approximately $85 \%$ are phosphorites and the remaining $\sim 15 \%$ are apatites [23].

Natural calcium orthophosphates occur in most geological environments, usually as accessory minerals $(<5 \%)$. Concentrations sufficient for economic use $(>15 \%)$ are also available. The largest world deposits of natural apatites are located in Russia (the Khibiny and Kovdor massifs, Kola peninsula [37]), Brazil and Zambia, while the largest world deposits of natural phosphorites are located in Morocco, Russia, Kazakhstan, USA (Florida, Tennessee), China and Australia, as well as in the oceans [19-23]. Most of natural calcium orthophosphates occur as small polycrystalline structures (spherulitic clusters). Larger crystals are rare [24]. They usually have the crystal structure of apatites (hexagonal system, space group $P 6_{3} / \mathrm{m}$ ). Giant crystals including "a solid but irregular mass of green crystalline apatite, 15 feet long and 9 feet wide" and a single euhedral crystal from the Aetna mine measuring $2.1 \times 1.2 \mathrm{~m}$ with an estimated weight of six tons have been found [25,26]. None of them is a pure compound; they always contain admixtures of other elements. For example, ions of calcium might be partially replaced by $\mathrm{Sr}, \mathrm{Ba}, \mathrm{Mg}, \mathrm{Mn}, \mathrm{K}, \mathrm{Na}, \mathrm{Fe}$; ions of orthophosphate may be partly replaced by $\mathrm{AsO}_{4}{ }^{3-}, \mathrm{CO}_{3}{ }^{2-}$ and $\mathrm{VO}_{4}{ }^{3-}$ [38]; ions of hydroxide, chloride, bromide, carbonate and oxide may to a certain extent substitute fluoride in the crystal lattice of natural apatites [27]. In principle, the crystal structure of apatites can incorporate half the periodic table in its atomic arrangement. Ease of atomic substitution for apatite leaves this mineral open to a wide array of compositions. This might be related to the fact that the apatite structure type displays porous properties [39]. The substitutions in apatites are usually in trace concentrations but large concentrations and even complete solid solutions exist for certain substituents (e.g., $\mathrm{F}^{-}$and $\mathrm{OH}^{-}$). To make things even more complicated, some ions in the crystal structure may be missing, leaving the crystallographic defects, which leads to formation of non-stoichiometric compounds. Figure 1 shows examples of polycrystalline and single-crystalline samples of natural FA.

The manufacture of elementary phosphorus (white and red) [40], phosphoric acids, various phosphorus-containing chemicals and, especially, agricultural fertilizers (namely, superphosphate [41, 42] and ammonium orthophosphates [43]) are the major industrial applications of natural calcium orthophosphates. This consumes up to $85 \%$ of the world production. The total capacity of industrial plants in the world exceeds 25 million tons $\left(\mathrm{as}_{2} \mathrm{O}_{5}\right)$ of phosphate fertilizers per year with an annual increase of $2-3 \%$ [20]. 
Figure 1. Polycrystalline (left) and single-crystalline (right) FA of a geological origin. The single crystal has a grey-green color due to incorporated ions of transition metals $[16,17]$.
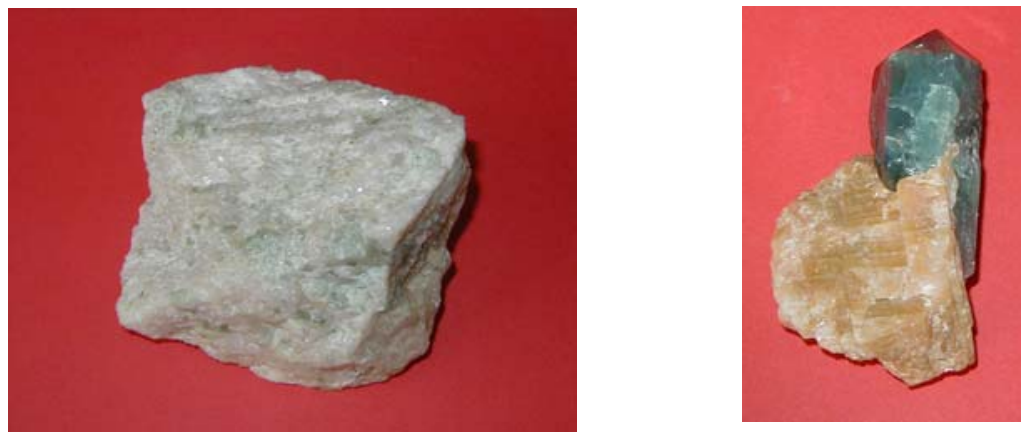

In biological systems, many organisms, ranging from bacteria and isolated cells to invertebrates and vertebrates, synthesize calcium orthophosphates [44]. Formation of calcium orthophosphates in primitive organisms is believed to enable the storage and regulation of essential elements such as calcium, phosphorus and, possibly, magnesium. The morphology of precipitates in these organisms (small intracellular nodules of amorphous calcium phosphates often located in mitochondria) complies with the necessities for rapid mobilization and intracellular control of the concentration of these elements [45]. In vertebrates calcium orthophosphates occur as the principal inorganic constituent of normal (bones, teeth, fish enameloid, deer antlers and some species of shells) and pathological (dental and urinary calculus and stones, atherosclerotic lesions, etc.) calcifications [13,46-51]. Except for small portions of the inner ear, all hard tissue of the human body is formed of calcium orthophosphates. Structurally, they occur mainly in the form of poorly crystallized non-stoichiometric Na-, Mg- and carbonate-containing hydroxyapatite (often called biological apatite [52] or dahllite [56]). The main constituents of human bones are calcium orthophosphates ( $60-70 \mathrm{wt} \%)$, collagen [60] $(\sim 20-30 \mathrm{wt} \%)$ and water (up to $10 \mathrm{wt} \%)$ [50,53-55,61-63]. Detailed information on the chemical composition of the most important human normal calcified tissues is compiled in Table 1. One should note that the values mentioned in Table 1 are approximate; the main constituents can vary by a percent or more [64].

\section{The Members of the Calcium Orthophosphate Family}

In the ternary system $\mathrm{Ca}(\mathrm{OH})_{2}-\mathrm{H}_{3} \mathrm{PO}_{4}-\mathrm{H}_{2} \mathrm{O}\left(\right.$ or $\mathrm{CaO}-\mathrm{P}_{2} \mathrm{O}_{5}-\mathrm{H}_{2} \mathrm{O}$ ) [65-67] there are eleven [68] known non-ion-substituted calcium orthophosphates with the $\mathrm{Ca} / \mathrm{P}$ molar ratio within 0.5 and 2.0 (Table 2). Table 3 lists their crystallographic data [14,73-75]. The most important parameters are the molar $\mathrm{Ca} / \mathrm{P}$ ratio, basicity/acidity and solubility. These parameters strongly correlate with the solution $\mathrm{pH}$. The lower the $\mathrm{Ca} / \mathrm{P}$ molar ratio is, the more acidic and water-soluble the calcium orthophosphate is [13-15]. One can see that the solubility ranges from high values for acidic compounds, such as MCPM, to very low values for basic compounds, such as apatites, which allow calcium orthophosphates to be dissolved, transported from one place to another and precipitated, when necessary. Crystallization, dissolution and phase transformation processes of different calcium orthophosphates under various experimental conditions have been reviewed recently [76]. 
Table 1. Comparative composition and structural parameters of inorganic phases of adult human calcified tissues. Due to the considerable variation found in biological samples, typical values are given in these cases $[13,63]$.

\begin{tabular}{|c|c|c|c|c|c|}
\hline Composition, wt.\% & Enamel & Dentin & Cementum & Bone & HA \\
\hline Calcium $^{[\mathrm{a}]}$ & 36.5 & 35.1 & {$[\mathrm{c}]$} & 34.8 & 39.6 \\
\hline Phosphorus (as $\mathrm{P})^{[\mathrm{a}]}$ & 17.7 & 16.9 & {$[\mathrm{c}]$} & 15.2 & 18.5 \\
\hline $\mathrm{Ca} / \mathrm{P}\left(\right.$ molar ratio) ${ }^{[\mathrm{a}]}$ & 1.63 & 1.61 & {$[\mathrm{c}]$} & 1.71 & 1.67 \\
\hline Sodium $^{[\mathrm{a}]}$ & 0.5 & 0.6 & {$[\mathrm{c}]$} & 0.9 & - \\
\hline Magnesium $^{[\mathrm{a}]}$ & 0.44 & 1.23 & {$[\mathrm{c}]$} & 0.72 & - \\
\hline Potassium $^{[\mathrm{a}]}$ & 0.08 & 0.05 & {$[c]$} & 0.03 & - \\
\hline Carbonate $\left(\text { as } \mathrm{CO}_{3}{ }^{2-}\right)^{[\mathrm{b}]}$ & 3.5 & 5.6 & {$[c]$} & 7.4 & - \\
\hline Fluoride $^{[\mathrm{a}]}$ & 0.01 & 0.06 & {$[\mathrm{c}]$} & 0.03 & - \\
\hline Chloride $^{[\mathrm{a}]}$ & 0.30 & 0.01 & {$[\mathrm{c}]$} & 0.13 & - \\
\hline Pyrophosphate (as $\left.\mathrm{P}_{2} \mathrm{O}_{7}{ }^{4-}\right)^{[\mathrm{b}]}$ & 0.022 & 0.10 & {$[\mathrm{c}]$} & 0.07 & - \\
\hline Total inorganic ${ }^{[\mathrm{b}]}$ & 97 & 70 & 60 & 65 & 100 \\
\hline Total organic ${ }^{[\mathrm{b}]}$ & 1.5 & 20 & 25 & 25 & - \\
\hline Water $^{[b]}$ & 1.5 & 10 & 15 & 10 & - \\
\hline \multicolumn{6}{|l|}{$\begin{array}{l}\text { Crystallographic properties: } \\
\text { Lattice parameters ( } \pm 0.003 \AA \text { ) }\end{array}$} \\
\hline$a$-axis, $\AA$ & 9.441 & 9.421 & [c] & 9.41 & 9.430 \\
\hline$c$-axis, $\AA$ & 6.880 & 6.887 & {$[c]$} & 6.89 & 6.891 \\
\hline Crystallinity index, $(\mathrm{HA}=100)$ & $70-75$ & $33-37$ & {$[c]$} & $33-37$ & 100 \\
\hline Typical crystal sizes (nm) $[311,362,364]$ & $10^{5} \times 50 \times 50$ & $35 \times 25 \times 4$ & [c] & $50 \times 25 \times 4$ & $200-600$ \\
\hline Ignition products $\left(800^{\circ} \mathrm{C}\right)$ & \multicolumn{3}{|c|}{$\beta-\mathrm{TCP}+\mathrm{HA} \beta-\mathrm{TCP}+\mathrm{HA} \beta-\mathrm{TCP}+\mathrm{HA}$} & $\mathrm{HA}+\mathrm{CaO}$ & HA \\
\hline Elastic modulus (GPa) & 80 & 15 & {$[\mathrm{c}]$} & $0.34-13.8$ & 10 \\
\hline Tensile strength $(\mathrm{MPa})$ & 10 & 100 & [c] & 150 & 100 \\
\hline
\end{tabular}

Due to the triprotic equilibrium that exists within orthophosphate-containing solutions, variations in $\mathrm{pH}$ alter the relative concentrations of the four polymorphs of orthophosphoric acid (Figure 2) and thus both the chemical composition and the amount of the calcium orthophosphates that forms by direct precipitation [77]. The solubility isotherms of different calcium orthophosphates are available in literature $[66,67,78,79]$. However, very recently, the classic solubility data of calcium orthophosphates $[66,67,78,79]$ were mentioned to be inappropriate [80]. According to the authors, all previous solubility calculations were based on simplifications, which are only crudely approximate. The problem lies in incongruent dissolution, leading to phase transformations and lack of the detailed solution equilibria. Using an absolute solid-titration approach, the true solubility isotherm of HA was found to lie substantially lower than previously reported. In addition, contrary to a wide belief, DCPD appeared not to be the most stable phase below $\mathrm{pH} \sim 4.2$, where CDHA was less soluble [80]. A brief description of all calcium orthophosphates is given below. 
Table 2. Existing calcium orthophosphates and their major properties [78,79].

\begin{tabular}{|c|c|c|c|c|c|}
\hline $\begin{array}{l}\mathrm{Ca} / \mathbf{P} \text { ionic } \\
\quad \text { ratio }\end{array}$ & Compound & Chemical formula & $\begin{array}{c}\text { Solubility at } \\
25^{\circ} \mathrm{C},-\log \left(\mathrm{K}_{\mathrm{s}}\right)\end{array}$ & $\begin{array}{c}\text { Solubility at } \\
25^{\circ} \mathrm{C}, \mathrm{g} / \mathrm{L}\end{array}$ & $\begin{array}{l}\text { pH stability } \\
\text { range in } \\
\text { aqueous } \\
\text { solutions at } \\
25^{\circ} \mathrm{C} \\
\end{array}$ \\
\hline 0.5 & Monocalcium phosphate monohydrate (MCPM) & $\mathrm{Ca}\left(\mathrm{H}_{2} \mathrm{PO}_{4}\right)_{2} \cdot \mathrm{H}_{2} \mathrm{O}$ & 1.14 & $\sim 18$ & $0.0-2.0$ \\
\hline 0.5 & Monocalcium phosphate anhydrous (MCPA) & $\mathrm{Ca}\left(\mathrm{H}_{2} \mathrm{PO}_{4}\right)_{2}$ & 1.14 & $\sim 17$ & {$[\mathrm{c}]$} \\
\hline 1.0 & Dicalcium phosphate anhydrous (DCPA), mineral monetite & $\mathrm{CaHPO}_{4}$ & 6.90 & $\sim 0.048$ & {$[c]$} \\
\hline 1.33 & Octacalcium phosphate (OCP) & $\mathrm{Ca}_{8}\left(\mathrm{HPO}_{4}\right)_{2}\left(\mathrm{PO}_{4}\right)_{4} \cdot 5 \mathrm{H}_{2} \mathrm{O}$ & 96.6 & $\sim 0.0081$ & $5.5-7.0$ \\
\hline 1.5 & $\alpha$-Tricalcium phosphate $(\alpha-$ TCP $)$ & $\alpha-\mathrm{Ca}_{3}\left(\mathrm{PO}_{4}\right)_{2}$ & 25.5 & $\sim 0.0025$ & [a] \\
\hline 1.5 & $\beta$-Tricalcium phosphate $(\beta$-TCP) & $\beta-\mathrm{Ca}_{3}\left(\mathrm{PO}_{4}\right)_{2}$ & 28.9 & $\sim 0.0005$ & [a] \\
\hline $1.2-2.2$ & Amorphous calcium phosphate (ACP) & $\begin{array}{c}\mathrm{Ca}_{\mathrm{x}} \mathrm{H}_{\mathrm{y}}\left(\mathrm{PO}_{4}\right)_{\mathrm{z}} \cdot \mathrm{nH}_{2} \mathrm{O}, \mathrm{n}=3- \\
4.5 ; 15-20 \% \mathrm{H}_{2} \mathrm{O}\end{array}$ & [b] & [b] & $\sim 5-12^{[\mathrm{d}]}$ \\
\hline 1.67 & Fluorapatite (FA) & $\mathrm{Ca}_{10}\left(\mathrm{PO}_{4}\right)_{6} \mathrm{~F}_{2}$ & 120.0 & $\sim 0.0002$ & $7-12$ \\
\hline 2.0 & Tetracalcium phosphate (TTCP), mineral hilgenstockite & $\mathrm{Ca}_{4}\left(\mathrm{PO}_{4}\right)_{2} \mathrm{O}$ & $38-44$ & $\sim 0.0007$ & [a] \\
\hline
\end{tabular}

\footnotetext{
${ }^{[a]}$ These compounds cannot be precipitated from aqueous solutions.

${ }^{[b]}$ Cannot be measured precisely. However, the following values were found: $25.7 \pm 0.1(\mathrm{pH}=7.40), 29.9 \pm 0.1(\mathrm{pH}=6.00), 32.7 \pm 0.1(\mathrm{pH}=5.28)$.

${ }^{[c]}$ Stable at temperatures above $100^{\circ} \mathrm{C}$.

${ }^{[\mathrm{d}]}$ Always metastable.

${ }^{\left[{ }^{[e]}\right.}$ Occasionally, CDHA is named as precipitated HA.

${ }^{[\mathrm{ff}}$ In the case $x=1$ (the boundary condition with $\mathrm{Ca} / \mathrm{P}=1.5$ ), the chemical formula of CDHA looks as follows: $\mathrm{Ca}_{9}\left(\mathrm{HPO}_{4}\right)\left(\mathrm{PO}_{4}\right)_{5}(\mathrm{OH})$.
} 
Table 3. Crystallographic data of calcium orthophosphates [14,73-75].

\begin{tabular}{|c|c|c|c|c|}
\hline Compound & Space group & Unit cell parameters & $\mathbf{Z}^{[\mathrm{a}]}$ & $\begin{array}{l}\text { Density, } \\
\mathrm{g} \mathrm{cm}^{-3}\end{array}$ \\
\hline MCPM & triclinic $P \overline{1}$ & $\begin{array}{l}a=5.6261(5), b=11.889(2), c=6.4731(8) \AA, \\
\alpha=98.633(6)^{\circ}, \beta=118.262(6)^{\circ}, \gamma=83.344(6)^{\circ}\end{array}$ & 2 & 2.23 \\
\hline $\mathrm{MCPA}$ & triclinic $P \overline{1}$ & $\begin{array}{c}a=7.5577(5), b=8.2531(6), c=5.5504(3) \AA \\
\alpha=109.87(1)^{\mathrm{o}}, \beta=93.68(1)^{\mathrm{o}}, \gamma=109.15(1)^{\mathrm{o}}\end{array}$ & 2 & 2.58 \\
\hline DCPD & monoclinic $I \mathrm{a}$ & $a=5.812(2), b=15.180(3), c=6.239(2) \AA, \beta=116.42(3)^{\circ}$ & 4 & 2.32 \\
\hline DCPA & triclinic $P \overline{1}$ & $\begin{array}{l}a=6.910(1), b=6.627(2), c=6.998(2) \AA \\
\alpha=96.34(2)^{\mathrm{o}}, \beta=103.82(2)^{\mathrm{o}}, \gamma=88.33(2)^{\mathrm{o}}\end{array}$ & 4 & 2.89 \\
\hline OCP & triclinic $P \overline{1}$ & $\begin{aligned} a=19.692(4), b= & 9.523(2), c=6.835(2) \AA, \alpha=90.15(2)^{\circ}, \beta= \\
& 92.54(2)^{\circ}, \gamma=108.65(1)^{\mathrm{o}}\end{aligned}$ & 1 & 2.61 \\
\hline$\alpha$-TCP & monoclinic $P 2_{1} / \mathrm{a}$ & $a=12.887(2), b=27.280(4), c=15.219(2) \AA, \beta=126.20(1)^{\circ}$ & 24 & 2.86 \\
\hline$\beta$-TCP & rhombohedral $R 3 \mathrm{cH}$ & $a=b=10.4183(5), c=37.3464(23) \AA, \gamma=120^{\circ}$ & $21^{[b]}$ & 3.08 \\
\hline HA & $\begin{array}{c}\text { monoclinic } P 2_{1} / \mathrm{b} \\
\text { or hexagonal } P 6_{3} / \mathrm{m}\end{array}$ & $\begin{aligned} a= & 9.84214(8), b=2 a, c=6.8814(7) \AA, \gamma=120^{\circ} \text { (monoclinic); } \\
& a=b=9.4302(5), c=6.8911(2) \AA, \gamma=120^{\circ} \text { (hexagonal) }\end{aligned}$ & $\begin{array}{l}4 \\
2 \\
\end{array}$ & 3.16 \\
\hline FA & hexagonal $P 6_{3} / \mathrm{m}$ & $a=b=9.367, c=6.884 \AA, \gamma=120^{\circ}$ & 2 & 3.20 \\
\hline TTCP & monoclinic $P 2_{1}$ & $a=7.023(1), b=11.986(4), c=9.473(2) \AA, \beta=90.90(1)^{\circ}$ & 4 & 3.05 \\
\hline
\end{tabular}

${ }^{[\mathrm{a}]}$ Number of formula units per unit cell.

${ }^{[b]}$ Per the hexagonal unit cell.

Figure 2. $\mathrm{pH}$ variation of ionic concentrations in triprotic equilibrium for phosphoric acid solutions. Reprinted from Ref. [77] with permission.

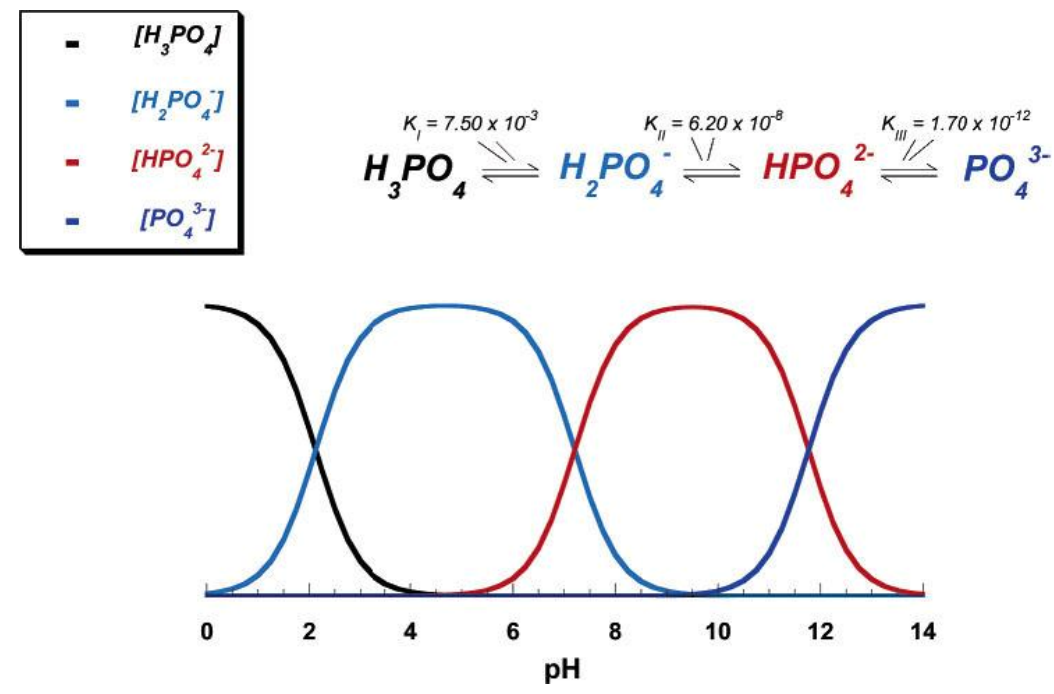

\section{1. $M C P M$}

MCPM (monocalcium phosphate monohydrate, $\mathrm{Ca}\left(\mathrm{H}_{2} \mathrm{PO}_{4}\right)_{2} \cdot \mathrm{H}_{2} \mathrm{O}$; the chemically correct name is calcium dihydrogen phosphate monohydrate) is both the most acidic and water-soluble compound. It precipitates from highly acidic solutions that are normally used in industry of phosphorus-containing fertilizer production ("triple superphosphate") [20]. At temperatures above $100{ }^{\circ} \mathrm{C}$, it releases a molecule of water and transforms into MCPA. Due to high acidity and solubility, MCPM is never 
found in biological calcifications. Moreover, pure MCPM is not biocompatible [81] with bone [83]. However, MCPM is used in medicine as a component of several self-hardening calcium orthophosphate cements [84-87]. In addition, MCPM is used as a nutrient, acidulant and mineral supplement for dry baking powders, food, feed and some beverages $[88,89]$. Coupled with $\mathrm{NaHCO}_{3}$, MCPM is used as a leavening agent for both dry baking powders and bakery dough. MCPM might be added to salt-curing preserves, pickled and marinated foods. According to the European Classification of Food Additives, MCPM is marked as additive E341. Occasionally, MCPM is added to toothpastes. In addition, MCPM might be added to ceramics and glasses, while agriculture is the main consumer of a technical grade MCPM, where it is used as a fertilizer $[20,88]$.

\section{2. $M C P A$}

MCPA (monocalcium phosphate anhydrous, $\mathrm{Ca}\left(\mathrm{H}_{2} \mathrm{PO}_{4}\right)_{2}$; the chemically correct name is calcium dihydrogen phosphate anhydrous) is the anhydrous form of MCPM. It crystallizes under the same conditions as MCPM, but at temperatures above $100{ }^{\circ} \mathrm{C}$ (e.g., from highly concentrated mother liquors during fertilizer production). Like MCPM, MCPA never appears in calcified tissues and is not biocompartible due to its acidity. There is no current application of MCPA in medicine. Due to the similarity with MCPM, in many cases, MCPA might be used instead of MCPM [20,88]; however, its hydroscopic properties reduce its commercial applications.

\subsection{DCPD}

DCPD (dicalcium phosphate dihydrate, $\mathrm{CaHPO}_{4} \cdot 2 \mathrm{H}_{2} \mathrm{O}$; the chemically correct name is calcium hydrogen phosphate dihydrate; the mineral brushite [90]) can be easily crystallized from aqueous solutions at $\mathrm{pH}<6.5$. It transforms into DCPA at temperatures above $80{ }^{\circ} \mathrm{C}$. Briefly, DCPD crystals consist of $\mathrm{CaPO}_{4}$ chains arranged parallel to each other, while lattice water molecules are interlayered between them. Using surface X-ray diffraction, Arsic et al. determined the atomic structure of the $\{010\}$ interface of DCPD with water [91]. Since DCPD contains water layers as part of its crystal structure, special ordering properties at the interface are expected. This interface consists of two water bilayers with different ordering properties. The first is highly ordered and can be considered as part of the DCPD crystal structure. Surprisingly, the second water bilayer exhibits no in-plane order but shows only layering in the perpendicular direction. It has been proposed that the low level of water ordering at the interface is correlated with the low solubility of DCPD in water [91]. Many additional data on DCPD, as well as a good picture of DCPD atomic structure are available in literature [92].

DCPD is of biological importance because it is often found in pathological calcifications (dental calculi, crystalluria, chondrocalcinosis and urinary stones) and some carious lesions [13,46-48]. It has been proposed as an intermediate in both bone mineralization and dissolution of enamel in acids (dental erosion) [13,46,47]. In medicine, DCPD is used in calcium orthophosphate cements [85, 93-96] and as an intermediate for tooth remineralization. DCPD is added to toothpaste both for caries protection (in this case, it is coupled with F-containing compounds such as $\mathrm{NaF}$ and/or $\mathrm{Na}_{2} \mathrm{PO}_{3} \mathrm{~F}$ ) and as a gentle polishing agent [97-101]. Other applications include a flame retardant [102], a slow release fertilizer, glass production, as well as calcium supplement in food, feed and cereals [88]. The importance of DCPD as a constituent of infant's food was discovered as early as in 1917 [103]. In food 
industry, it serves as a texturizer, bakery improver and water retention additive. In the diary industry, DCPD is used as a mineral supplement. If added to food products, DCPD should be identified as E341 according to the European Classification of Food Additives. In addition, plate-like crystals of DCPD might be used as a non-toxic, anticorrosive and passivating pigment for some basecoat paints.

\subsection{DCPA}

DCPA (dicalcium phosphate anhydrous, $\mathrm{CaHPO}_{4}$; the chemically correct name is calcium hydrogen phosphate anhydrous; the mineral monetite [104]) is the anhydrous form of DCPD. It is less soluble than DCPD due to the absence of water inclusions. Like DCPD, DCPA can be crystallized from aqueous solutions, but at $100{ }^{\circ} \mathrm{C}$. A calcium-deficient DCPA was prepared recently. It might be sintered at $300{ }^{\circ} \mathrm{C}$ [105]. Unlike DCPD, DCPA occurs in neither normal nor pathological calcifications. It is used in calcium phosphate cements [95,106-110]. Other applications include uses as a polishing agent, a source of calcium and phosphate in nutritional supplements (e.g., in prepared breakfast cereals, enriched flour and noodle products), a tabletting aid and a toothpaste component [88]. In addition, it is used as a dough conditioner in the food industry.

\section{5. $O C P$}

OCP (octacalcium phosphate, $\mathrm{Ca}_{8}\left(\mathrm{HPO}_{4}\right)_{2}\left(\mathrm{PO}_{4}\right)_{4} \cdot 5 \mathrm{H}_{2} \mathrm{O}$; the chemically correct name is octacalcium bis(hydrogenphosphate) tetrakis(phosphate) pentahydrate [74]) is often found as an unstable transient intermediate during the precipitation of the thermodynamically more stable calcium orthophosphates (e.g., CDHA) in aqueous solutions. Techniques for its preparation may be found elsewhere [111-114]. A partially hydrolyzed form of OCP with a $\mathrm{Ca} / \mathrm{P}$ molar ratio of 1.37 can be prepared as well [115]. The full hydrolysis of OCP into CDHA occurs within 6 hours [116]. The triclinic structure of OCP displays apatitic layers (with atomic arrangements of calcium and orthophosphate ions similar to those of HA) separated by hydrated layers (with atomic arrangements of calcium and orthophosphate ions similar to those in DCPD) [13-15,117]. A similarity in crystal structure between OCP and HA is one reason that the epitaxial growth of these phases is observed. Morphologically, OCP crystallizes as $\{100\}$ blades of triclinic pinacoidal symmetry, elongated along the $a$-axis and bordered by the forms $\{010\},\{001\}$ and $\{011\}$. It is generally assumed that, in solutions, the hydrated layer of the (100) face is the layer most likely exposed to solution. The water content of OCP crystals is about $1 / 5$ that of DCPD and this is partly responsible for its lower solubility.

OCP is of a great biological importance because it is one of the stable components of human dental and urinary calculi [118-120]. OCP was first proposed to participate as the initial phase in enamel mineral formation and bone formation through subsequent precipitation and stepwise hydrolysis of OCP by W. E. Brown [121-123]. It plays an important role in in vivo formation of apatitic biominerals. A "central OCP inclusion" (also known as "central dark line") is seen by transmission electron microscopy in many biological apatites and in some synthetically precipitated HA [124-127]. Although OCP has not been observed in vascular calcifications, it has been strongly suggested as a precursor phase to biological apatite found in natural and prosthetic heart valves [128,129]. In surgery, OCP is used for implantation into bone defects [130-135]. For comprehensive information on OCP, the readers are referred to a monograph [120]. 


\section{6. $\beta-T C P$}

$\beta$-TCP ( $\beta$-tricalcium phosphate, $\beta$-Ca $\mathrm{Ca}_{3}\left(\mathrm{PO}_{4}\right)_{2}$; the chemically correct name is calcium phosphate tribasic beta) cannot be precipitated from aqueous solutions. It is a high temperature phase, which can only be prepared at temperatures above $800{ }^{\circ} \mathrm{C}$ by thermal decomposition of CDHA or by solid-state interaction of acidic calcium orthophosphates, e.g., DCPA, with a base, e.g., CaO. Apart from the chemical preparation routes, ion-substituted $\beta$-TCP can be prepared by calcining of bones: such type of $\beta$-TCP is occasionally called "bone ash". In $\beta$-TCP, there are three types of crystallographically nonequivalent $\mathrm{PO}_{4}{ }^{3-}$ groups located at general points of the crystal, each type with different intratetrahedral bond lengths and angles. At temperatures above $\sim 1125{ }^{\circ} \mathrm{C}, \beta$-TCP transforms into a high-temperature phase $\alpha$-TCP. Being the stable phase at room temperature, $\beta$-TCP is less soluble in water than $\alpha$-TCP (Table 2). Furthermore, the ideal $\beta$-TCP structure contains calcium ion vacancies that are too small to accommodate calcium ions, but allow for the inclusion of magnesium ions, which thereby stabilize the structures.

Pure $\beta$-TCP never occurs in biological calcifications. Only the $\mathrm{Mg}$-substituted form called whitlockite [136] $\left(\beta\right.$-TCMP - $\beta$-tricalcium magnesium phosphate, $\beta$ - $\left.(\mathrm{Ca}, \mathrm{Mg})_{3}\left(\mathrm{PO}_{4}\right)_{2}\right)$ is found in dental calculi and urinary stones, dentinal caries, salivary stones, arthritic cartilage, as well as in some soft-tissue deposits [13,46-48,143]. However, it has not been observed in enamel, dentin or bone. In biomedicine, $\beta$-TCP is used in calcium orthophosphate bone cements [144-147]. In combination with HA, $\beta$-TCP forms a biphasic calcium phosphate (BCP [148]) [151-160]. Both $\beta$-TCP [161] and BCP [151-160] are widely used as a bone substitution bioceramics. Pure $\beta$-TCP is added to some brands of toothpaste as a gentle polishing agent. Multivitamin complexes with calcium orthophosphate are widely available in the market and $\beta$-TCP is used as the calcium phosphate there. In addition, it serves as a texturizer, bakery improver and anti-clumping agent for dry powdered food (flour, milk powder, dried cream, cocoa powder). In addition, $\beta$-TCP is added as a dietary or mineral supplement to food and feed, where it is marked as E341 according to the European Classification of Food Additives. Occasionally, it might be used as an inert filler in pelleted drugs. Other applications comprise porcelains, pottery, enamel, using as a component for mordants and ackey, as well as a polymer stabilizer [88]. $\beta$-TCP of a technical grade (as either calcined natural phosphorites or bone dust) is used as a slow release fertilizer for acidic soils [20].

\section{7. $\alpha-T C P$}

$\alpha$-TCP ( $\alpha$-tricalcium phosphate, $\alpha-\mathrm{Ca}_{3}\left(\mathrm{PO}_{4}\right)_{2}$; the chemically correct name is calcium phosphate tribasic alpha) is usually prepared from $\beta$-TCP by heating above $\sim 1125{ }^{\circ} \mathrm{C}$ and it might be considered a high temperature phase of $\beta$-TCP. However, at the turn of the millennium, the previously forgotten data that the presence of silicates stabilized $\alpha$-TCP at lower temperatures of $800-1000{ }^{\circ} \mathrm{C}$ [162] has been rediscovered again. Such type of $\alpha$-TCP is called "silicon stabilized $\alpha$-TCP" [163-168].

Although $\alpha$-TCP and $\beta$-TCP have exactly the same chemical composition, they differ by the crystal structure (Table 3 ) and solubility (Table 2). In addition, $\beta$-TCP is more stable than the $\alpha$-phase [169]. Therefore, of them, $\alpha$-TCP is more reactive in aqueous systems, has a higher specific energy and it can be hydrolyzed to a mixture of other calcium phosphates. It never occurs in biological calcifications but in medicine chemically pure $\alpha$-TCP is used in calcium phosphate cements $[85,93-96,108-110,170$, 
171]. Pure $\alpha$-TCP has received not much interest in the biomedical field. The disadvantage of using $\alpha$ TCP is its quick resorption rate, which limits its application in this area. However, the silicon stabilized $\alpha$-TCP (more precisely as a biphasic composite with HA) has been commercialized as a starting material to produce bioresorbable porous ceramic scaffolds to be used as artificial bone grafts [161,163-167]. Theoretical insights into bone grafting properties of the silicon-stabilized $\alpha$-TCP may be found in Ref. [172]. Surface and adsorption properties of $\alpha$-TCP are described in Ref. [173]. Technical grade $\alpha$-TCP can be used as a fertilizer [88].

\section{8. $A C P$}

ACP (amorphous calcium phosphate, $\mathrm{Ca}_{\mathrm{x}} \mathrm{H}_{\mathrm{y}}\left(\mathrm{PO}_{4}\right)_{\mathrm{z}} \cdot \mathrm{nH}_{2} \mathrm{O}, \mathrm{n}=3-4.5 ; 15-20 \% \mathrm{H}_{2} \mathrm{O}$ ) is often encountered as a transient phase during the formation of calcium orthophosphates in aqueous systems. Usually, ACP is the first phase precipitated from a supersaturated solution prepared by rapid mixing of solutions containing ions of calcium and orthophosphate [14,174-179]. ACP is thought to be formed at the beginning of the precipitation due to a lower surface energy than that of OCP and apatites [175]. The amorphization level of ACP increases with the concentration increasing of $\mathrm{Ca}-$ and $\mathrm{PO}_{4}{ }^{-}$ containing solutions, as well as at a higher solution $\mathrm{pH}$ and a lower crystallization temperature. A continuous gentle agitation of as precipitated ACP in the mother solution, especially at elevated temperatures, results in a slow recrystallization and formation of better crystalline compounds, such as CDHA $[13,14]$. The lifetime of ACP in aqueous solution was reported to be a function of the presence of additive molecules and ions, $\mathrm{pH}$, ionic strength and temperature. Thus, ACP may persist for appreciable periods and retain the amporphous state under some specific experimental conditions [180]. The chemical composition of ACP strongly depends on the solution $\mathrm{pH}$ and the concentrations of mixing solutions. For example, ACP with $\mathrm{Ca} / \mathrm{P}$ ratios in the range of 1.18 (precipitated at solution $\mathrm{pH}=6.6$ ) to 1.53 (precipitated at solution $\mathrm{pH}=11.7)[14,181]$ and even to $2.5[13,46,47]$ have been described. The presence of poly(ethylene glycol) [182], ions of pyrophosphate, carbonate and/or magnesium in solution during the crystallization promotes formation of ACP and slows down its further transformation into more crystalline calcium orthophosphates, while the presence of fluoride has the opposite effect $[13-15,63,183]$. The solution-mediated transformation of ACP to CDHA, which can be described by a "first-order" rate law, is a function only of the solution $\mathrm{pH}$ and depends upon the experimental conditions which regulate both the dissolution of ACP and the formation of early HA nuclei [184].

As all amorphous compounds are characterized by a lack of the long-range order, it is problematic to discuss the crystal structure of ACP (it is X-ray amorphous). Concerning the short-range order in $\mathrm{ACP}$, it is uncertain either, because it depends on the preparation conditions, storage, admixtures, etc. It is well known that ACP contains $10-20 \%$ by weight of tightly bound water, which is removed by vacuum drying at elevated temperature [185]. Infrared spectra of ACP show broad featureless phosphate absorption bands. Electron microscopy of ACP usually shows featureless nearly spherical particles with diameters in the range of 20 to $200 \mathrm{~nm}$. However, there is a questionable opinion that ACP has an apatitic structure but with a crystal size so small, that it is X-ray amorphous. This is supported by X-ray absorption spectroscopic data (EXAFS) on biogenic and synthetic samples [186189]. On the other hand, it was proposed that the basic structural unit of ACP is a $9.5 \AA$ diameter, 
roughly spherical cluster of ions with the composition $\mathrm{Ca}_{9}\left(\mathrm{PO}_{4}\right)_{6}$ (Figure 3) $[14,181,190,191]$. These clusters were found experimentally as first nuclei during the crystallization of HA and a model was developed to describe the crystallization of HA as a step-wise assembly of these units [192] (see HA below). Biologically, ACP (often containing ions of $\mathrm{Na}, \mathrm{Mg}$, carbonate and pyrophosphate) is found in soft-tissue pathological calcifications (e.g., heart valve calcifications of uremic patients) [13,46-48]. In medicine, pure ACP is used in calcium orthophosphate cements [93-95] and as a filling material in dentistry. Bioactive composites of ACP with polymers have properties suitable for use in dentistry [193-196] and surgery [197-200]. Due to a reasonable solubility and physiological pH of aqueous solutions, ACP appeared to be consumable by some microorganisms and, due to this reason, it might be added as a mineral supplement to culture media. Non-biomedical applications of ACP comprise its using as a component for mordants and ackey. In food industry, ACP is used for syrup clarification. Occasionally, it is used as inert filler in pelleted drugs. In addition, ACP is used in glass and pottery production and as a raw material for production of some organic phosphates. For further details on ACP, interested readers are referred to specialized reviews [191,201].

Figure 3. A model of ACP structure. Reprinted from Ref. [190] with permission.

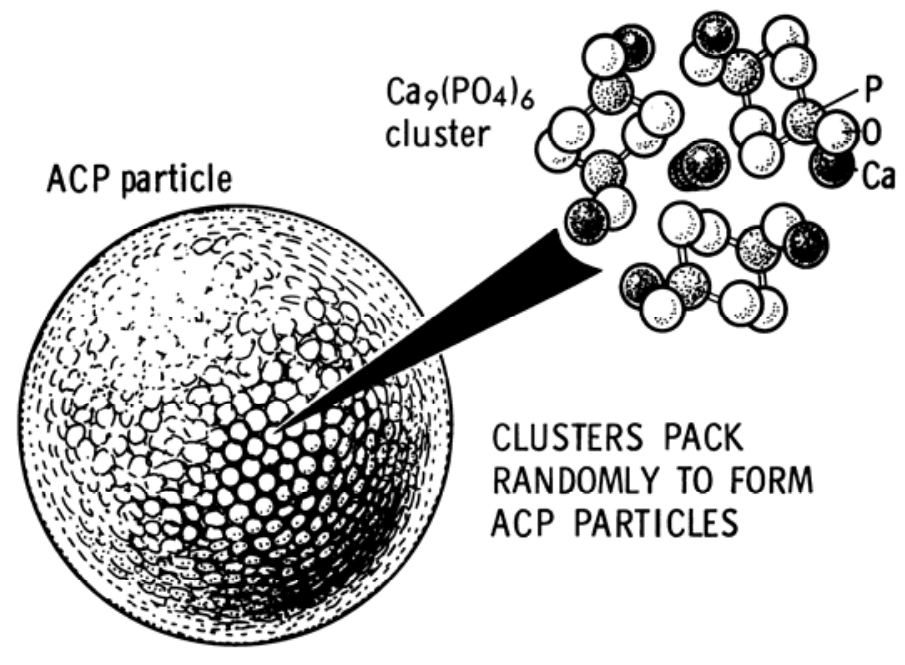

\section{9. $C D H A$}

CDHA (calcium-deficient hydroxyapatite, $\left.\mathrm{Ca}_{10-x}\left(\mathrm{HPO}_{4}\right)_{x}\left(\mathrm{PO}_{4}\right)_{6-x}(\mathrm{OH})_{2-x}(0<x<1)\right)$ can be easily prepared by simultaneous addition of calcium- and orthophosphate-containing solutions into boiling water, followed by boiling the suspension for several hours. During this time, the initially precipitated ACP is restructured and transformed into CDHA [202]. Therefore, there are many similarities in the structure, properties and application between the precipitated in alkaline solutions $(\mathrm{pH}>8) \mathrm{ACP}$ and CDHA. Recent data indicated on presence of intermediate phases during further hydrolysis of CDHA to a more stable HA-like phase [206]. CDHA crystals are poorly crystalline and of submicron dimensions. It has a very large specific surface area, typically $25-100 \mathrm{~m}^{2} / \mathrm{g}$. On heating above $700{ }^{\circ} \mathrm{C}$, dry $\mathrm{CDHA}$ with $\mathrm{Ca} / \mathrm{P}=1.5$ will convert to $\beta$-TCP and that with $1.5<\mathrm{Ca} / \mathrm{P}<1.67$ will convert into a 
mixture of HA and $\beta$-TCP (the above-mentioned BCP) [151-159]. A reasonable solid-state mechanism of a high-temperature transformation of CDHA into BCP has been proposed [207,208].

The variability in $\mathrm{Ca} / \mathrm{P}$ molar ratio of $\mathrm{CDHA}$ has been explained through different models: surface adsorption, lattice substitution and intercrystalline mixtures of HA and OCP [209]. Due to a lack of stoichiometry, CDHA usually contains other ions [45]. The extent depends on the counter-ions of the chemicals used for preparation (e.g., $\mathrm{Na}^{+}, \mathrm{Cl}^{-}$). Direct determinations of the CDHA structures are still missing and the unit cell parameters remain uncertain. However, the long-range order exists and the following lattice parameters have been reported for formate $\left(\mathrm{HCO}_{2}{ }^{-}\right)$containing $\mathrm{CDHA}$ with $\mathrm{Ca} / \mathrm{P}=$ 1.596 (ionic): $a=9.4729(20)$ and $c=6.8855(9) \AA . \mathrm{Ca}^{2+}$ ions were lost exclusively from $\mathrm{Ca} 2$ sites, while the $\mathrm{PO}_{4}$ tetrahedron volume and $\mathrm{P}-\mathrm{O}$ bonds were $4.4 \%$ and $1.4 \%$ smaller, respectively, than those in HA [210].

A systematic study of defect constellations in CDHA is available in the literature [211]. As a first approximation, CDHA may be considered as HA with some ions missing [212]. The more calcium is deficient, the more disorder and imperfections are in CDHA structure [213]. According to the chemical formula of CDHA (Table 2), there are vacancies of $\mathrm{Ca}^{2+}$ (mainly on $\mathrm{Ca} 2$ sites) and $\mathrm{OH}^{-}$ions in crystal structure of this compound [210-216]. However, nothing is known about the vacancies of orthophosphate ions: in CDHA, a portion of $\mathrm{PO}_{4}{ }^{3-}$ ions is either protonated (as $\mathrm{HPO}_{4}{ }^{2-}$ ) or substituted by other ions (e.g., $\mathrm{CO}_{3}{ }^{2-}$ ) [217]. Theoretical investigations of the defect formation mechanism relevant to non-stoichiometry in CDHA are available elsewhere [218].

Unsubstituted CDHA (i.e. containing ions of $\mathrm{Ca}^{2+}, \mathrm{PO}_{4}{ }^{3-}, \mathrm{HPO}_{4}{ }^{2-}$ and $\mathrm{OH}^{-}$only) does not exist in biological systems. The ion substituted $\mathrm{CDHA}: \mathrm{Na}^{+}, \mathrm{K}^{+}, \mathrm{Mg}^{2+}, \mathrm{Sr}^{2+}$ for $\mathrm{Ca}^{2+} ; \mathrm{CO}_{3}{ }^{2-}$ for $\mathrm{PO}_{4}{ }^{3-}$ or $\mathrm{HPO}_{4}{ }^{2-} ; \mathrm{F}^{-}, \mathrm{Cl}^{-}, \mathrm{CO}_{3}{ }^{2-}$ for $\mathrm{OH}^{-}$, plus some water forms biological apatite - the main inorganic part of animal and human normal and pathological calcifications $[13,45,46]$. Therefore, CDHA is a very promising compound for industrial manufacturing of artificial bone substitutes. Non-biomedical applications of CDHA are similar to those of ACP. Recently, CDHA was found to possess catalytic activity for the production of biogasoline [219].

\subsection{0. $H A$}

HA (or OHAp) (hydroxyapatite [220], $\mathrm{Ca}_{5}\left(\mathrm{PO}_{4}\right)_{3}(\mathrm{OH})$, but usually written as $\mathrm{Ca}_{10}\left(\mathrm{PO}_{4}\right)_{6}(\mathrm{OH})_{2}$ to denote that the crystal unit cell comprises two molecules) is the second most stable and least soluble calcium orthophosphate after FA. Chemically pure HA crystallizes in the monoclinic space group $P 2_{1} / \mathrm{b}$ [221]. However, at temperatures above $250{ }^{\circ} \mathrm{C}$, there is a monoclinic to hexagonal phase transition in HA (space group $P 6_{3} / \mathrm{m}$ ) $[14,74,181,222,223]$. The detailed description of the HA structure was first reported in 1964 [224] and its interpretation in terms of aggregation of $\mathrm{Ca}_{9}\left(\mathrm{PO}_{4}\right)_{6}$ clusters, the so-called Posner's clusters, has been widely used since publication of the article by Posner and Betts [185]. The $\mathrm{Ca}_{9}\left(\mathrm{PO}_{4}\right)_{6}$ clusters appeared to be energetically favored in comparison to alternative candidates including $\mathrm{Ca}_{3}\left(\mathrm{PO}_{4}\right)_{2}$ and $\mathrm{Ca}_{6}\left(\mathrm{PO}_{4}\right)_{4}$ clusters [225]. In hexagonal HA, the hydroxide ions are more disordered within each row, when compared with the monoclinic form, pointing either upward or downward in the structure. This induces strains that are compensated for by substitutions or ion vacancies. Some impurities, like partial substitution of hydroxide by fluoride or chloride, stabilize the hexagonal structure of HA at ambient temperature. Due to this reason, hexagonal 
HA is seldom the stoichiometric phase and very rare single crystals of natural HA always exhibit the hexagonal space group. The hexagonal structure of HA is a more common one for biomedical applications. The crystal structure of HA is well described elsewhere [14,73-75], the detailed analysis of the electronic structure, bonding, charge transfer and optical properties are also available [226,227], while the readers interested in Posner's clusters are referred to other papers [225,228-230]. A shell model has been developed to study the lattice dynamics of HA [231].

Several techniques may be utilized for HA preparation; they can be divided into solid-state reactions and wet methods [232], which include precipitation, hydrothermal and hydrolysis of other calcium orthophosphates. Even under the ideal stoichiometric conditions, the precipitates are generally non-stoichiometric, suggesting intermediate formation of precursor phases. HA can be prepared in aqueous solutions by mixing exactly stoichiometric quantities of $\mathrm{Ca}$ - and $\mathrm{PO}_{4}$-containing solutions at $\mathrm{pH}>9$, followed by boiling for several days in $\mathrm{CO}_{2}$-free atmosphere (the ageing or maturation stage), filtration, drying and, usually, sintering at about $1000{ }^{\circ} \mathrm{C}$ [233]. As the first precipitates are rich in nonapatitic environments (see ACP and CDHA), the ageing stage appears to be very important: the $\mathrm{Ca} / \mathrm{P}$ molar ratio of 1.67 was found to be attained in as little as 5 hours after the completion of the reaction at $90^{\circ} \mathrm{C}$ [234]. The surface of freshly precipitated HA is composed of a structured hydrated layer containing easily exchangeable mobile ionic species [235]. Usually unsintered HA is poorly crystalline and often non-stoichiometric, resembling the aforementioned CDHA. However, highly crystalline HA can be prepared from an aqueous solution [236]. Microcrystalline samples of HA can also be prepared by solid-state reaction of other calcium phosphates (e.g., MCPM, DCPA, DCPD, OCP) with CaO, $\mathrm{Ca}(\mathrm{OH})_{2}$, or $\mathrm{CaCO}_{3}$ at temperatures above $1200{ }^{\circ} \mathrm{C}$ in an atmosphere of equal volumes of water and nitrogen. HA can be prepared by hydrothermal synthesis [14,181,237]. A water-free synthesis can be performed in ethanol from $\mathrm{Ca}(\mathrm{OEt})_{2}\left(\mathrm{Et}=\right.$ ethyl) and $\mathrm{H}_{3} \mathrm{PO}_{4}$ [238,239]. In addition, $\mathrm{HA}$ can be prepared by mechanochemical synthesis of a dry mixture of $\mathrm{CaO}$ and DCPD [232,240] or from coral skeletal carbonate by hydrothermal exchange [241-243]. Relatively large single crystals of HA might be prepared from those of chlorapatite [244] or by recently developed controlled homogeneous precipitation method [245]. Lower sized particles of HA might be prepared by a pyrosol technique, where an aerosol, containing calcium and orthophosphate ions in the adequate ratio, is transported to a furnace where the pyrolisis takes place [246]. Synthesis of nanosized HA has also been described [247,248], while the chronological development of nanosized HA synthesis can be found in another paper [249]. Two-dimensional nanocrystalline HA may be also synthesized [250]. Space-grown and terrestrial HA crystals were found to differ in size: the former appeared to be at least $1-1.5$ orders of magnitude bigger in length [251,252]. Transparent HA ceramics can be prepared as well [253-256]. Detailed information on HA synthesis is available elsewhere [257-263]. In addition, there are good reviews on HA solubility, crystal growth and intermediate phases of HA crystallization [264], as well as on HA dissolution [265]. The electronic and crystallographic structures of apatites can be found in another paper [226].

Pure HA never occurs in biological systems. However, due to the chemical similarities to bone and teeth mineral (Table 1), HA is widely used as a coating on orthopedic (e.g., hip joint prosthesis) and dental implants [266-272]. HA particles might be implanted as well [273]. Due to a great similarity to biological apatite, HA has been used for a long time in liquid chromatography of nucleic acids, proteins and other biological compounds [274-281] and for drug delivery purposes [282,283]. Also, 
HA is added to some brands of toothpaste as a gentle polishing agent instead of calcium carbonate. Besides, it can be used as an environmentally friendly filler for elastomers [284], a sorbent of poisonous chemical elements [285] and a carrier for catalysts [286,287]. To conclude this topic, one should mention some other reviews devoted to HA and its biomedical applications [288-293].

\subsection{FA}

FA (or FAp) (fluorapatite, $\mathrm{Ca}_{5}\left(\mathrm{PO}_{4}\right)_{3} \mathrm{~F}$, but is usually written as $\mathrm{Ca}_{10}\left(\mathrm{PO}_{4}\right)_{6} \mathrm{~F}_{2}$ to denote that the crystal unit cell comprises two molecules) is the hardest (5 according to the Mohs' scale of mineral hardness), most stable and least soluble compound among all calcium orthophosphates (Table 2). Perhaps, such "extreme" properties of FA are related to the specific position of $\mathrm{F}^{-}$ions in the center of $\mathrm{Ca} 2$ triangles of the crystal structure [74]. Due to its properties, FA is the only calcium orthophosphate that naturally forms large deposits suitable for the commercial use [19-22] (see also Figure 1). Preparation techniques for chemically pure FA are similar to the aforementioned ones for HA, but the synthesis must be performed in presence of the necessary amount of $\mathrm{F}^{-}$ions (usually, $\mathrm{NaF}^{-}$or $\mathrm{NH}_{4} \mathrm{~F}$ is added). Unlike that for HA (see CDHA), no data are available on calcium-deficient FA. Under some special crystallization conditions, FA might form unusual dumbbell-like fractal morphology that finally closed to spheres (Figure 4) [294-299]. A hierarchical structure for FA was proposed [300]. The crystal structure of FA for the first time was studied in 1930 [301,302] and is well described elsewhere [14,73-75,303]. The detailed analysis of the electronic structure, bonding, charge transfer and optical properties is available as well [227]. In addition, there are reviews on FA solubility [264] and the dissolution mechanism [265].

Figure 4. A biomimetically grown aggregate of FA that was crystallized in a gelatin matrix. Its shape can be explained and simulated by a fractal growth mechanism. Scale bar: $10 \mu \mathrm{m}$ (taken from Ref. [295] with permission).

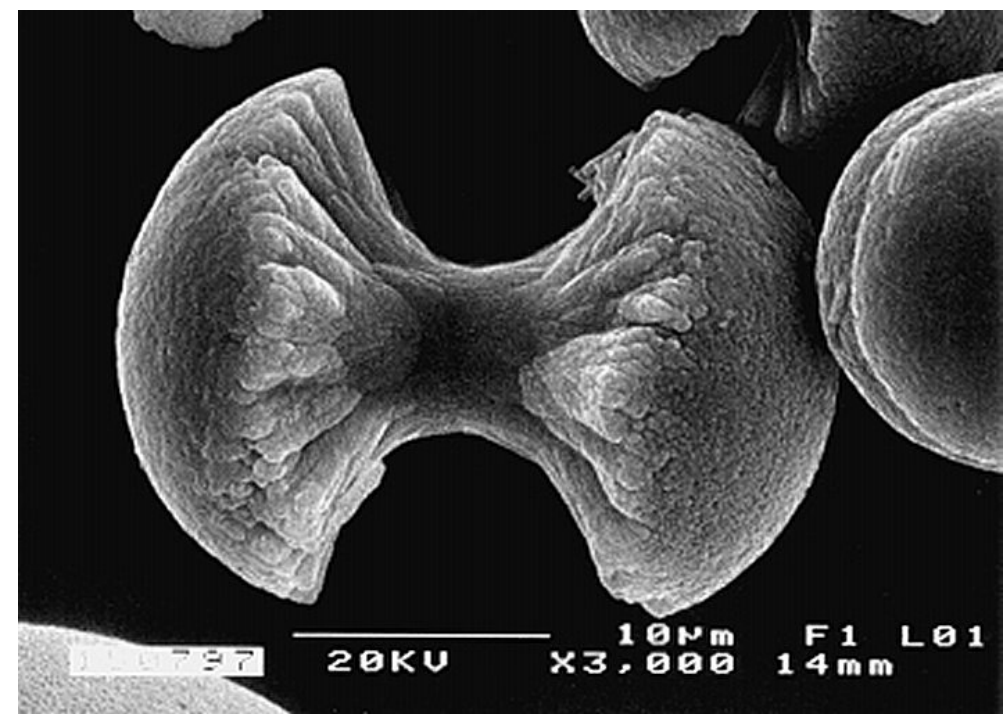

FA easily forms solid solutions with HA with any desired F/OH molar ratio. Such compounds are called fluorhydroxyapatites (FHA) or hydroxyfluorapatites (HFA) and described with a chemical formula $\mathrm{Ca}_{10}\left(\mathrm{PO}_{4}\right)_{6}(\mathrm{OH})_{2-x} \mathrm{~F}_{x}$, where $0<x<2$. If the $\mathrm{F} / \mathrm{OH}$ ratio is either uncertain or not important, 
the chemical formula of FHA and HFA is often written as $\mathrm{Ca}_{10}\left(\mathrm{PO}_{4}\right)_{6}(\mathrm{~F}, \mathrm{OH})_{2}$. The lattice parameters, crystal structure, solubility and other properties of FHA and HFA lay in between those for the chemically pure FA and HA [304-308].

Like pure HA, pure FA never occurs in biological systems. Obviously, a lack of the necessary amount of toxic fluorides (the acute toxic dose of fluoride is $\sim 5 \mathrm{mg} / \mathrm{kg}$ of body weight) in living organisms is the main reason of this fact (pure FA contains $3.7 \%$ mass. F). Shark teeth enameloid [63,309-314] and some exoskeletons of mollusks [315] seem to be the only exceptions because they contain substantial amounts of FA. Among all normal calcified tissues of humans, the highest concentration of fluorides is found in bones and the lowest - in dental enamel [316] (Table 1). However, even in bones, the total amount of fluorides is not enough to form FA; it is generally considered that the inorganic part of bones consists of ion-substituted CDHA. Due to the lowest solubility, good chemical stability and toxicity of high amounts of fluorides, chemically pure FA is rarely used as a bone substituting material [323]. However, due to the ability to form FHA and/or HFA, minor amounts of fluorides might be intentionally added to calcium orthophosphate biomaterials [324-330]. The effect of fluoride contents in FHA on both osteoblast behavior [331] and leukemia cells proliferation [332] has been described.

\subsection{TTCP}

TTCP (or TetCP) (tetracalcium phosphate or tetracalcium phosphate monoxide $\mathrm{Ca}_{4}\left(\mathrm{PO}_{4}\right)_{2} \mathrm{O}$; the mineral hilgenstockite [333]) is the most basic calcium orthophosphate. However, its solubility in water is higher than that of HA (Table 2). TTCP cannot be precipitated from aqueous solutions. It can be prepared only by a solid-state reaction above $1300{ }^{\circ} \mathrm{C}$, e.g., by heating homogenized equimolar quantities of DCPA and $\mathrm{CaCO}_{3}$ in dry air, or in a flow of dry nitrogen [14,181,336]. DCPA might be replaced by ammonium orthophosphates [337]. These reactions should be carried out in a dry atmosphere, under vacuum or with rapid cooling (to prevent uptake of water and formation of HA). TTCP is not very stable in aqueous solutions: it slowly hydrolyses to HA and calcium hydroxide $[14,181]$ and consequently, TTCP is never found in biological calcifications. In medicine, TTCP is widely used for preparation of various self-setting calcium phosphate cements [78,86,93,106,338]; however, to the best of my knowledge, there is no commercial bone-substituting product consisting solely of TTCP.

There is an opinion [74], that the aforementioned calcium orthophosphates might be classified into three major structural types: (i) the apatite type, $\mathrm{Ca}_{10}\left(\mathrm{PO}_{4}\right)_{6} \mathrm{X}_{2}$, which includes HA, FA, CDHA, OCP and TTCP; (ii) the glaserite type, named after the mineral glaserite, $\mathrm{K}_{3} \mathrm{Na}\left(\mathrm{SO}_{4}\right)_{2}$, which includes all polymorphs of TCP and, perhaps, ACP; (iii) the $\mathrm{Ca}-\mathrm{PO}_{4}$ sheet-containing compounds, which include DCPD, DCPA, MCPM and MCPA. According to the authors, a closer examination of the structures revealed that all available calcium orthophosphates could be included into distorted glaserite type structures, but with varying degrees of distortion [74].

\subsection{Substituted Calcium Orthophosphates}

To conclude this part, one should briefly mention carbonateapatite [339-343], chlorapatite [344,345] and various ion-substituted calcium orthophosphates [45,346]. Usually, they are of a non- 
stoichiometric nature and there are too many of them to be mentioned in one review; therefore, the readers are referred to books and monographs covering the subject [13-15,19,21,27,63,181,289,293]. In addition, there is a very good review, in which the structures of more than 75 chemically different apatites have been discussed [73].

It is interesting to note, that chemical elements not found in natural bones can be intentionally incorporated into calcium orthophosphate biomaterials to produce special properties. For example, addition of $\mathrm{Ag}^{+}[347,348], \mathrm{Zn}^{2+}$ and $\mathrm{Cu}^{2+}$ [348] has been used for imparting antimicrobial effects, while radioactive isotopes of ${ }^{90} \mathrm{Y}$ [349], ${ }^{153} \mathrm{Sm}$ [350-352] and ${ }^{186} \mathrm{Re}$ [350] have been incorporated into HA bioceramics and injected into knee joints to treat rheumatoid joint synovitis [349,350,352]. More to the point, apatites were found to be able to incorporate individual molecules, such as water, oxygen and carbon dioxide [45].

\section{Biological Calcium Orthophosphate Hard Tissues}

Biological mineralization (biomineralization) is the process of in vivo formation of inorganic minerals [311,312]. As shown in Table 1 and discussed above, in the bodies of mammals the vast majority of both normal and pathological calcifications consist of ion-substituted calcium orthophosphates, mainly of apatitic structure [50,353]. On an element scale, bone apatite nanocrystals exhibit a variety of substitutions and vacancies that make the $\mathrm{Ca} / \mathrm{P}$ molar ratio diverge from the stoichiometric HA ratio of 1.67. The impurities in biological apatite of bones and teeth introduce significant stresses into the crystal structure, which make it less stable and more reactive. Among all substituting ions, the presence of $4-8 \%$ of carbonates instead of orthophosphate anions (so called, Btype substitution [13-15,343]) and of $0.5-1.5 \%$ of $\mathrm{Mg}$ is of the special importance because it leads to large lattice strain and significantly increases the solubility [353,354]. High concentrations of magnesium and carbonates in bone or dentin compared with enamel (Table 1) may explain a higher solubility and a lower crystallinity (smaller crystal size) of bone or dentin compared with enamel. In addition, the crystals of biological apatite are always very small, which also increases its solubility when compared with that for the chemically pure HA and even CDHA [45]. Small dimensions and a low crystallinity are two distinct features of biological apatite, which, combined with their nonstoichiometric composition, inner crystalline disorder and presence of other ions in the crystal lattice, allow explaining their special behavior. For example, the small crystal size means that a large percentage of the atoms are on the surface of the crystal, providing a large specific surface area for sorption of ions, proteins and drugs [354,355]. The major properties of biological apatite are summarized in Figure 5. It is interesting to note, that the solubility and equilibrium phenomena of calcium orthophosphates related to the calcification process have been studied, at least, since $1925[356,357]$.

The calcium orthophosphate nature of bones was first determined in 1913 [358]. This discovery was clarified afterwards, suggesting that the bone mineral could be carbonated apatite [359,360]. Further optical and X-ray analysis of bones and other mineralized tissues matched analyses of two apatites: FA and dahllite [361]. Additional historical data on this point are available in literature [44]. Nowadays, according to Weiner and Wagner: "the term bone refers to a family of materials, all of which are built up of mineralized collagen fibrils" [362,363]. For mammals, this family of materials includes dentin - 
the material that constitutes the inner layers of teeth, cementum - the thin layer that binds the roots of teeth to the jaw, deer antlers and some other materials [362,364]. It is worth noting, that bones and teeth contain almost $99 \%$ of the total body calcium and about $85 \%$ of the total body phosphorus that amounts to a combined mass of approximately $2 \mathrm{~kg}$ in an average person [365,366]. In addition, it is important to recognize that calcium orthophosphates of bones are by no means inert; they play an important role in the metabolic functions of the body. The recent data on the physico-chemical and crystallographic study of biological apatite have been reviewed elsewhere [367]. Besides, there is a comprehensive review on the application of surface science methods to study the properties of dental materials and related biomaterials [368].

Figure 5. Crystal structure of biological apatites. Powder X-ray diffraction patterns and infrared spectra of enamel, dentine and bone. Reprinted from Ref. [355] with permission.

\section{biological apatites}

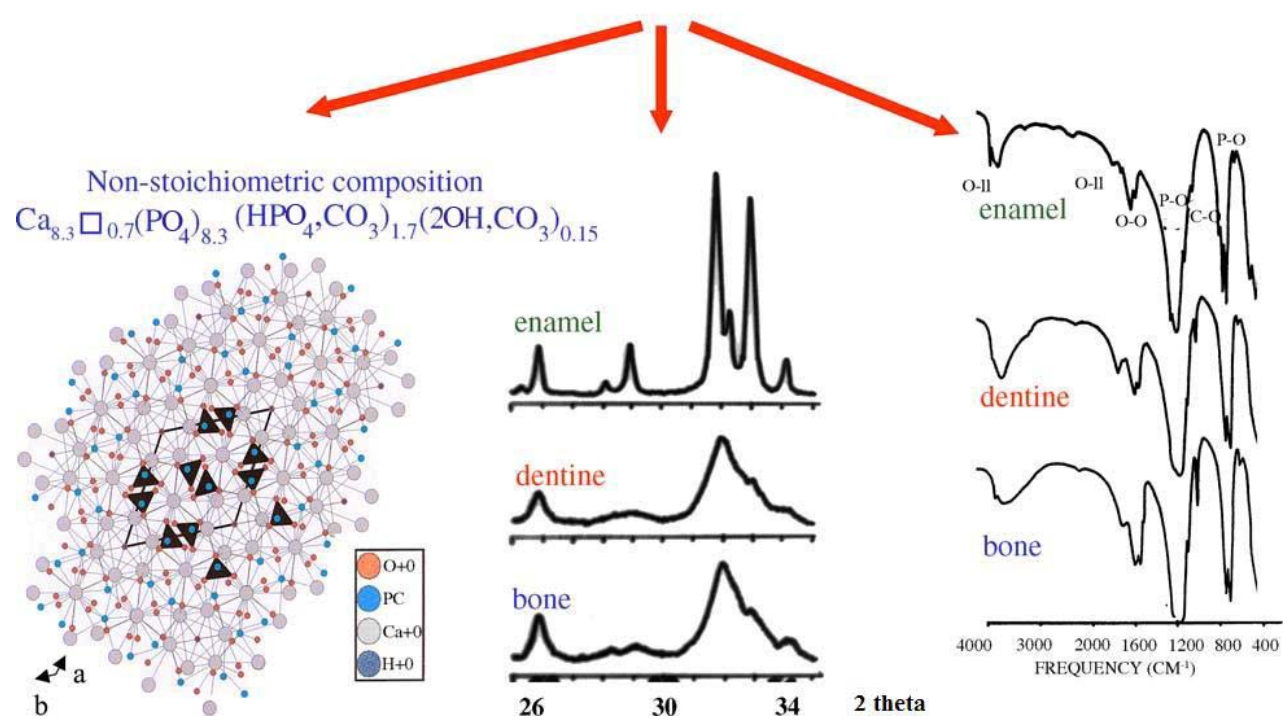

\subsection{Bone}

Bone (Latin: os), also called osseous tissue, is a type of hard endoskeletal connective tissue found in many vertebrate animals. All bones of a single animal are, collectively, known as the skeleton. True bones are present in bony fish (osteichthyes) and all tetrapods. Bones support body structures, protect internal organs and, in conjunction with muscles, facilitate movement [369]. In addition, bones are also involved with blood cell formation, calcium metabolism and act for mineral storage. From the material point of view, bone is a dynamic, highly vascularized tissue that is formed from a complicated composite containing both inorganic (Table 1) and biooorganic compounds (chiefly, collagen) [353,370-376]. The inorganic to biooorganic ratio is approximately $75 \%$ to $25 \%$ by dry weight and about $65 \%$ to $35 \%$ by volume. This ratio not only differs among animals, among bones in the same animal and over time in the same animal, but also it exerts a major control over the material properties of bone, such as its toughness, ultimate strength and stiffness. In general, load-bearing ability of bones depends on not only architectural properties, such as cortical thickness and bone diameter, but also 
intrinsic, size-independent, material properties such as porosity, level of mineralization, crystal size and properties derived from the organic phase of bone [377]. A higher mineral to collagen ratio typically yields stronger, but more brittle, bones [378-380]. For example, bone from the leg of a cow has a relatively high concentration of calcium orthophosphates (for support), whereas bone from the antler of a deer has a relatively high concentration of collagen (for flexibility) [80]. It is interesting to note, that bone exhibits several physical properties such as piezoelectricity [381] and pyroelectricity [382].

Stability of the mineral composition of bones has a very long history: calcium orthophosphates were found in dinosaur fossils [31,383-386]. Therefore, organisms have had a great deal of time to exploit the feedback between composition and structure in apatite, on the one hand, and benefit from its biological functionality, on the other. Bones of modern animals is a relatively hard and lightweight porous composite material, formed mostly of biological apatite (i.e., CDHA with ionic substitutions). It has relatively high compressive strength but poor tensile strength [387]. While bone is essentially brittle, it has a degree of significant plasticity contributed by its organic components. Usually bone is composed of a relatively dense outer layer (cortical or compact bone) covering an internal mesh-like structure (average porosity of $75-95 \%$ ) of cancellous (other terms: spongy, trabecular) bone, the density of which is about $0.2 \mathrm{~g} / \mathrm{cm}^{3}$ but it may vary at different points (Figure 6). The porosity reduces the strength of bones but also reduces their weight.

Cortical bone makes up a large portion of skeletal mass; but due to its high density $\left(\sim 1.80 \mathrm{~g} / \mathrm{cm}^{3}\right)$ it has a low surface area. Cancellous bone has an open meshwork or honeycomb-like structure. It has a relatively high surface area but forms a smaller portion of the skeleton. Bone is a porous material with the pore sizes range from 1 to $100 \mu \mathrm{m}$ in normal cortical bone and 200 to $400 \mu \mathrm{m}$ in trabecular bone. 55 to $70 \%$ of the pores in trabecular bone are interconnected [13,46,47,61-63,311,362,371-375,388-391].

Bone can be either woven or lamellar. The fibers of woven bone are randomly aligned and as the result have a low strength. In contrast, lamellar bone has parallel fibers and is much stronger. Woven bone is put down rapidly during growth or repair [392] but as growth continues, it is often replaced by lamellar bone. The replacement process is called "secondary bone formation" and described in detail elsewhere [393 and references therein]. In addition, bones might be long, short, flat and irregular. The sizes and shapes of bones reflect their function. Namely, broad and flat bones, such as scapulae, anchor large muscle masses, flat skull bones protect the brain, ribs protect the lungs, pelvis protects other internal organs, short tubular bones in the digits of hands and feet provide specific grasping functions, hollow and thick-walled tubular bones, such as femur or radius, support weight and long bones enable locomotion [394,395]. Long bones are tubular in structure (e.g., the tibia). The central shaft of a long bone is called the diaphysis and has a medullar cavity filled with bone marrow (Figure 6). Surrounding the medullar cavity is a thin layer of cancellous bone that also contains marrow. The extremities of the bone are called the epiphyses and are mostly cancellous bone covered by a relatively thin layer of compact bone. Short bones (e.g., finger bones) have a similar structure to long bones, except that they have no medullar cavity. Flat bones (e.g., the skull and ribs) consist of two layers of compact bone with a zone of cancellous bone sandwiched between them. Irregular bones (e.g., vertebrae) do not conform to any of the previous forms. Thus, bones are shaped in such a manner that strength is provided only where it is needed. All bones contain living cells embedded in a mineralized organic matrix that makes up the main bone material [394-396]. The structure of bone is most easily 
understood by differentiating between seven levels of organization because bone exhibits a strongly hierarchical structure (Figure 7) [289,311,353,362,370-375,381-386,388-391,397-399].

Figure 6. General structure of a mammalian bone. Other very good graphical sketches of the mammalian bone structure are available in Refs. [50,355].

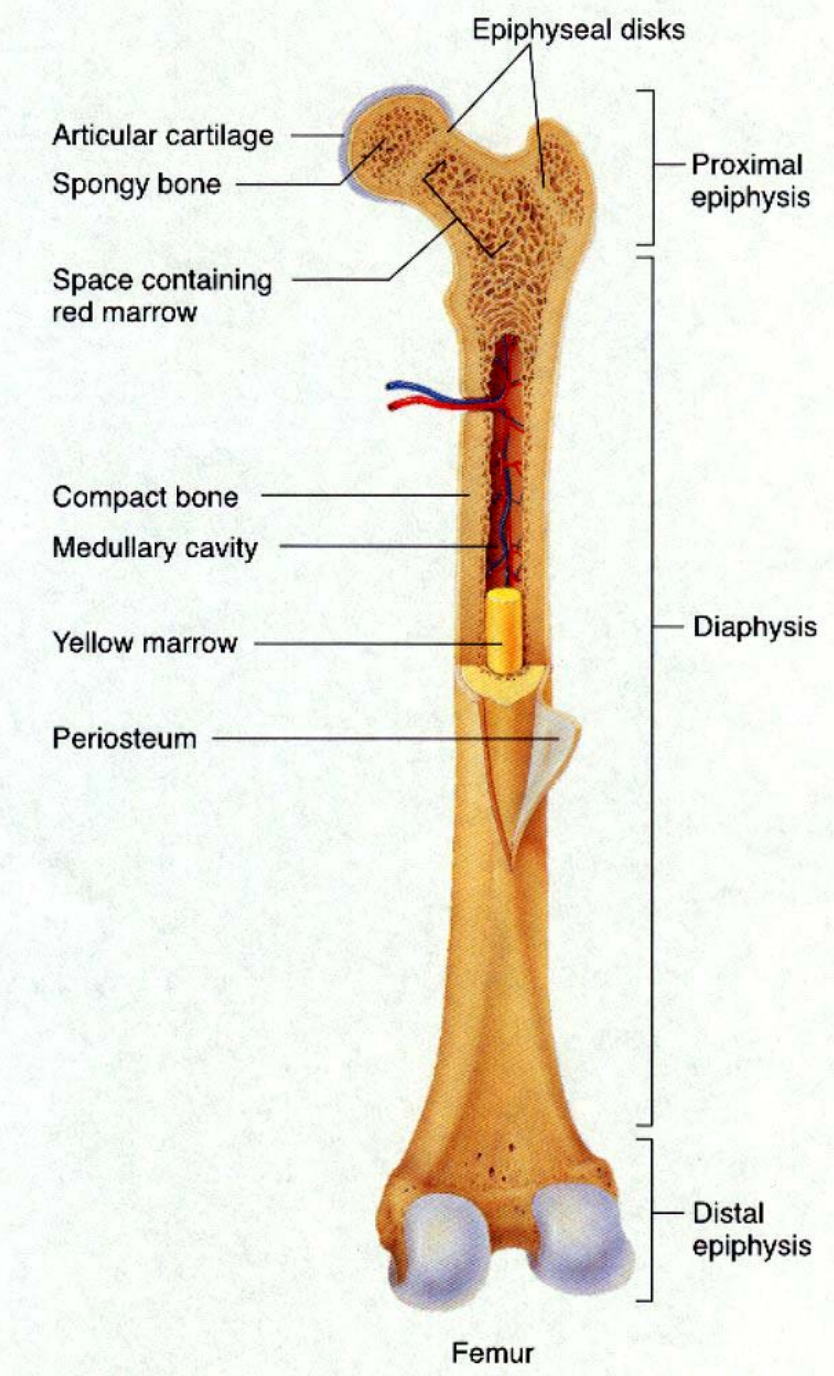

The mechanical properties of bone reconcile high stiffness and high elasticity in a manner that is not yet possible with synthetic materials [400]. Cortical bone specimens have been found to have tensile strength in the range of $78.8-151.0 \mathrm{MPa}$ in longitudinal direction and 51.0 - 56.0 $\mathrm{MPa}$ in transversal direction. Bone's elasticity is also important for its function giving the ability to the skeleton to withstand impact. Estimates of modulus of elasticity of bone samples are of the order of $17.0-20.0 \mathrm{GPa}$ in longitudinal direction and of $6.0-13.0 \mathrm{GPa}$ in the transversal direction [401]. The elastic properties of bone were successfully modeled at the level of mineralized collagen fibrils via step-by-step homogenization from the staggered arrangement of collagen molecules up to an array of parallel mineralized fibrils [402]. Recent investigations revealed that bone deformation was not homogeneous but distributed between a tensile deformation of the fibrils and a shearing in the interfibrillar matrix between them $[403,404]$. Furthermore, there is a good review on the effects of the microscopic and nanoscale structure on bone fragility [405]. 
Figure 7. The seven hierarchical levels of organization of the zebrafish skeleton bone. Level 1: Isolated crystals and part of a collagen fibril with the triple helix structure. Level 2: Mineralized collagen fibrils. Level 3: The array of mineralized collagen fibrils with a cross-striation periodicity of nearly 60-70 $\mathrm{nm}$. Level 4: Two fibril array patterns of organization as found in the zebrafish skeleton bone. Level 5: The lamellar structure in one vertebra. Level 6: A vertebra. Level 7: Skeleton bone. Reprinted from Ref. [418] with permission. Other good graphical sketches of the hierarchical structure of bones are available in Refs. [362,400].

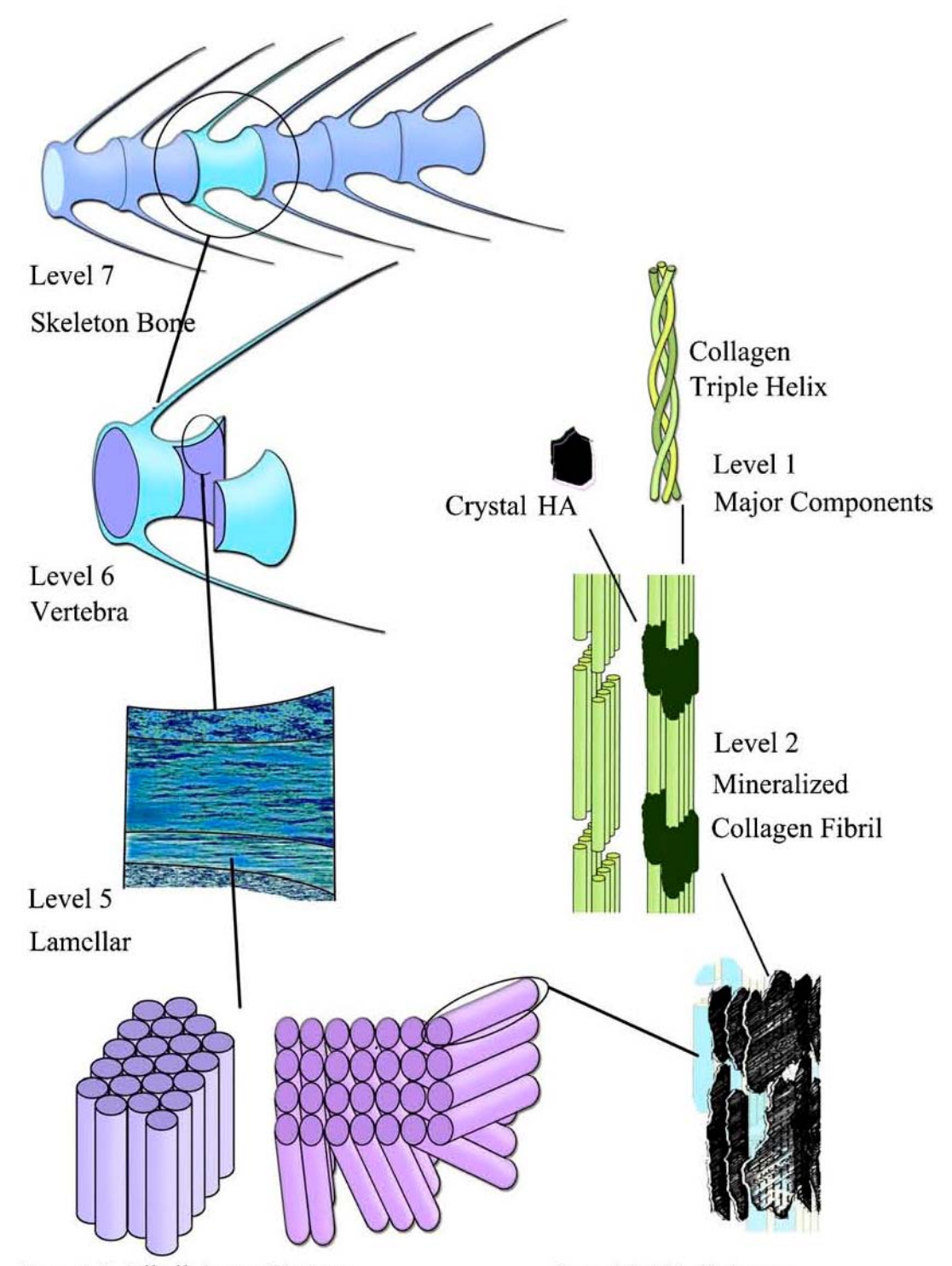

Level 4 Fibril Array Pattern

Level 3 Fibril Array

Nanoscopically, the constituting building blocks of bone are mineralized collagen fibrils of 80 to $100 \mathrm{~nm}$ thickness and a length of a few to tens of microns. These are composites of biological apatite and molecules of type I collagen [50,362,370,376,406]. Some evidence for direct physical bonding between the collagen fibers and apatite crystals in bone has been found [407]. Eppell et al. used atomic force microscopy to measure the crystallites of mature cow bone [408]. They are always platelet-like (elongated along the crystallographic $c$-axis) and very thin [49,409-411], with remarkably uniform thicknesses (determined in transmission electron microscopy) of $2-4 \mathrm{~nm}$ [412] (just a few unit cells 
thick - see Table 1). The nanocrystals of biological apatite exist in bones not as discrete aggregates but rather as a continuous phase, which is indirectly evidenced by a very good strength of bones. This results in a very large surface area facing extracellular fluids, which is critically important for the rapid exchange of ions with these fluids. The nanocrystals of biological apatite are inserted in a nearly parallel way into the collagen fibrils, while the latter are formed by self-assembly [413] of collagen triple helices [362,370,415-418] using the self-organization mechanism [419,420]. Recent data from electron diffraction studies revealed that that the mineral plates of biological apatite are not quite as ordered as previously assumed [393]. This imperfect arrangement of nearly parallel crystals has been supported by recent SAXS and transmission electron microscopy studies [421].

The lowest level of hierarchical organization of bone has been simulated by CDHA precipitation on peptide-amphiphile nanofibers [420]. However, apatite platelets nucleating on the surface of peptide tubules are not similar to the nanostructure of bone and they are only an example of surface induced nucleation (and not accurately characterized either), while the nanostructure of bone consists of intrafibrillar platelets intercalated within the collagen fibrils. Olszta and Gower were the first to truly duplicate the bone nanostructure [393]. Unfortunately, the interface between collagen and crystals of biological apatite is still poorly understood; for the available details, the readers are referred to a review devoted to the structure and mechanical quality of the collagen/mineral nano-composite of bones [406]. There is still no clear idea why the crystals of biological apatite are platelet-shaped even though dahllite has hexagonal crystal symmetry [311,362,371-375,381-386,388-391]. One possible reason is that they grow via an OCP transition phase, which crystals are plate-shaped [362].

The processes of bone formation (ossification) and growth are very complicated ones and it is difficult to describe them without making a deep invasion into biology. It has been studied for decades [392] but still there are missing points. Briefly, it is considered that bones appear and grow as the result of calcification (or biomineralization) of connective tissues, mainly cartilage [353,393]. The ossified tissue is invaginated with blood vessels, which bring ions of calcium and orthophosphate to be deposited in the ossifying tissue. The biomineralization process is controlled to some extent by cells and the organic matrices made by those cells facilitate the deposition of crystals [396]. There is an opinion, that, initially, the mineral crystals are formed in an environment rich in the so-called SIBLING (Small Integrin-Binding LIgand N-linked Glycoprotein) proteins. As bone crystals grow, there is greater association with proteins, such as osteocalcin, that regulate remodeling [422]. Thus, in vivo formation of hard tissues always occurs by mineral reinforcement of the previously formed network of soft tissues [353,393-395,418].

Cartilage is composed of cells (chondrocytes and their precursor forms known as chondroblasts), fibers (collagen and elastic fibers) and extracellular matrix (proteoglycans, which are a special class of heavily glycosylated glycoproteins) [423-425]. The initial stage involves the synthesis and extracellular assembly of the collagen matrix framework of fibrils. At the second stage, the chondrocytes calcify the matrix before undergoing the programmed cell death (apoptosis). At this point, blood vessels penetrate this calcified matrix, bringing in osteoblasts, which use the calcified cartilage matrix as a template to build bone, thus completing ossification [423-425].

During ossification, the crystals of biological apatite grow with a specific crystalline orientation the $c$-axes of the crystals are roughly parallel to the long axes of the collagen fibrils within which they are deposited [353,362,364-368,371-373,376, 393]. Earlier, it was believed that this process occurred 
via epitaxial growth mechanism [426]. The same was suggested for dentin and enamel [427,428] (see below), as well as for more primitive living organisms. For example, in the shell of the fossil marine animal Lingula brachiopod unguis that consists of a biological apatite, the crystal $c$-axes are oriented parallel to the $\beta$-chitin fibrils $[315,429-432]$. Therefore, the orientation of biological apatite crystals parallel to the long axes of the organic framework could be a general feature of calcium orthophosphate biomineralization. However, the degree of biological apatite orientation appears to be a useful parameter to evaluate in vivo stress distribution, nano-scale microstructure and the related mechanical function, the regenerative process of the regenerated bone and to diagnose bone diseases such as osteoarthritis $[433,434]$. It is interesting to note, that contrary to what might be expected in accordance with possible processes of dissolution, formation and remineralization of hard tissues, no changes in phase composition of mineral part, crystal sizes (length, width and thickness) and arrangement of crystals on collagen fibers were detected in abnormal (osteoporotic) human bones compared to the normal ones [435].

Some animals, such as newts, are able to regenerate amputated limbs. This is, of course, of high interest in regenerative medicine. Bone regeneration in the forelimbs of mature newts was studied by noninvasive X-ray microtomography to image regenerating limbs from 37 to 85 days. The missing limb skeletal elements were restored in a proximal-to-distal direction, which reiterated the developmental patterning program. However, in contrast to this proximal-distal sequence, the portion of the humerus distal to the amputation site was found to fail to ossify in synchrony with the regenerating radius and ulna. This finding suggests that the replacement of cartilage with mineralized bone close to the amputation site is delayed with respect to other regenerating skeletal elements [436].

Unlike other mineralized tissues, bone continuously undergoes a remodeling process, as it is resorbed by specialized cells called osteoclasts and formed by another type of cells called osteoblasts (so called "bone lining cells") in a delicate equilibrium [353,393,396,437,438]. The purpose of remodeling is the release of calcium and the repair of micro-damaged bones from everyday stress. Osteoblasts are mononuclear cells primarily responsible for bone formation. They contain alkaline phosphatase, which enzymatically produces orthophosphate anions needed for the mineralization. In addition, there is one more type of the cells called osteocytes that originate from osteoblasts, which have migrated into, become trapped and surrounded by bone matrix, which they themselves produce [353,371-374,393-396].

If osteoblasts are bone-forming cells, osteoclasts are multinuclear, macrophage-like cells, which can be described as bone destroying cells because they mature and migrate to discrete bone surfaces [396,437,438]. Upon arrival, active enzymes, such as acid phosphatase, are secreted against the mineral substrate that causes dissolution. This process, called bone resorption, allows stored calcium to be released into systemic circulation and is an important process in regulating calcium balance [437,438]. The iteration of remodeling events at the cellular level is influential on shaping and sculpting the skeleton both during growth and afterwards. That is why mature bone consists of a very complex mesh of bone patches, each of which has both a slightly different structure and a different age [311,353,362,364-368,371-373,393]. The interested readers are suggested to read a review on the interaction between biomaterials and osteoclasts [439].

There is still no general agreement on the chemical mechanism of bone formation. It is clear that the inorganic part of bone consists of biological apatite, i.e. CDHA with ionic substitutions but without 
the detectable amounts of hydroxide [440-444]. However, the recent results of solid-state nuclear magnetic resonance on fresh-frozen and ground whole bones of several mammalian species revealed that the bone crystal $\mathrm{OH}^{-}$was readily detectable; a rough estimate yielded an $\mathrm{OH}^{-}$content of human cortical bone of about $20 \%$ of the amount expected in stoichiometric HA [445]. Various in vitro experiments on precipitation of CDHA and HA revealed that none of these compounds is directly precipitated from supersaturated aqueous solutions containing calcium and orthophosphate ions: some intermediate phases (precursors) are always involved [13,46,47,124-129,174-178]. Depending on the both solution $\mathrm{pH}$ and crystallization conditions, three calcium orthophosphates (DCPD, ACP and OCP) are discussed as possible precursors of CDHA precipitation in vitro. For this reason, the same calcium orthophosphates are suggested as the precursors of biological apatite formation in vivo.

The transient nature of the precursor phase of bone, if it exists at all, makes it very difficult to detect, especially in vivo [446]. However, in 1966 W. E. Brown proposed that OCP was the initial precipitate that then acted as a template upon which biological apatite nucleates [123]. This idea was extended in his further investigations [447-450]. The principal support for this concept derived from the following: (i) the close structural similarity of OCP and HA [121,122]; (ii) formation of interlayered single crystals of OCP and HA (pseudomorphs of OCP); (iii) the easier precipitation of OCP compared with HA; (iv) the apparent plate- or lath-like habit of biological apatites that does not conform to hexagonal symmetry, but looks like a pseudomorph of triclinic OCP; (v) the presence of $\mathrm{HPO}_{4}{ }^{2-}$ in bone mineral, particularly in newly formed bones [367]. Some evidences supporting this idea were found using high-resolution transmission electron microscopy: computer-simulated lattice images of the "central dark line" in mineralized tissues revealed that it consisted of OCP [124-126]. Recently, Raman spectroscopic indication for an OCP precursor phase was found during intramembranous bone formation [451]. Other evidences of OCP to HA transformation, including a mechanistic model for central dark line formation, may be found in the literature [452].

Simultaneously with Brown, the research group led by Posner proposed that ACP was the initially precipitated phase of bone and dentin mineral formation in vivo, thus explaining the nonstoichiometric $\mathrm{Ca} / \mathrm{P}$ ratio in bones and teeth [453-455]. This conclusion was drawn from the following facts: (i) when calcium orthophosphates are prepared by rapid precipitation from aqueous solutions containing ions of calcium and orthophosphate at $\mathrm{pH}>8.5$, the initial solid phase is amorphous; (ii) mature bone mineral is composed of a mixture of ion-substituted ACP and poorly crystallized ionsubstituted CDHA; (iii) early bone mineral has a lower crystallinity than mature bone and the observed improvement in crystallinity with the age of the bone mineral is a result of a progressive reduction in the ACP content [367,453-461]. However, there are thermodynamic data proving that the transition of freshly precipitated ACP into CDHA involves intermediate formation of OCP $[462,463]$. Recently the discovery of a stable amorphous calcium carbonate in sea urchin spines [464] reawakened the suggestion that a transient amorphous phase might also exist in bones [393,465-468]. Even more recently, evidence of an abundant ACP phase in the continuously forming fin bones of zebrafish was found [469]. The modern points of view on the bone formation mechanisms have been summarized in a recent excellent review [393], to which the interested readers are referred.

The maturation mechanism of bone minerals is not well established, mainly because of the difficulties involved in the nanostructural analyses of bone minerals [393,470]. Only indirect evidence for the in vivo bone mineral maturation is available. For example, X-ray diffraction patterns of bones 
from animals of different ages show that the reflections become sharper with age increasing [55,471]. This effect is more pronounced in the crystallographic $a$-axis [(310) reflections] as compared to the $c$ axis [(002) reflections] [472,473]. In addition, other changes, like an increase of $\mathrm{Ca}^{2+}$ content and a decrease of $\mathrm{HPO}_{4}{ }^{2-}$, occur in bone mineral with age [474-477]. Both the crystal sizes and carbonate content were found to increase during aging in rats and cows $[475,476]$. From a chemical point of view, these changes indicate to a slow transformation of poorly crystallized non-apatitic calcium orthophosphates into a better-crystallized ion-substituted CDHA [306]. While there are still many gaps in our knowledge, the researchers seem to be comfortable in stating that in all but the youngest bone and dentin, the only phase present is a highly disordered, highly substituted biological apatite.

Earlier, a debate related to the question on whether bone formation was an active or a passive biomineralization process. Briefly, an "active process" means the assembly of calcium orthophosphate nanocrystals into bones due to an activity of the suitable cells (e.g., osteoblasts), i.e. within a matrix vesicle. Such structures have been discovered by transmission electron microscopy for bone and teeth formation [478,479]. A "passive process" does not require involvement of cells and means mineralization from supersaturated solutions with respect to the precipitation of biological apatite. In the latter case, thermodynamically, biomineralization might occur at any suitable nucleus. The collagen fibrils have a specific structure with a $67 \mathrm{~nm}$ periodicity and $35-40 \mathrm{~nm}$ gaps or holes between the ends of the collagen molecules where bone mineral is incorporated in the mineralized fibril [311,362,363,376,394,395]. Such a nucleation within these holes would lead to discrete crystals with a size related to the nucleating cavity in the collagen fibril. It was proposed that a temporary absence of the specific inhibitors might regulate the process of bone formation [480-482].

To conclude the bone subject, let us briefly mention on the practical application of bones. Cut and polished bones from a variety of animals are sometimes used as a starting material for jewelry and other crafts. Ground cattle bone is occasionally used as a fertilizer. In the Stone Age, bone was used to manufacture art, weapons, needles, catchers, amulets, pendants, headdresses, etc. Furthermore, in medicine, bones are used for bone graft substitutes, e.g., allografts from cadavers.

\subsection{Teeth}

Teeth (singular: tooth) are dense structures found in the jaws of many vertebrates. They have various structures to allow them to fulfill their different purposes. The primary function of teeth is to tear, smell and chew food, while for carnivores it is also a weapon. Therefore, teeth have to withstand a range of physical and chemical processes, including compressive forces (up to $\sim 700 \mathrm{~N}$ ), abrasion and chemical attack due to acidic foods or products of bacterial metabolism [368]. The roots of teeth are covered by gums. From the surface teeth are covered by enamel of up to $\sim 2 \mathrm{~mm}$ thick at the cutting edges of the teeth, which helps to prevent cavities on the teeth. The biggest teeth of some gigantic animals (elephants, hippopotamuses, walruses, mammoths, narwhals, etc.) are known as tusks or ivory.

Similar to the various types of bones, there are various types of teeth. The shape of the teeth is related to the animal's food, as well as its evolutionary descent. For example, plants are hard to digest, so herbivores have many molars for chewing. Carnivores need canines to kill and tear and since meat is easy to digest, they can swallow without the need for molars to chew the food well. Thus, the following types of teeth are known: molars (used for grinding up food), carnassials (used for slicing 
food), premolars (small molars), canines (used for tearing apart food) and incisors (used for cutting food). While humans only have two sets of teeth, some animals have many more: for example, sharks grow a new set of teeth every two weeks. Some other animals grow just one set during the life, while teeth of rodents grow and wear away continually through the animal gnawing, maintaining constant length $[483,484]$.

Similar to bones, the inorganic part of teeth also consist of biological apatite [485]. The stability of the mineral composition of teeth also has a very long history: namely, calcium orthophosphates were found in fossil fish teeth [486]. Recent investigations of biological apatite from fossil human and animal teeth revealed its similarity to the modem biological apatite [487].

The structure of teeth appears to be even more complicated than that of bone (Figure 8). Unlike bone, teeth consist of at least two different materials: enamel that is a hard outer layer consisting of calcium orthophosphates and dentin, which is a bone-like inner layer, the bulk of the tooth. In addition, there is a thin layer around the tooth roots called cementum - it covers the anatomic root of the tooth. Cementum is a bone-like material similar to dentin, which connects the teeth to the jaw [488]. Finally, there is the core called pulp (commonly called "the nerve") - it is a remnant of the embryologic organ for tooth development and contains nerves and blood vessels necessary for tooth function (Figure 8) $[394,395,483,484]$. Both dentin and cementum are mineralized connective tissues with an organic matrix of collagenous proteins, while the inorganic component of them consists of biological apatite. As shown in Table 1, dentin, cementum and bone are quite similar and for general purposes of material science they can be regarded as being essentially the same material [311,362,364-368,371375,381,382,384-386,388-391,406,410,411,415,474,475]. Thus, most statements made in the previous chapter for bone are also valid for dentin and cementum; however, unlike bones, both dentin and cementum lack vascularization [489].

Dental enamel is the outermost layer of teeth. It is white and translucent and its true color can only be observed at the cutting edges of the teeth. Enamel is highly mineralized and acellular, so it is not a living tissue. Nevertheless, it is sufficiently porous for diffusion and chemical reactions to occur within its structure, particularly acidic dissolution (dental caries) and remineralization from saliva (possible healing of caries lesions). Enamel is the hardest substance in the body [387] and forms a solid, tough and wear-resistant surface for malaxation. In the mature state, it contains up to $98 \%$ of inorganic phase (Table 1). The crystals of biological apatite of enamel are much larger as evidenced by higher crystallinity (reflecting greater crystal size and perfection) demonstrated in their X-ray diffraction patterns, than those of bone and dentin. Besides, enamel apatite has fewer ionic substitutions than bone or dentin mineral and more closely approximates the stoichiometric HA [394]. The organic phase of enamel does not contain collagen. Instead, enamel has two unique classes of proteins called amelogenins and enamelins. While the role of these proteins is not fully understood yet, it is believed that both classes of proteins aid in the enamel development by serving as a framework support $[483,484,490]$. The large amount of minerals in enamel accounts not only for its strength but also for its brittleness. Dentin, which is less mineralized and less brittle, compensates for enamel and is necessary as a support $[483,484]$. Shark enameloid is an intermediate form bridging enamel and dentin. It has enamel-like crystals of fluoridated biological apatite associated with collagen fibrils [45,309-314]. Due to the presence of fluorides, biological apatite of shark enameloid shows both higher crystal sizes and a more regular hexagonal symmetry if compared to non-fluoridated biological 
apatite of bones and teeth [63]. Similar correlation between the presence of fluorides and crystal dimensions was found for enamel [491].

Figure 8. A schematic drawing of a tooth. Other very good graphical sketches of the mammalian tooth structure, including the hierarchical levels, are available in Refs. [353,400].

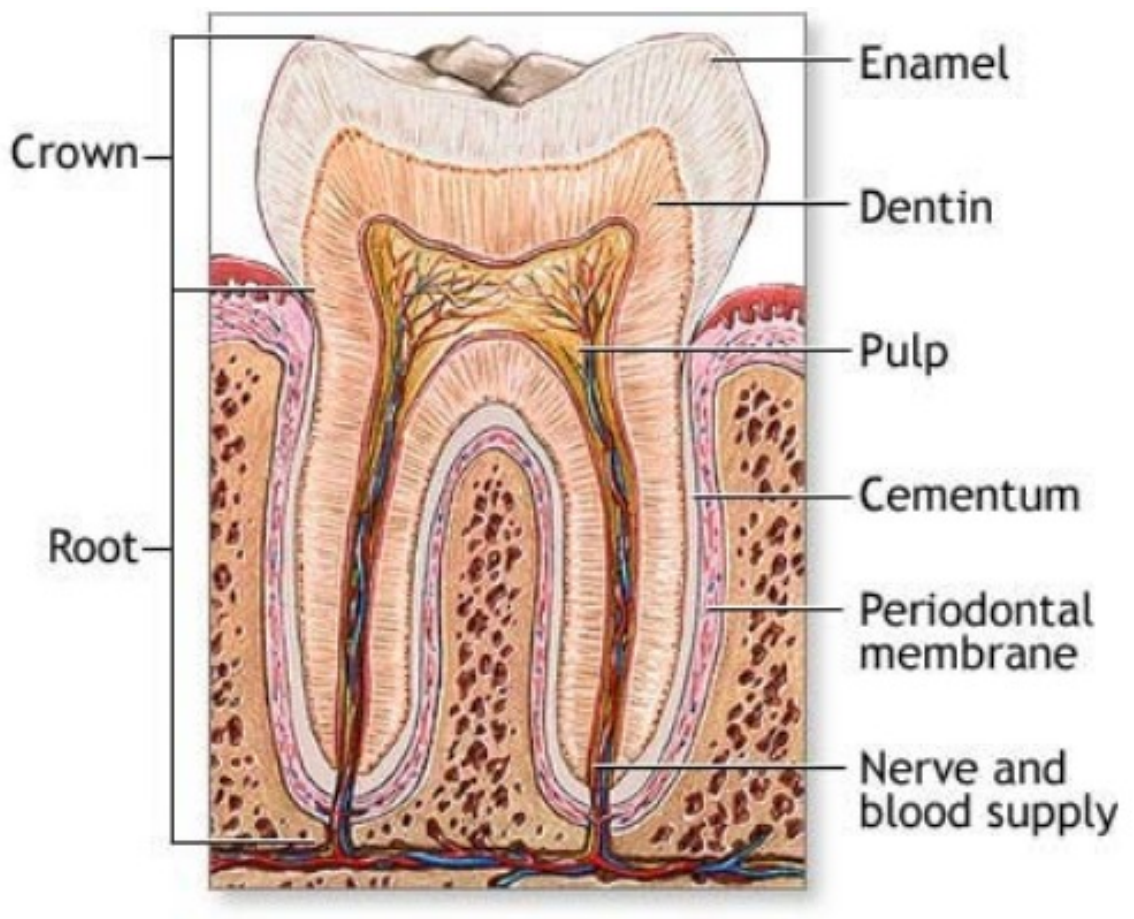

Like that for bones, seven levels of structural hierarchy have been also discovered in human enamel; moreover, the analysis of the enamel and bone hierarchical structure suggests similarities of the scale distribution at each level [353,401,492]. On the mesoscale level, there are three main structural components: a rod, an interrod and aprismatic enamel. Among them, the enamel rod (formerly called an enamel prism) is the basic unit of enamel. It is a tightly packed mass of biological apatite in an organized pattern. Each rod traverses uninterrupted through the thickness of enamel. They number 5 to 12 million rods per crown. The rods increase in diameter ( 4 up to 8 microns) as they flare outward from the dentin-enamel junction (DEJ). Needle-like enamel rods might be tens of microns long (up to $100 \mu \mathrm{m}$ ) but sometimes only $50 \mathrm{~nm}$ wide and $30 \mathrm{~nm}$ thick (Figure 9) [483,484,493-500]. They are quite different from the much smaller crystals of dentin and bone (Table 1), but all of them consist of biological apatite [296,501,502]. In cross section, an enamel rod is best compared to a keyhole, with the top, or head, oriented toward the crown of the tooth and the bottom, or tail, oriented toward the root of the tooth.

The arrangement of the crystals of biological apatite within each enamel rod is highly complex. Enamel crystals in the head of the enamel rod are oriented parallel to the long axis of the rod. When found in the tail of the enamel rod, the crystals' orientation diverges slightly from the long axis $[483,484]$. The arrangement of the enamel rods is understood more clearly than their internal structure. Enamel rods are found in rows along the tooth (Figure 9) and, within each row, the long axis of the enamel rod is generally perpendicular to the underlying dentin [483,484,493-497]. A recent AFM 
study indicated that CDHA crystals in enamel exhibited regular subdomains or subunits with distinct chemical properties related to topographical features and gave rise to patterned behavior in terms of the crystal surface itself and the manner in which it responded to low $\mathrm{pH}$ [503].

Figure 9. Scanning electron micrograph of the forming enamel of a continuously growing rat incisor showing ordered rods of calcium orthophosphates. Scale bar: $10 \mu \mathrm{m}$ (taken from Ref. [311] with permission).

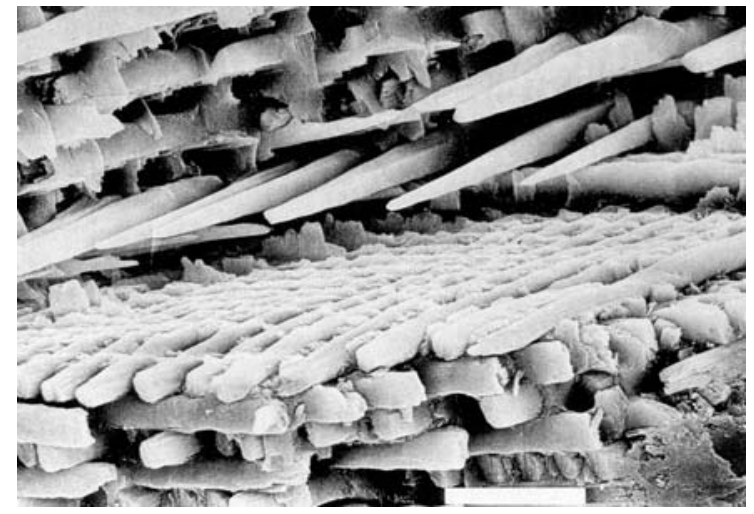

The second structural component of the enamel matrix is the interrod (or interprismatic) enamel, which surrounds and packs between the rods. The difference between the rod and the interrod is the orientation of apatite crystals; the rod contains aligned crystallites, whereas the mineral in the interrod is less ordered. These structures coalesce to form the tough tissue of enamel, which can withstand high forces and resist damage by crack deflection. The third structure, aprismatic enamel, refers to the structures containing apatite crystals that show no mesoscale or macroscale alignment [353]. Enamel is a selectively permeable membrane, allowing water and certain ions to pass via osmosis $[483,484]$.

The in vivo formation and development of teeth appears to be even more complicated when compared with the aforedescribed process of bone formation. It is a very complex biological process, by which teeth are formed from embryonic cells, grow and erupt into the mouth [396]. For human teeth enamel, dentin and cementum must all be developed during the appropriate stages of fetal development. Primary (baby) teeth start to form in utero between the sixth and eighth weeks, while the permanent teeth begin to form in utero in the twentieth week [483,484]. Recent data confirmed the necessity of calcium orthophosphates in the diet of pregnant and nursing mother to prevent early childhood dental caries [504].

As teeth consist of at least two materials with different properties (enamel and dentin), the tooth bud (sometimes called "the tooth germ" - that is an aggregation of cells that eventually forms a tooth) is organized into three parts: the enamel organ, the dental papilla and the dental follicle. The enamel organ is composed of at least four other groups of cells (for the biological details see Refs. [483,484]). Altogether, these groups of cells give rise to ameloblasts, which secrete enamel matrix proteins. The protein gel adjacent to ameloblasts is supersaturated with calcium orthophosphates, which leads to the precipitation of biological apatite. Similarly, the dental papilla contains cells that develop into odontoblasts, which are dentin-forming cells. The dental follicle gives rise to three important entities: cementoblasts, osteoblasts and fibroblasts. Cementoblasts form the cementum of a tooth. Osteoblasts give rise to the alveolar bone around the roots of teeth (see bone formation above). Fibroblasts develop the periodontal ligaments that connect teeth to the alveolar bone through cementum [394-396,483,484]. 
The first detectable crystals in enamel formation are flat thin ribbons [495-497], that were reported to be OCP [388,505-507], $\beta-(\mathrm{Ca}, \mathrm{Mg})_{3}\left(\mathrm{PO}_{4}\right)_{2}$ [506] or DCPD [440,443]. The crystallization process of enamel is different from that for bone or dentin: amelogenin being hydrophobic self-assembles into nanospheres that guide the growth of the ribbon-like dental enamel crystals. During maturation of enamel, the mineral content increases from initially $\sim 45$ wt. $\%$ up to $\sim 98-99$ wt. $\%[440,483,484]$. The enamel crystal rods widen and thicken by additional growth $[440,443,508]$ with a simultaneous increase of the $\mathrm{Ca} / \mathrm{P}$ molar ratio [508] and a decrease in carbonate content [509-511], finally resulting in the most highly mineralized and hardest substance produced by vertebrates. It is interesting to note that in the radular teeth of chitons, ACP was found to be the first-formed calcium orthophosphate mineral, which over a period of weeks was transformed to dahllite [512].

The crystal faces expressed in enamel are always (100) face and at the ends presumably (001) $[513,514]$, which are the ones usually found in HA. The centers of enamel crystals contain a linear structure known as the "central dark line" (this line was also observed in bone and dentin), which consists of OCP [124-127]. As described above for bones, X-ray diffraction shows that the crystals of younger dentin are less crystalline than those of more mature dentin [474]. Therefore, maturation of dentin also means a slow transformation of biological calcium orthophosphates from ion-substituted ACP to a better-crystallized ion-substituted CDHA.

The development of individual enamel and dentin crystals was studied by high-resolution transmission electron microscopy [515-517]. Both processes appear to be roughly comparable and were described in a four-step process. The first two steps include the initial nucleation and formation of nanometer-sized particles of biological apatite. They are followed by ribbon-like crystal formation, which until recently was considered as the first step of biological crystal formation [515-517]. These complicated processes, starting with the heterogeneous nucleation of inorganic calcium orthophosphates on an organic extracellular matrix, are controlled in both tissues by the organic matrix and are under cellular control [518]. To complicate the process even further, regular and discrete domains of various charges or charge densities on the surface of CDHA crystals derived from the maturation stage of enamel development were recently discovered by a combination of atomic and chemical force microscopy [519]. Binding of organic molecules (e.g., amelogenin [519]) at physiological solution $\mathrm{pH}$ appears to occur on the charged surface domains of CDHA. The modern visions on dental tissue research have been reviewed recently [520].

The dentin-enamel junction (DEJ) is the interface between the dentin and enamel. It is the remnant of the onset of enamel formation because enamel grows outwards from this junction [484,521,522]. DEJ plays an important role in preventing crack propagation from enamel into dentin [523]. The major steps of enamel crystal growth at the junction have been described above but the mechanism of the junction formation is still debatable. Some authors claim that the enamel crystals grow epitaxially on the pre-existing dentin crystals because of a high continuity between enamel and dentin crystals [524526]. Others have shown that enamel crystals are formed at a given distance from the dentin surface [505-507,527] and could either reach dentin crystals by a subsequent growth [528] or remain distant [527,529]. In addition, there are a cementum-enamel junction (CEJ) [530], who is quite similar to DEJ, and a cementum-dentin junction (CDJ) [488,531].

Enamel formation, or amelogenesis, is a highly regulated process involving precise genetic control as well as protein-protein interactions, protein-mineral interactions and interactions involving the cell 
membrane. Much is still unknown about the interactions between proteins present in the enamel matrix and the final crystalline phase of biological apatite [353,532]. At some point before the tooth erupts into the mouth the ameloblasts are broken down. Consequently, enamel, unlike bones, has no way to regenerate itself using the process of "active mineralization" (see aforementioned debate on bone formation) because there is no biological process that repairs degraded or damaged enamel $[483,484]$. In addition, certain bacteria in the mouth feed on the remains of foods, especially sugars. They produce lactic acid, which dissolves the biological apatite of the enamel in a process known as enamel demineralization that takes place below the critical $\mathrm{pH}$ of about 5.5. Similar process called enamel erosion occurs when a person consumes acid (citric, lactic, phosphoric, etc.) containing soft drinks [493,533-536]. Evidences exist that there is a preferential loss of carbonates and $\mathrm{Mg}$ during the acid dissolution of mineral in dental caries. Luckily, saliva gradually neutralizes the acids that cause the $\mathrm{pH}$ of the tooth surface to rise above the critical $\mathrm{pH}$. This might cause partial enamel remineralization, the return of the dissolved calcium orthophosphates to the enamel. Until recently, it was generally agreed, that if there was sufficient time between the intake of foods (generally, two to three hours) and the damage was very limited, the teeth could repair themselves by the "passive mineralization" process [537]. Data on increased remineralization of tooth enamel by milk containing added casein phosphopeptide - ACP nanocomplexes [538] are in support of this hypothesis.

Recently, by using atomic force microscopy nano-indentation technique it was discovered that the previously demineralized samples of enamel further exposed to remineralizing solutions did show a crystalline layer of calcium orthophosphates formed on the enamel surface. Unfortunately, the reprecipitated deposits of calcium orthophosphates always consisted of loosely packed crystals and did not protect the underlying enamel from a subsequent acid attack. Furthermore, these surface deposits have been completely removed by either a toothbrush or a short exposure to an erosive acidic solution [493,539-541]. In this context, it should be emphasized that the term remineralization, which is often misused in the literature, should imply the process of mineral growth that goes hand in hand with a strengthening effect of the weakened enamel surface. Since no strengthening of an exposure to remineralizing solutions was observed, it might be considered that no "passive mineralization" was found (in spite of the real evidence of the re-precipitated surface deposits of calcium orthophosphates) [493,540,541]. Thus, the enamel self-repairing ability by the passive remineralization appears to be doubtful, while the active remineralization is impossible. However, investigations in this field keep going [542,543].

An amount of fluoride added to either toothpaste or mouthwash lowers the solubility of calcium orthophosphates (by formation of FHA on the surface) and therefore improves the acid-resistance of dental enamel [296,317-322,544]. Furthermore, fluorides also reduce the production of acids by bacteria in the mouth by reducing their ability to metabolize sugars.

To conclude the teeth subject, let us briefly mention on the practical application of teeth. Due to relatively small dimensions of normal teeth, only tusks and ivory of giant animals are used. For example, both the Greek and Roman civilizations used large quantities of ivory to make high value works of art, precious religious objects and decorative boxes for costly objects. Ivory was often used to form the whites of the eyes of statues. Prior to the introduction of plastics, it was used for billiard balls, piano keys, buttons and ornamental items. The examples of modern carved ivory objects are small statuary, netsukes, jewelry, flatware handles and furniture inlays. 


\subsection{Antlers}

Deer antlers (Figure 10) are unique biological structures since their growth rate is without parallel in vertebrates and because they are the only bony appendages in mammals capable of complete regeneration. This allows for basic research in bone biology without the interference of surgical procedures and their adverse effects in animals where samples are obtained. In addition, antlers also allow for the gathering of a large amount of samples from different populations to assess nutritional and ecological effects on bone composition and structure [545-548]. They are costly sexual secondary characters of male deer and constitute 1 to $5 \%$ of the body weight [549].

Figure 10. A schematic picture of a deer antler. A good cross-sectional image of a deer antler is available in Ref. [400].

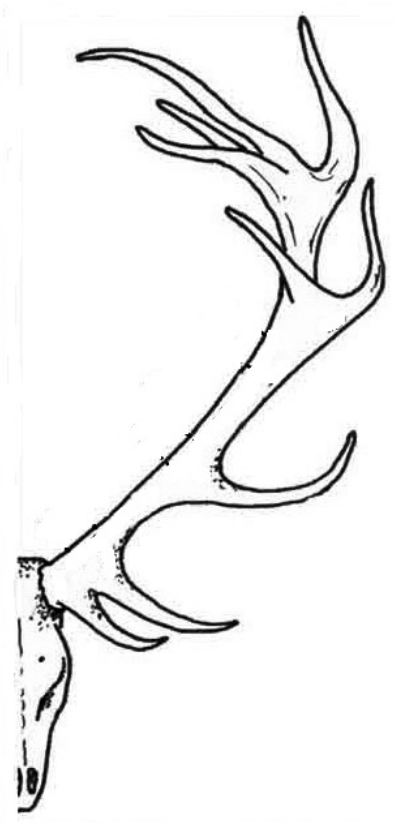

Antlers are not true horns; they are a simple extension of bone, so they have a matrix of biological apatite similar to that of mammalian bones [550]. Antlers are large and complex horn-like appendages of deer consisting of bony outgrowths from the head with no covering of keratin as is found in true horns. Usually, they begin growing in March and reach maturity in August. In winter, antlers fall off; a process known as shedding. Similar to bones, antlers contain pores and can withstand applied stresses of over $300 \mathrm{MPa}$ [551-554], which is even higher than that of bones (Table 1). Therefore, antlers are occasionally considered an almost unbreakable bone [380]. Each antler grows from an attachment point on the skull called a pedicle. While an antler is growing, it is covered with highly vascularized skin called velvet, which supplies oxygen and nutrients to the growing bone. Once the antler has achieved its proper size, the velvet starts to dry out, cracks and breaks off, while the antler's bone dies. Fully developed antlers consist of dead bone only [555-564]. It was found that food processing cannot supply the mineral needs required for antler growth and thus, male deer must temporary resorb calcium orthophosphate minerals from their own skeleton for antler growth [555-567]. Detailed studies revealed that daily food intake provided between 25 and $40 \%$ of calcium needed for antler mineralization, which resulted in a temporary skeleton demineralization [566,567]. 
Antlers are a good model to study bone biology because they are accessible, shed after mating season and cast every year [568]. However, people seldom come across the antlers in the woods. Rabbits and rodents such as mice and chipmunks eat antlers (and bones of wild animals after they die) for calcium. Rodents and rabbits also gnaw bones and antlers to sharpen their incisors. Due to an extremely high growth rate, which can achieve $2-4 \mathrm{~cm}$ per day [555], combined with a very fast biomineralization, these unique appendages might be a well-suited animal model for studying the disturbances of bone formation induced by additives (e.g., by excess of fluoride) [557]. Antler size and external characteristics were found to be influenced by nutrition, climatic variability and other factors. Thus, since antlers are periodically replaced, the analysis of naturally cast antlers offers the opportunity for a continuous and a noninvasive monitoring of the environmental pollution by these additives [557]. Recently, the first attempt to evaluate a potential use of deer antlers as a bone regeneration biomaterial has been performed [569]. To conclude this part, associated with aristocracy, antlers have adorned European castles and hunting lodges for centuries. Today, furnishings and accessories made from antlers are featured in fine homes throughout the world and are a reflection of grace and elegance.

\section{Pathological Calcification of Calcium Orthophosphates}

In the body of mammals, osteoblasts and odontoblasts fix ions of calcium and orthophosphate and then precipitate biological apatite onto an organic matrix. This is the process of physiological biomineralization that is restricted to the specific sites in skeletal tissues, including growth plate cartilage, bones and teeth [63,311]. Normally, mammals are supposed to die with calcium orthophosphates located in bones and teeth (and antlers for male deer) only and nowhere else, because under the normal conditions soft tissues are not mineralized. Unfortunately, owing to ageing, various diseases and under certain pathological conditions blood vessels and some internal organs are calcified as well. This process is called pathological calcification or ectopic mineralization and leads to a morbidity and a mortality [63,311,570]. In general, any type of abnormal accumulation of calcium orthophosphates in wrong places is accounted for by a disruption of systemic defense mechanism against calcification [571].

To the best of my knowledge, the first paper on a negative influence of unwanted depositions of calcium orthophosphates in the body was published as early as in 1911 [572]. This finding was confirmed in later studies [573,574]. Unwanted depositions always lead to various diseases, for instance: soft tissue calcification (in damaged joints, blood vessels, dysfunctional areas in the brain, diseased organs, scleroderma, prostate stones) [575-580], kidney and urinary stones [13,581-584], dental pulp stones and dental calculus [118,119,585-587], salivary stones [588], gall stones, pineal gland calcification, atherosclerotic arteries and veins [48,589-592], coronary calcification [593], cardiac skeleton, damaged cardiac valves [594], calcification on artificial heart valves [595-599], carpal tunnel [600], cataracts [601], malacoplakia, calcified menisci [602,603], dermatomyositis $[604,605]$ and other [63]. In addition, there is a metastatic calcification of nonosseous viable tissue occurring throughout the body, but it primarily affects the interstitial tissue of the blood vessels, kidney, lungs and gastric mucosa [606]. A metastatic calcification is defined as a deposition of calcium orthophosphates in previously normal tissue due to an abnormal biochemistry with disturbances in the 
calcium or phosphorus metabolism [607]. Common causes of the metastatic calcification include hyperparathyroidism, chronic renal disease, massive bone destruction in widespread bone metastases and increased intestinal calcium absorption. One author has mentioned on "apatite diseases" which are characterized by the appearance of needle-like crystals comparable to those of bone apatite in the fibrous connective tissue [608]. All these cases are examples of a calcinosis, which might be described as a formation of calcium orthophosphate deposits in any soft tissue. In dentistry, a calculus or a tartar refers to a hardened plaque on the teeth, formed by the presence of saliva, debris and minerals. Its rough surface provides an ideal medium for bacterial growth, threatening the health of the gums and absorbing unaesthetic stains far more easily than natural teeth [13].

Contrary to the mineral phases of the normal calcifications (bone, dentine, enamel, cementum, antlers), which consist of only one type of calcium orthophosphate (namely, biological apatite), the mineral phases of abnormal and/or pathological calcifications are found to occur as single or mixed phases of other types of calcium orthophosphates (ACP, DCPD, OCP, $\left.\beta-(\mathrm{Ca}, \mathrm{Mg})_{3}\left(\mathrm{PO}_{4}\right)_{2}\right)$ and/or other phosphatic and non-phosphatic compounds (e.g., magnesium orthophosphates, calcium pyrophosphates, calcium oxalates, etc.) in addition to or in place of biological apatite (Table 4) $[13,15,47,63,92,152,609-613]$. This happens because in the places of pathological calcifications the solution $\mathrm{pH}$ is often relatively low. Given that nucleation and crystal growth is not a highly regulated process in any pathological deposits, there is not likely just one fundamental formation mechanism for all possible calcification types. Furthermore, various bioorganic impurities in the local environment undoubtedly influence the crystallization process, resulting in a great variety of pathological deposits. Thus, it is a highly complex problem. In some cases, the chemical composition of an unwanted inorganic phase might depend on the age of the pathological calcification and its location. For example, DCPD is more frequently found in young ( 3 months or younger) calculus, biological apatite is present in all ages of calculus, while $\beta-(\mathrm{Ca}, \mathrm{Mg})_{3}\left(\mathrm{PO}_{4}\right)_{2}$ occurs more frequently in sub-gingival calculus. In mature calculus, the relative abundance of OCP, $\beta-(\mathrm{Ca}, \mathrm{Mg})_{3}\left(\mathrm{PO}_{4}\right)_{2}$ and biological apatite also differ between the inner and outer layers [47]. It is interesting to note that the mineral phases of animal calculus (e.g., from dog) was found to consist of calcium carbonate and biological apatite, while human calculi do not contain calcium carbonate [47,614].

Some findings suggested that the mechanisms and factors regulating the physiological biomineralization might be similar to those influencing the ectopic mineralization: both were initiated by various organics (i.e., membrane-enclosed particles released from the plasma membrane of mineralization-competent cells), that were present [615-617]. In addition, other regulators (activators and inhibitors) of physiological mineralization have been identified and characterized. Besides, some evidences indicate that the same factors also contribute to the regulation of ectopic mineralization [615-622]. What's more, the biological fluids (e.g., serum, saliva, synovial fluids) are normally supersaturated with respect to biological apatite precipitation [13,47,311]; therefore, in principle, calcification is thermodynamically feasible in any part of the body. However, normally it is not the case. Therefore, in the healthy body, the appropriate inhibitory mechanisms must be at work to prevent a superfluous calcification of soft tissues. These inhibition mechanisms are a hot research topic in molecular medicine but this subject is beyond the scope of current review. The interested readers are forwarded, for example, to a very interesting review on molecular recognition at the protein/HA 
interface [623]. More to the point, molecular, endocrine and genetic mechanisms of arterial calcification have been reviewed in another paper [624].

Table 4. Occurrence of various calcium phosphates in biological systems (human) [47].

\begin{tabular}{|c|c|}
\hline Calcium phosphate & Occurrence \\
\hline biological apatite & $\begin{array}{c}\text { enamel, dentin, bone, dental calculi, } \\
\text { stones, urinary stones, soft-tissue } \\
\text { deposits }\end{array}$ \\
\hline OCP & dental calculi and urinary stones \\
\hline DCPD & $\begin{array}{c}\text { dental calculi, crystalluria, } \\
\text { chrondrocalcinosis, in some carious } \\
\text { lesions }\end{array}$ \\
\hline$\beta-(\mathrm{Ca}, \mathrm{Mg})_{3}\left(\mathrm{PO}_{4}\right)_{2}$ & $\begin{array}{l}\text { dental calculi, salivary stones, arthritic } \\
\text { cartilage, soft-tissue deposits }\end{array}$ \\
\hline $\mathrm{Ca}_{2} \mathrm{P}_{2} \mathrm{O}_{7} \cdot 2 \mathrm{H}_{2} \mathrm{O}$ & pseudo-gout deposits in synovium fluids \\
\hline $\mathrm{ACP}$ & $\begin{array}{l}\text { heart calcifications in uremic patients, } \\
\text { kidney stones }\end{array}$ \\
\hline
\end{tabular}

To conclude this part, it is worth remembering that calcium orthophosphates of biological origin are sparingly soluble in aqueous solutions. Removing them from the places of unwanted deposition would be an equivalent of demineralizing bone; that is a challenge. Therefore, the majority of therapeutic approaches are directed at preventing the progression of pathological calcifications. Among them, a chelation therapy might be of some interest to chemists and materials researchers because it deals with chemical processes $[625,626]$. Recently, the general principles of demineralization and decalcification (i.e., removing the mineral Ca-containing compounds (phosphates and carbonates) from the organic matrix) have been extensively reviewed [627,628], to which the interested readers are referred.

\section{Calcium Orthophosphates as Biomaterials and Bioceramics}

A number of definitions have been developed for the term "biomaterials". The consensus developed by experts in this field is the following: biomaterials are defined as synthetic or natural materials to be used to replace parts of a living system or to function in intimate contact with living tissue [82]. In general, biomaterials are intended to interface with biological systems to evaluate, treat, augment or replace any tissue, organ or function of the body and are now used in a number of different applications throughout the body [629,630]. Biomaterials are different from biological materials because the former are the materials that are accepted by living tissues and, therefore, might be used for tissue replacements, while the latter are the materials being produced by biological systems (wood, cotton, bones, chitin, etc.) [400]. In addition, there are biomimetic materials, which are not made by living organisms but have the composition, structure and properties similar to those of biological 
materials. Further, bioceramics might be defined as biomaterials of the ceramic origin. In general, it can have structural functions as joint or tissue replacements, be used as coatings to improve the biocompatibility of metal implants and function as resorbable lattices, which provide temporary structures and a framework that is dissolved and/or replaced as the body rebuilds tissue. Some types of bioceramics even feature a drug-delivery capability [631].

The performance of living tissues is the result of millions of years of evolution, while the performance of acceptable artificial substitutions those humankind has designed to repair damaged hard tissues are only a few decades old. Archaeological findings exhibited in museums showed that materials used to replace missing human bones and teeth have included animal or human (from corpses) bones and teeth, shells, corals, ivory (elephant tusk), wood, as well as some metals (gold or silver). For instance, the Etruscans learned to substitute missing teeth with bridges made from artificial teeth carved from the bones of oxen, while in the 17 th century a piece of dog skull was successfully transplanted into the damaged skull of a Dutch duke. The Chinese recorded the first use of dental amalgam to repair decayed teeth in the year $659 \mathrm{AD}$, while pre-Columbian civilizations used gold sheets to heal cranial cavities following trepanation [632]. Due to the practice of cremation in many societies, not much is known about prehistoric materials used to replace bones lost to accident or disease.

In the past, many implantations failed because of infection or a lack of knowledge about toxicity of the selected materials. In this frame, the use of calcium orthophosphates as biomaterials and bioceramics is based upon their similarity with the mineral phase of bone and teeth $[311,312,362,363]$. However, according to available literature, the first attempt to use calcium orthophosphates (it was TCP) as an artificial material to repair surgically created defects in rabbits was performed in 1920 [633]. In general, calcium orthophosphate-based biomaterials can be prepared from various sources $[634,635]$. Unfortunately, up to now, all attempts to synthesize bone replacement materials for clinical applications featuring the physiological tolerance, biocompatibility and a long term stability have had only a relative success; it comes to show a superiority and a complexity of the natural structures [355].

Generally, living organisms might treat artificial implants as bioinert, biotolerant, bioactive or bioresorbable biomaterials [82,629,630,636]. Bioinert (e.g., zirconia, alumina, carbon and titanium) and biotolerant (e.g., polymethyl methacrylate (PMMA), titanium and Co-Cr alloy) materials will evoke a physiological response to form a fibrous capsule, thus, isolating the material from the body. Calcium orthophosphates (both non-substituted and ion-substituted) fall into the categories of bioactive and bioresorbable materials [636]. A bioactive material will dissolve slightly but promote the formation of a layer of biological apatite before interfacing directly with the tissue at the atomic level, that result in the formation of a direct chemical bond with bone. Such an implant will provide a good stabilization for materials that are subject to mechanical loading. A bioresorbable material will dissolve and allow a newly formed tissue to grow into any surface irregularities but may not necessarily interface directly with the material [289,637-641]. Bioceramics made of dense HA would be a good example of a bioactive material, while porous scaffolds made of BCP (i.e., $\beta$-TCP + HA [151-160], $\alpha$-TCP + HA [163-166]) or bone grafts made of CDHA [642], TCP [643] and/or ACP $[199,644]$ appear to be the examples of bioresorbable materials. Unfortunately, calcium orthophosphate bioceramics possess poor mechanical properties that do not allow them to be used in load-bearing areas [645]. For this reason, the medical applications of calcium orthophosphates are 
currently focused on the production of non-load-bearing implants, such as pieces for middle ear surgery, filling of bone defects in oral or orthopedic surgery, as well as coating of dental implants and metallic prosthesis $[355,646]$. The mechanical properties of calcium orthophosphate biomaterials and bioceramics have been reviewed elsewhere [266,647]. In addition, there is a good review on the recent developments in processing and surface modification of HA [648].

In spite of serious mechanical limitations, biomaterials and bioceramics of calcium orthophosphates are available in various physical forms: particles, blocks (dense or porous), injectable compositions, self-setting cements, coatings on metal implants, composites with polymers, etc. [649]. A porous surface provides mechanical fixation in addition to providing sites on the surface that allow chemical bonding between biomaterials and bone [650]. For example, porous HA bioceramics can be colonized by bone tissues [651-653]. Therefore, macroporosity (pore size $>100 \mu \mathrm{m}$ ) in solid biomaterials is intentionally introduced by addition of various porogens, which consist of crystals or particles of either volatile or soluble substances (e.g., naphthalene, sucrose, $\mathrm{NaHCO}_{3}$, gelatin, PMMA microbeads) [152,289,654-658]. Sintering particles, preferably spheres of equal size, is another way to generate porous three-dimensional (3D) bioceramics of calcium orthophosphates. A wetting solution such as polyvinyl alcohol is usually used to aid compaction, which is achieved by cold isostatic pressing the particles into cylinders at approximately $200 \mathrm{MPa}$ [659]. As hardly any effect of macropore sizes (150, 260, 510 and $1220 \mu \mathrm{m}$ ) on the in vivo response was observed [660], there is no need to create bioceramics with very big pores; however, the pores must be interconnected. Microporosity (pore size $<10 \mu \mathrm{m}$ ) results from the sintering process, while dimensions of the pores depend on temperature and sintering time. Creation of the desired porosity in bioceramics is a rather complicated engineering task and the interested readers are referred to the special literature [152,199,656,661-672].

The sintering stage appears to be of a great importance to produce bioceramics with the required properties. Several processes occur during sintering of calcium orthophosphates. Firstly, moisture, carbonates and all volatile chemicals remaining from the synthesis stage, such as ammonia, nitrates and any organic compounds, are removed as gaseous products. Secondly, the removal of these gases facilitates the production of dense materials during sintering. Thirdly, these chemical changes are accompanied by a concurrent increase in crystal size and a decrease in the specific surface area. Fourthly, there is the chemical decomposition of all acidic orthophosphates and their transformation into other phosphates (e.g., $2 \mathrm{HPO}_{4}{ }^{2-} \rightarrow \mathrm{P}_{2} \mathrm{O}_{7}{ }^{4-}+\mathrm{H}_{2} \mathrm{O}$ ). Besides, sintering causes toughening of the ceramics [673]. Further details on the sintering processes of calcium orthophosphates are available elsewhere [13,14,233,266,289,641].

Studies showed that increasing the specific surface area and pore volume of biomaterials for tissue repair might greatly accelerate the kinetic process of biological apatite deposition and therefore enhance the bone-forming bioactivity [674]. More importantly, the precise control over porosity, pore size and internal pore architecture of biomaterials on different length scales is essential for understanding of the structure-bioactivity relationship and the rational design of better bone-forming biomaterials $[675,676]$.

Calcium orthophosphates in a number of forms and compositions are currently either in use or under consideration in many areas of dentistry and orthopedics, with even more in development. For example, bulk material, available in dense and porous forms, is used for alveolar ridge augmentation, immediate tooth replacement and maxillofacial reconstruction [13,46,677]. Further applications 
include orbital implants (Bio-Eye ${ }^{\circledR}$ ) $[678,679]$, increment of the hearing ossicles, spine fusion and repair of bone defects [680,681]. In order to permit growth of new bone into bone defects, a suitable bioresorbable material should fill the defects. Otherwise, ingrowth of fibrous tissue might prevent bone formation within the defects. Today, a large number of different calcium orthophosphate bioceramics for the treatment of bone defects is available on the market. As an example, the readers are referred to a thorough physicochemical characterization of 14 calcium phosphate-based bone substitution materials in comparison to natural bone [682]. Commercial and trade names of several very important types of calcium orthophosphate bioceramics may be found in the iterature $[682,683]$.

Chemically, calcium orthophosphate bioceramics are based on HA, $\beta$-TCP, $\alpha$-TCP and/or BCP (i.e., a composite of HA with $\alpha$ - or $\beta$-TCP) $[13,46,151-161,164-167,169,172,173,677,684]$. The BCP concept is determined by the optimum balance of a more stable phase of HA and a more soluble TCP. General requirements for the ideal bone grafts are as follows: pores of some $100 \mu \mathrm{m}$ size, a biodegradation rate comparable to the formation of bone tissue (i.e., between a few months and about two years) and the sufficient mechanical stability. When compared to $\alpha$ - and $\beta$-TCP, HA is a more stable phase under the physiological conditions, as it has a lower solubility and a slower resorption kinetics $[13,46,677]$. As implants made of calcined HA are present in bone defects for many years after implantation, bioceramics made of $\beta$-TCP, $\alpha$-TCP, CDHA or BCP $[63,153,155,156,163-$ $169,172,173,685]$ are more preferable for medical purposes. According to both observed and measured bone formation parameters, calcium orthophosphates were ranked as follows: low sintering temperature $\mathrm{BCP}$ (rough and smooth) $\approx$ medium sintering temperature $\mathrm{BCP} \approx \mathrm{TCP}>$ calcined low sintering temperature $\mathrm{HA}>$ non-calcined low sintering temperature $\mathrm{HA}>$ high sintering temperature BCP (rough and smooth) $>$ high sintering temperature HA (calcined and non-calcined) [685]. In the case of BCP, its biodegradation kinetics depends on the HA/ $\beta$-TCP ratio: the higher the ratio, the lower the degradation rate [157]. Figure 11 shows some randomly chosen examples of commercially available calcium orthophosphate bioceramics for use as bone grafts.

The need of biomaterials for minimal invasive surgery has induced the development of a concept of self-setting bone cements made from calcium orthophosphates to be applied as injectable and/or mouldable bone substitutes [78,84-87,93-96,106-110,144-147,170,171,338,654,655,668,685-689]. This is a low temperature bioceramics. Two major types of cements are possible. The first one is a dry mixture of two different calcium orthophosphates (a basic one and an acidic one), in which, after being wetted, the setting reaction occurs according to an acid-base reaction. The second type of calcium orthophosphate cements is when the initial and final calcium orthophosphates have the same $\mathrm{Ca} / \mathrm{P}$ molar ratio. Typical examples are ACP with $\mathrm{Ca} / \mathrm{P}$ molar ratio within $1.50-1.67$ and $\alpha$-TCP: they form CDHA upon contact with an aqueous solution $[685,686]$. Upon mixing with water, initial calcium orthophosphate(s) are dissolved and precipitated into less soluble calcium orthophosphates, which causes the cement setting. During the precipitation reaction, new crystals grow and become entangled, thus providing a mechanical rigidity to the cement. Setting of these cements occurs mostly within the initial 6 hours, yielding a $\sim 80 \%$ conversion to the final products and a compressive strength of $40-60$ $\mathrm{MPa}$. The rate of hardening is strongly influenced by a powder to liquid ratio and addition of other chemicals [106,170,685-689]. Despite a large number of formulations, all calcium orthophosphate cements can only form two different end products: CDHA and DCPD [685,686]. 
Figure 11. General appearance of various commercial calcium orthophosphate-based bone graft materials.

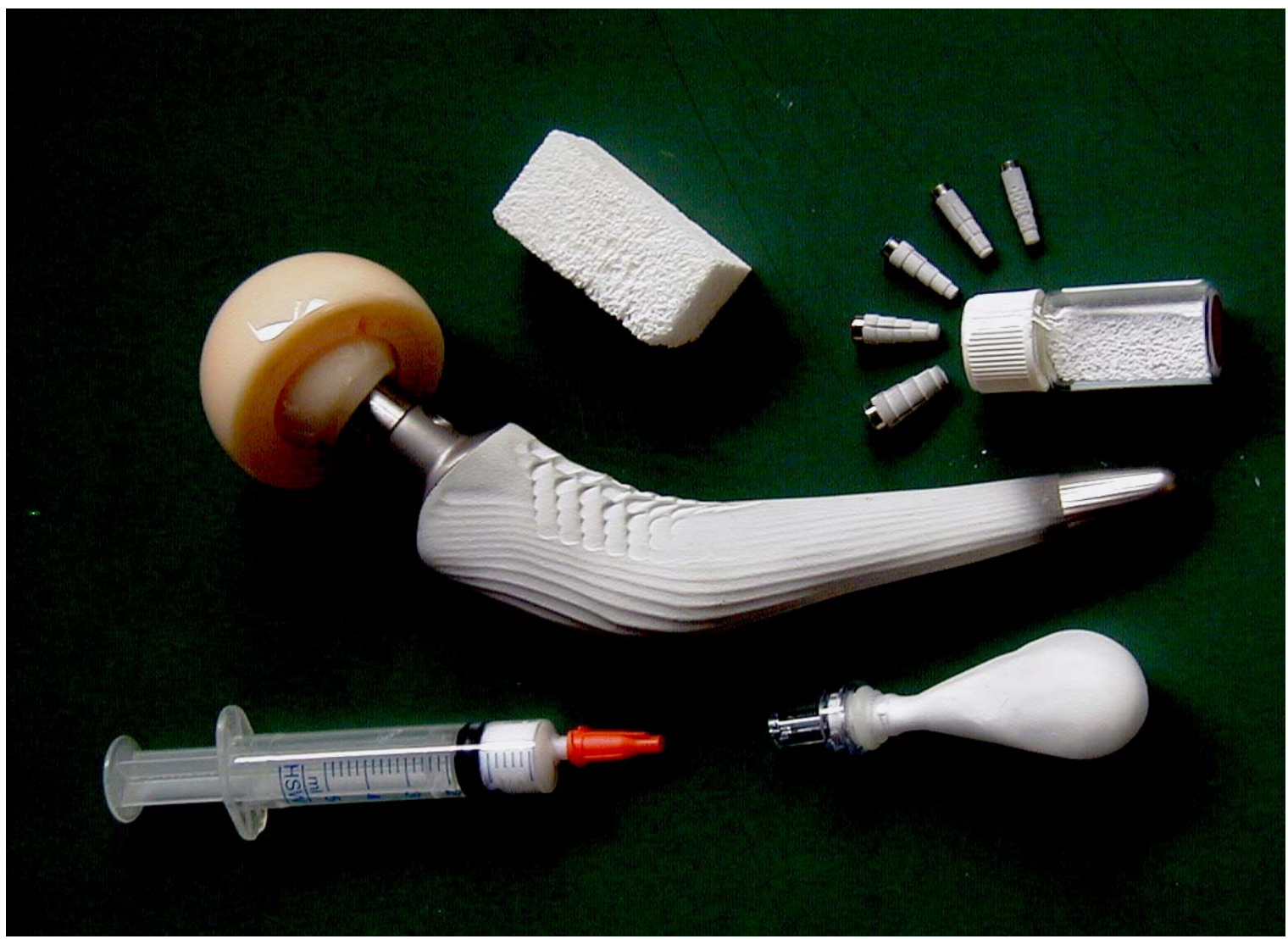

The first animal study on a calcium orthophosphate cement was performed in 1991: the cement consisting of TTCP and DCPA was investigated histologically by implanting disks made of this cement within the heads of nine cats [690,691]. All calcium orthophosphate cements are biocompartible, bioactive and bioresorbable. The structure and composition of the hardened cements is close to that of bone mineral; therefore, the material of these cements can easily be used by bone remodeling cells for reconstruction of damaged parts of bones [170,685,686]. The biomechanical evaluation of calcium orthophosphate cements for use in vertebroplasty might be found elsewhere [692]. Unfortunately, the cements possess a low mechanical strength; this property might be improved by reinforcement with polymers [693]. A good adaptation to the defect geometry is the major advantage of bone cements, when compared to implantation of bulk ceramics and scaffolds [78,170,266,338,685,686,689].

Injectable bone substitutes (IBS) made of calcium orthophosphates and an aqueous solution of a hydrophilic biodegradable polymer are another type of biomaterials for minimal invasive surgery [156,694-700]. They look as pastes of a high viscosity but possessing enough fluidity to be injected into bone defects by a standard syringe with a needle. These materials are perfectly biocompatible and potentially resorbable and, thanks to their initial plasticity, they can fit bone defects very easily, without necessity to elaborate shaping of implantation site. During bioresorption of IBS, bone cells are able to invade the spaces released by disappearance of the biodegradable polymer. Creation of the required level of viscosity to prevent IBS from segregation and phase separation during the shelf life is 
the major task of the polymer in IBS, while calcium orthophosphates is the building material for bone healing. In terms of application, IBS more or less similar to the aforementioned bone cements but, unlike the cements, IBS do not possess the self-setting abilities since no chemical reactions occur between the components [701]. Besides, there are paste-like formulations consisting of a suspension of pure HA in water prepared by a wet chemical reaction [702-704]. Further details on IBS are available elsewhere [156,694-700]. Recently, injectable and macroporous calcium orthophosphate cement scaffolds, combining the advantages of IBS and bone cements, have been developed [705]. The future development of both IBS and calcium orthophosphate bone cements can be seen in introduction of living cells into their composition [706,707].

Calcium orthophosphate coatings on metals are often applied in medicine [288]. Metallic implants are encountered in endoprostheses (total hip joint replacements) and artificial teeth sockets. The requirement for a sufficient mechanical stability necessitates the use of a metallic body for such devices. As metals usually do not undergo bone bonding, i.e. do not form a mechanically stable link between the implant and bone tissue, ways have been sought to improve the mechanical contact at the interface $[708,709]$. The major way is to coat the metal with calcium orthophosphate ceramics that generally exhibit bone-bonding ability between the metal and bone [636,710,711]. The list of most important coating techniques is comprised in Table 5, while the main advantages and drawbacks of each coating technique, as well as the important properties of the deposed calcium orthophosphates, are discussed in details elsewhere [268,288,289,712-720]. Clinical results for HA-coated metallic implants revealed that they had much longer life times after implantation than uncoated devices. Namely, HA coating as a system of fixation of hip implants was found to work well in the short to medium term (8 years [721], 15 years [722], 17 years [723] and 19 years [724]). Similar data for HAcoated dental implants are also available $[725,726]$. The longer-term clinical results are awaited with a great interest. The biomedical aspects of osteoconductive [727] coatings for total joint arthroplasty have been reviewed elsewhere [728].

The perfect biomaterial for medical applications would not only be biocompatible but also have physical properties similar to those of the tissue being replaced or repaired. Researchers therefore have sought ways of combining calcium orthophosphate bioceramics with other materials to tailor properties such as strength and elasticity to meet system requirements. This has led to a large variety of bone substituting composites and hybrid biomaterials made of calcium orthophosphate bioceramics and (bio)organic compounds (usually, polymers, preferably, biodegradable ones). This approach appeared due to the poor mechanical properties (namely: a low elasticity, a high brittleness, a low tensile strength, a low fracture toughness and a poor impact resistance) of bone substitutes made of calcium orthophosphates only [266,271,272]. In addition, it is worth reminding that all biologically formed calcified tissues (bones, teeth, antlers, shells, etc.) appear to be very complicated composites of (bio)organic and inorganic phases [13,46,47,63,258,311,362,363]. In such composites, the mineral component provides the strength whereas the (bio)organic component contributes to the ductility. This combination of strength and ductility leads to an energy absorption prior to failure [390]. A list of the suitable calcium orthophosphates (except of MCPM and MCPA - both are too acidic and, therefore, are not biocompatible) is mentioned in Table 2, while there is an even greater choice of biocompatible polymers those can be divided into two major groups: synthetic polymers (e.g., polyesters, PMMA, poly-e-caprolactone) and polymers of biological origin (e.g., collagen, gelatin, chitosan, alginate, 
modified starch, cellulose esters). Various ways have been already realized to bring these two components together into biocomposites, like simple mechanical mixing or co-precipitation. Usually, powder forms of calcium orthophosphates are used to produce biocomposites. It is also possible to introduce porosity into such biocomposites that is advantageous for most applications as bone substitution material. Such biocomposites might possess the unique properties; for example, there is a recent report on shape memory properties of poly(D,L-lactide)/HA biocomposites [729].

The topic of the composite biomaterials made of calcium orthophosphates and organic/biological compounds was first introduced in 1981 by Prof. William Bonfield, who realized the application potential of calcium orthophosphates as fillers in polymer-bioceramics biocomposites and the move was envisaged towards an improved mechanical performance of HA bioceramics [730]. Biocomposites of polymers and calcium orthophosphate bioceramics can confer favorable mechanical properties, including strength due to the ceramic phase, toughness and plasticity due to the polymer phase, as well as a graded mechanical stiffness. Another advantage of such biomaterials is that they are sufficiently soft and ductile to be shaped by a surgeon in the operating theatre. Although current technologies can yet reproduce neither the multistage biosynthesis, nor the hierarchical structure, nor the mechanical properties of bones, the synthesis of various types of calcium orthophosphate-based biocomposites and hybrid biomaterials is a strong and very promising research area. The interested readers are referred to other papers and reviews on this subject [289,390,391,731-743].

To conclude this part, the bioactivity mechanism of calcium orthophosphate biomaterials and bioceramics should be described. Strangely enough, a careful search in the literature revealed only three publications $[268,744,745]$ where the bioactivity mechanism of calcium orthophosphates had been briefly described. For example, the chemical changes occurring after exposure of a synthetic HA ceramic to both in vivo (implantation in human) and in vitro (cell culture) conditions were studied. A small amount of HA was phagocytized but the major remaining part behaved as a secondary nucleator as evidenced by the appearance of a newly formed mineral [744]. In vivo, the cellular activity (e.g., by macrophages or osteoclasts) associated with acidic environment were found to result in partial dissolution of calcium orthophosphate bioceramics, causing liberation of calcium and orthophosphate ions onto the microenvironment. The liberated ions increased the supersaturation condition of the biologic fluid, causing precipitation of biological apatite nanocrystals with simultaneous incorporating of various ions presented in the biologic fluid. Infrared spectroscopic analyses demonstrated that these nanocrystals were intimately associated with an organic component (probably proteins) that might also have originated from the biologic fluid or serum [745].

Therefore, one should better rely on the bioactivity mechanism of other biomaterials, particularly of bioactive glasses - the concept introduced by Hench [271,272]. The mechanism of bonding of bioactive glasses to living tissue involves a sequence of 11 successive reaction steps. The initial five steps occurred on the surface of biomaterials are "chemistry" only, while the remaining six steps belong to "biology" because the latter include colonization by osteoblasts, followed by proliferation and differentiation of the cells to form a new bone that had a mechanically strong bond to the implant surface (Figure 12). Therefore, in the case of bioactive glasses the border between "dead" and "alive" is located between stages 5 and 6 . 
Table 5. Various techniques to deposit bioresorbable coatings of calcium orthophosphates on metal implants [268,712].

\begin{tabular}{|c|c|c|c|}
\hline Technique & Thickness & Advantages & Disadvantages \\
\hline Thermal spraying & $\begin{array}{c}30-200 \\
\mu \mathrm{m}\end{array}$ & High deposition rates; low cost & $\begin{array}{l}\text { Line of sight technique; high } \\
\text { temperatures induce } \\
\text { decomposition; rapid cooling } \\
\text { produces amorphous coatings }\end{array}$ \\
\hline Sputter coating & $0.5-3 \mu \mathrm{m}$ & $\begin{array}{l}\text { Uniform coating thickness on flat } \\
\text { substrates; dense coating }\end{array}$ & $\begin{array}{l}\text { Line of sight technique; } \\
\text { expensive; time consuming; } \\
\text { produces amorphous coatings }\end{array}$ \\
\hline $\begin{array}{l}\text { Pulsed laser } \\
\text { deposition }\end{array}$ & $0.05-5 \mu \mathrm{m}$ & $\begin{array}{c}\text { Coating by crystalline and } \\
\text { amorphous phases; dense and } \\
\text { porous coating }\end{array}$ & Line of sight technique \\
\hline $\begin{array}{l}\text { Dynamic mixing } \\
\text { method }\end{array}$ & $0.05-1.3 \mu \mathrm{m}$ & High adhesive strength & $\begin{array}{c}\text { Line of sight technique; } \\
\text { expensive; produces amorphous } \\
\text { coatings }\end{array}$ \\
\hline Dip coating & $\begin{array}{l}0.05-0.5 \\
\mathrm{~mm}\end{array}$ & $\begin{array}{l}\text { Inexpensive; coatings applied } \\
\text { quickly; can coat complex } \\
\text { substrates }\end{array}$ & $\begin{array}{c}\text { Requires high sintering } \\
\text { temperatures; thermal expansion } \\
\text { mismatch }\end{array}$ \\
\hline Sol-gel technique & $<1 \mu \mathrm{m}$ & $\begin{array}{l}\text { Can coat complex shapes; low } \\
\text { processing temperatures; } \\
\text { relatively cheap as coatings are } \\
\text { very thin }\end{array}$ & $\begin{array}{l}\text { Some processes require } \\
\text { controlled atmosphere } \\
\text { processing; expensive raw } \\
\text { materials }\end{array}$ \\
\hline $\begin{array}{l}\text { Electrophoretic } \\
\text { deposition }\end{array}$ & $\begin{array}{l}0.1-2.0 \\
\mathrm{~mm}\end{array}$ & $\begin{array}{l}\text { Uniform coating thickness; rapid } \\
\text { deposition rates; can coat complex } \\
\text { substrates }\end{array}$ & $\begin{array}{l}\text { Difficult to produce crack-free } \\
\text { coatings; requires high sintering } \\
\text { temperatures }\end{array}$ \\
\hline $\begin{array}{l}\text { Biomimetic } \\
\text { coating }\end{array}$ & $<30 \mu \mathrm{m}$ & $\begin{array}{l}\text { Low processing temperatures; can } \\
\text { form bonelike apatite; can coat } \\
\text { complex shapes; can incorporate } \\
\text { bone growth stimulating factors }\end{array}$ & $\begin{array}{l}\text { Time consuming; requires } \\
\text { replenishment and a pH } \\
\text { constancy of simulated body } \\
\text { fluid }\end{array}$ \\
\hline $\begin{array}{l}\text { Hot isostatic } \\
\text { pressing }\end{array}$ & $\begin{array}{c}0.2-2.0 \\
\mu \mathrm{m}\end{array}$ & Produces dense coatings & $\begin{array}{l}\text { Cannot coat complex substrates; } \\
\text { high temperature required; } \\
\text { thermal expansion mismatch; } \\
\text { elastic property differences; } \\
\text { expensive; removal/interaction } \\
\text { of encapsulation material }\end{array}$ \\
\hline $\begin{array}{l}\text { Electrochemical } \\
\text { deposition }\end{array}$ & $\begin{array}{l}0.05-0.5 \\
\mathrm{~mm}\end{array}$ & $\begin{array}{l}\text { Uniform coating thickness; rapid } \\
\text { deposition rates; can coat complex } \\
\text { substrates; moderate temperature, } \\
\text { low cost }\end{array}$ & $\begin{array}{c}\text { The } \\
\text { coating/substrate bonding is not } \\
\text { strong enough }\end{array}$ \\
\hline
\end{tabular}


Figure 12. The sequence of interfacial reactions involved in forming a bond between tissue and bioactive glasses. The border between "dead" and "alive" occurs approximately at stage 6. Reprinted from Ref. [272] with permission.

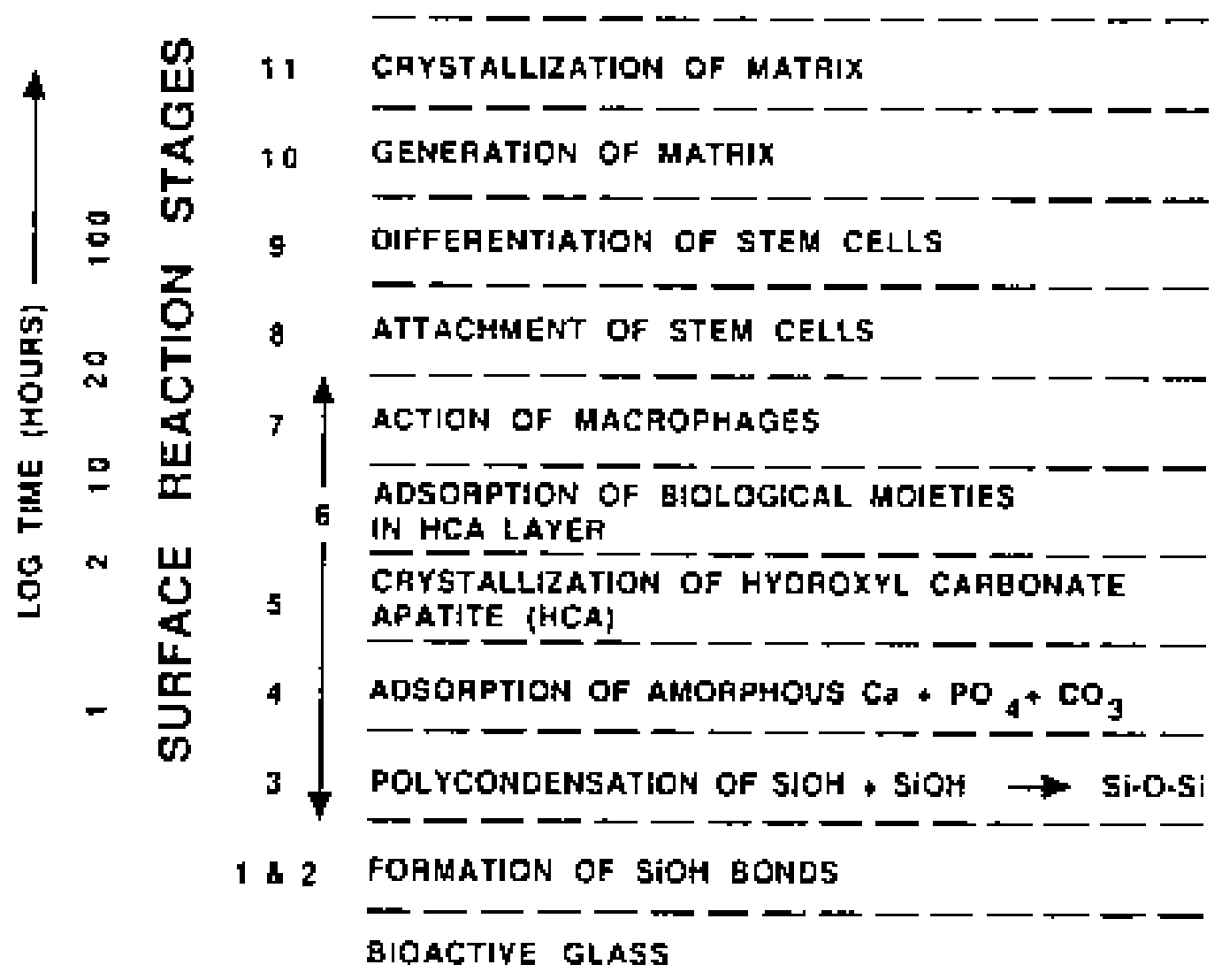

According to Hench, all bioactive materials "form a bone-like apatite layer on their surfaces in the living body and bond to bone through this apatite layer. The formation of bone-like apatite on artificial material is induced by functional groups, such as $\mathrm{Si}-\mathrm{OH}$ (in the case of biological glasses), $\mathrm{Ti}-\mathrm{OH}$, $\mathrm{Zr}-\mathrm{OH}, \mathrm{Nb}-\mathrm{OH}, \mathrm{Ta}-\mathrm{OH},-\mathrm{COOH}$ and $-\mathrm{H}_{2} \mathrm{PO}_{4}$ (in the case of other materials). These groups have specific structures revealing negatively charge and induce apatite formation via formations of an amorphous calcium compound, e.g., calcium silicate, calcium titanate and ACP" [271,272]. For want of anything better, the bioactivity mechanism of calcium orthophosphates can also be described by Figure 12 by omission of several initial stages, as it was actually made for HA in Refs. [268,745], where three initial chemical stages of the Hench's mechanism were replaced by partial dissolution of HA.

\section{Biomimetic Crystallization of Calcium Orthophosphates}

In general, biomimetics [746] (also known as bionics, biognosis and/or biomimicry) might be defined as application of the methods and systems found in nature to the study, design and construction of new engineering systems, materials, chemical compounds and modern technology. The concept is very old (e.g., the Chinese wanted to make artificial silk 3,000 years ago; Daedalus' wings were one of the early design failures) but the implementation is gathering momentum only recently. In spite of the tremendous achievements of modern science and technology, the nature's ability to 
assemble inorganic compounds into hard tissues (shells, spicules, teeth, bones, antlers, skeletons, etc.) is still not achievable by the synthetic procedures. This is not surprising - designs found in nature are the result of millions of years of evolution and competition for survival. The models that failed are fossils; those that survived are the success [747]. In the frames of this review, biomimetics is considered as mimicking natural manufacturing methods to generate artificial calcified tissues (grafts, implants, prostheses) those might be used as temporary or permanent replacements of the missing, lost, injured or damaged bones and teeth. It is important to notice, that precipitation of calcium orthophosphates and calcium carbonates have been considered to correlate with bone formation, at least, since 1923 [748].

As this is mainly the subject of crystallization of calcium orthophosphates, the matter of choosing the correct experimental conditions and well-mimicking solutions is of the primary importance. The easiest way to perform the crystallization would be mixing of aqueous solutions containing the ions of calcium and orthophosphate [13-15]. Unfortunately, such type of crystallization provides precipitates with the properties (chemical composition, $\mathrm{Ca} / \mathrm{P}$ ratio, crystallinity level, particle size distribution, etc.) far different from those of biological apatite. This can be explained by the following paramount differences between the in vivo and in vitro crystallization conditions [749]:

(i) In vitro crystallization normally occurs at permanently depleting concentrations of calcium and orthophosphate, while the concentrations of all ions and molecules are kept strictly constant during biological mineralization (the same is valid for the solution $\mathrm{pH}$ );

(ii) Chemical crystallization is a fast process (time scale of minutes to days), while the biological process is a slow one (time scale of weeks to years);

(iii) Many inorganic, bioorganic, biological and polymeric compounds are present in biological liquids (blood plasma, serum, saliva). Each of these compounds might act as an inhibitor, promoter, nucleator or even as a template for the growth of biological apatite [355]. In addition, each of them somehow influences the crystallization kinetics and might be either incorporated into the solid structure or co-precipitated with calcium orthophosphates.

(iv) Chemical crystallization is, by all means, a "passive" process, while the biological mineralization is strongly influenced by cells and occurs by the self-organization mechanisms $[396,419,420]$. Still there are no good ways to overcome this difference.

The first and the second differences might be overcome by using the appropriate crystallization techniques. The details are available elsewhere [749] but, briefly, the first problem can be overcome by either a continuous flow of a supersaturated solution [750,751] or using a constant-composition (CC) technique $[129,752,753]$. The second difference can be surpassed by a restrained diffusion of calcium and orthophosphate ions from the opposite directions in, for example, a double-diffusion (DD) crystallization device or in viscous gels [294-296,298,299,754]. The CC and DD techniques have been combined into a single constant-composition double-diffusion (CCDD) device, which currently seems to be the most advanced experimental tool to perform biomimetic crystallization [749,755-759]. However, in no case the CCDD device should be considered as the final construction; it still has much room for further improvement, e.g. by upgrading the design of the crystallization chamber [760]. Other constructions, e.g. to study calcification of biological heart valve prostheses [761], are also possible. In addition, one should keep in mind that the potential of the standard $\mathrm{CC}$ technique has not reached its 
limit yet: for example, recently a good mimicking of the self-organized microstructure of tooth enamel has been achieved [762].

The third major difference between the in vivo and in vitro crystallization conditions could be overcome by using the appropriate crystallization solutions [749]. The presence of calcium and orthophosphate ions in some biological fluids has been known, at least, since 1921 [763,764]. Therefore, the best way would be to perform experiments using natural liquids (blood serum, saliva, lymph, etc.), but this is not easy due to variability of the chemical and biochemical composition of natural liquids and problems with their storage. As stated before, using supersaturated aqueous solutions containing only the ions of calcium and orthophosphate appears to be unable to mimic the crystallization of biological apatite; therefore, more advanced solutions have been elaborated. To the best of my knowledge, Hanks' balanced salt solution (HBSS) [765] was the first successful simulating medium, containing the ions of calcium and orthophosphate together with other inorganic ions and glucose. HBSS is commercially available and still used in biomimetic experiments [766-768]; its chemical composition might be taken, e.g., from Refs. [769,770]. Other popular physiological solutions include $\alpha$-modified Eagle's [771] medium ( $\alpha$-MEM) and its variation Dulbecco's [772] modified Eagle's medium (DMEM), which contain numerous bioorganic (e.g., alanine, aspartic acid, glycine, biotin, vitamin $\mathrm{C}$, folic acid, riboflavin) and inorganic (e.g., $\mathrm{CaCl}_{2}, \mathrm{KCl}, \mathrm{NaCl}, \mathrm{NaH}_{2} \mathrm{PO}_{4}$ ) components [773-775], phosphate buffered saline (PBS) that contains only inorganic components (e.g., $\left.\mathrm{CaCl}_{2}, \mathrm{MgCl}_{2}, \mathrm{KCl}, \mathrm{KH}_{2} \mathrm{PO}_{4}, \mathrm{NaCl}, \mathrm{NaH}_{2} \mathrm{PO}_{4}\right)$ [776,777], as well as an artificial saliva containing both bioorganic (e.g., xantan gum or sodium carboxymethylcellulose, sorbitol, etc.) and inorganic (e.g., $\mathrm{CaCl}_{2}, \mathrm{MgCl}_{2}, \mathrm{KCl}, \mathrm{KH}_{2} \mathrm{PO}_{4}, \mathrm{NaCl}, \mathrm{KH}_{2} \mathrm{PO}_{4}$ ) compounds [778,779]. All these simulating solutions are commercially available.

However, the most popular biomimetic solution is a protein-free acellular simulated body fluid (SBF). It was introduced by Kokubo et al. [780] and occasionally named as Kokubo's SBF. It is a metastable aqueous solution with $\mathrm{pH} \sim 7.40$, supersaturated with respect to the precipitation of OCP, $\beta$-TCP, CDHA and HA [781], containing only inorganic ions in concentrations nearly equal to those in human blood plasma. However, the standard SBF formulation, firstly, contains the tris/ $\mathrm{HCl}$ buffer, and, secondly, the concentration of hydrogencarbonate $(4.2 \mathrm{mM})$ is only a fraction of that in blood plasma $(27 \mathrm{mM})$ [780]. The problem of a low concentration of hydrogencarbonate ions has been overcome by first introducing a "synthetic body fluid" [782-784] and later a revised SBF (rSBF) $[785,786]$. Due to the chemical similarity with human blood plasma, rSBF currently seems to be the best simulating solution. However, it contains Hepes buffer, loses $\mathrm{CO}_{2}$ in open vessels and does not contain any organic and/or biological molecules [785,786]. Other types of SBF are also available; the interested readers are referred to a leading opinion co-authored by the inventor of SBF [787], where the entire history and the classical preparation techniques of various SBF formulations are well described. Recently, another leading opinion on the suitability of SBFs for the in vitro bioactivity tests was published [788]. The authors demonstrated that (i) there is presently no enough scientific data to support the SBF suitability and (ii) even though bioactivity tests with SBFs are valid, the way the tests are generally conducted leaves room for further improvements. Furthermore, the preparation protocol of SBF solutions was reconsidered and a new procedure was suggested to improve the reproducibility of bioactivity tests [788]. The application of SBF for the surface mineralization of various materials in vitro has been reviewed in Ref. [789], while the theoretical analysis of calcium orthophosphate 
precipitation (the driving force and the nucleation rate based on the classical crystallization theory) in SBF is also available [781].

Further attempts to improve the biomimetic properties of SBF and rSBF have been performed [787,788]. Efforts were made to replace artificial buffers (tris/HCl, Hepes) with simultaneous increasing the concentration of hydrogencarbonates for SBF [790,791] or avoiding losses of $\mathrm{CO}_{2}$ from open vessels for rSBF [749,755-759] by means of permanent bubbling of gaseous $\mathrm{CO}_{2}$ through the solutions. Addition of the most important organic and biological compounds like glucose [757] and albumin [755] is another direction to improve biomimetic properties of SBFs; further improvements of biomimetic solutions are to be made in future. Occasionally, condensed solutions of SBF (e.g., 1.5fold, 2-fold [792,793], 5-fold [794,795] and even 10-fold [796]) are used to accelerate the precipitation; however, whenever possible this should be avoided because the application of condensed solutions of SBF leads to changes in the chemical composition of the precipitates; namely, the concentration of carbonates increases, while the concentration of orthophosphates decreases [797].

It is very difficult to mimic exactly the calcification process that occurs in bones and teeth. A step further would be to perform the precipitation from the simulating solutions on templates of biomineralization proteins for the control of crystal organization and properties. For example, there are successful attempts to crystallize calcium orthophosphates on collagen in order to obtain bone-like composites [391,798-803]. Such collagen/calcium orthophosphate composites are currently under investigation for clinical use. Other popular biomimetic matrixes to perform calcium orthophosphate crystallization comprise gelatin [294-296,298,299,804-806], chitosan [804,807,808], organic polyelectrolytes [809-812], titanium and its alloys [813-819], polymers [820], cellulose [821], selfassembled monolayers [822] and many other materials. Some of such materials are occasionally called "organoapatites" [353].

\section{Calcium Orthophosphates in Tissue Engineering}

All present day orthopedic implants lack three of the most critical characteristics of living tissues: (i) the ability to self-repair; (ii) the ability to maintain a blood supply; (iii) the ability to modify their structure and properties in response to environmental factors such as mechanical load [667]. Needless to say, bones not only possess all the aforementioned properties but, in addition, they are selfgenerating, hierarchical, multifunctional, nonlinear, composite and biodegradable; therefore, good artificial bone substitutes must possess similar properties [355].

The last two decades have seen a surge in creative ideas and technologies developed to tackle the problem of repairing or replacing diseased and damaged tissues, leading to the emergence of a new field in healthcare technology now referred to as tissue engineering. Tissue engineering is an interdisciplinary field that exploits a combination of living cells, engineering materials and suitable biochemical factors in a variety of ways to improve, replace, restore, maintain or enhance living tissues and whole organs [823]. This field of science [824] started more than a decade ago [825] and nowadays is at full research potential due to the following key advantages: (i) the solutions it provides are long-term, much safer than other options and cost-effective as well; (ii) the need for a donor tissue is minimal, which eliminates the immuno-suppression problems; (iii) the presence of residual foreign material is eliminated as well. As two of three major components (namely, living cells and 
biochemical factors) of tissue engineering appear to be far beyond the scope of this review, here the topic of tissue engineering is narrowed down to the engineering materials only.

Cells are generally implanted or seeded into an artificial structure, usually referred to as a scaffold, capable of supporting 3D tissue formation. The scaffolds are temporary matrices for bone growth and provide a specific environment and architecture for tissue development. They serve at least one of the following purposes: (i) allow cell attachment and migration; (ii) deliver and retain cells and biochemical factors; (iii) enable diffusion of vital cell nutrients and expressed products; (iv) exert certain mechanical and biological influences to modify the behavior of the cell phase [826]. To achieve the goal of tissue reconstruction, the scaffolds must meet some specific requirements. A reasonable surface roughness is necessary to facilitate cell seeding and fixation [827-829]. A high porosity and an adequate pore size are very important to provide diffusion throughout the whole structure of both cells and nutrients [828-834]. Biodegradability is very essential since scaffolds need to be resorbed by the surrounding tissues without the necessity of a surgical removal. The resorption rate has to coincide as much as possible with the rate of tissue formation [835]: this means that while cells are fabricating their own natural matrix structure around themselves, the scaffold is able to provide a structural integrity within the body and eventually it will break down leaving the newly formed tissue that will take over the mechanical load. Injectability is also an important factor for the clinical applications [685,686,694-699].

In the case of bone grafts, the aim of tissue engineering is to provide an artificially prepared porous scaffold made of calcium orthophosphates that provides the physical and chemical cues to guide cell seeding, differentiation and assembly into 3D tissues of a newly formed bone [836-840]. More to the point, bone-forming functions of cells can be dependent on grain morphology of the scaffolds. For example, osteoblast functions were found to be increased on nanofiber structures if compared to nanospherical ones because nanofibers more closely approximated the shape of biological apatite in bones [841]. To meet these needs, much attention is devoted to further modification of calcium orthophosphates [842]. From the chemical point of view, the modifications include synthesis of novel ion-substituted calcium orthophosphates [843-848], while from the material point of view the major research topics include nanocrystalline structures [290,849-858], organic-inorganic composites and hybrid biomaterials [289,731-739, 858-860], fibers and whiskers [861-868], micro- and nanospheres [859,869-872], porous 3D scaffolds made of ACP [199], HA [873-876] and BCP [877], structures with graded porosity [878] and hierarchically organized ones [879]. The influence of the porosity of HA ceramics on in vitro and in vivo bone formation studied by cultured rat bone marrow stromal cells has been studied [880]. The feasible production of ceramic scaffolds with tailored structure and properties opens up a spectacular future for calcium orthophosphates.

There are three principal therapeutic strategies for treating diseased or injured tissues in patients: (i) implantation of freshly isolated or cultured cells; (ii) implantation of tissues assembled in vitro from cells and scaffolds; (iii) in situ tissue regeneration. For cellular implantation, individual cells or small cellular aggregates from the patient or a donor are either injected into the damaged tissue directly or are combined with a degradable scaffold in vitro and then implanted. For tissue implantation, a complete 3D tissue is grown in vitro using patient or donor cells and a bioresorbable scaffold and then is implanted into the patients to replace diseased or damaged tissues. For in situ regeneration, a scaffold implanted directly into the injured tissue stimulates the body's own cells to promote local 
tissue repair [823,881]. In any case, simply trapping cells at a particular point on a surface is not enough: the cells must be encouraged to differentiate, which is impossible without the presence of suitable biochemical factors [882]. All previously mentioned clearly indicates that for the purposes of tissue engineering, calcium orthophosphates play only an auxiliary role; namely, they act as a suitable material to manufacture an appropriate 3D template, substrate or scaffold to be colonized by living cells before the successive implantation. However, the scaffolds themselves might be prepared from not only pure calcium orthophosphates but also organic-inorganic composites [883-889]. The in vitro evaluation of potential calcium orthophosphate scaffolds for tissue engineering has been described elsewhere [890], while the data on mechanical properties and porosity of calcium orthophosphates for use in tissue engineering are also available $[891,892]$. The effect of a HA-based biomaterial on gene expression in osteoblast-like cells was reported [893]. The influence of adsorbed serum proteins, RGD and proteoglycan-binding peptides on the adhesion of mesenchymal stem cells to HA was studied [894]. To conclude this part, the excellent biocompatibility of calcium orthophosphates, their possible osteoinductivity [745] and a high affinity for proteins and cells makes them very functional for hard tissue regeneration [895-897].

\section{Conclusions and Outlook}

By the end of the 20-th century, it became clear that calcium orthophosphate biomaterials and bioceramics by themselves could not provide a complete response to the clinical needs for artificial implants. Biomaterials with more demanding properties were required. Namely, in 1998, Hench published a forecast for the future of biomaterials development [898], where he noted that available that time bioactive materials (calcium orthophosphates, bioactive glasses and glass ceramics) had already improved prostheses lifetime but, unfortunately, any type of prosthesis had mechanical limitations. As the solution, he proposed that biomaterial researchers would need to focus on tissue regeneration instead of tissue replacement. A working hypothesis was announced: "Long-term survivability of prosthesis will be increased by the use of biomaterials that enhance the regeneration of natural tissues" [898]. One path to follow is the regeneration of bone using calcium orthophosphate scaffolds that mimic the structure of biological apatite, bond to bone and in some cases activate the genes within bone cells to stimulate new bone growth [667,823,881]. Thus, 10 years ago Hench predicted a rapid development of tissue engineering field, where calcium orthophosphates play an auxiliary role. The history has shown that tissue engineering, indeed, is a very rapidly developed field of science and research [899].

However, what can be said about calcium orthophosphates themselves? The major questions on chemistry, crystallization, ion-substitution, crystallography, thermodynamics and phase relationships for the chemically pure calcium orthophosphates have been answered in the 20-th century. Some topics for DCPD and CDHA have been additionally investigated in the field of calcium orthophosphate cements [686]. Conversely, calcium orthophosphates of biological origin, including the control of their morphology and interaction of calcium orthophosphate bioceramics with various bio- and organic compounds are not well investigated yet. The same is valid for nanocrystalline samples of calcium orthophosphates. Small amounts of bone-like apatite might be easily prepared by crystallization from SBF and rSBF but what can be said about larger quantities? A standard way of the 
concentration increasing causes chemical changes in the precipitates [797]. After a necessary technology is developed, one will have to think on scaffold preparation from this material, keeping in mind that any thermal treatment would destroy this material. A spark plasma sintering approach based on the use of pulsed current and enabling very fast heating and cooling rates seemed to be a first hint to achieve this goal [900]. However, a rapid development of calcium orthophosphate cements [686], which can be easily doped by the necessary chemical elements, seems to be a better solution of this problem. Furthermore, the existence of oxyapatite [68] remains to be questionable, as well as the bioactivity mechanism of calcium orthophosphates requires improving.

To date, although calcium orthophosphate biomaterials and bioceramics have been extensively studied for over 50 years, their ability to trigger bone formation is still incomparable with other biomaterials. Naturally, the biomaterials' field is shifting towards biologically active systems in order to improve their performance and to expand their use [901]. Due to this case, tissue engineering is the strongest direction of current research, which, in the case of calcium orthophosphates, means fabrication of proper substrates and/or scaffolds to carry cells, hormones and biochemical factors to be further used in surgery and medicine. Presumably, a synthesis of various types of calcium orthophosphate-based biocomposites and hybrid biomaterials [743] occupies the second important place. For example, even composites with carbon nanotubes already exist [902-904]! The third important place is occupied by investigations devoted to the synthesis and characterization of various nanoparticles and nanocrystals of calcium orthophosphates $[905,906]$, as well as by synthesis of calcium orthophosphates with controlled particle geometry [355]. In general, the geometry of crystal phases can be varied by controlling the precipitation conditions, such as temperature, solution $\mathrm{pH}$, concentration of the reagents, hydrodynamics, presence of various admixtures, inhibitors or promoters, ultrasonication, etc. All these approaches might be useful in preparation of calcium orthophosphate fibers, whiskers, hollow microspheres, etc. In addition, a great attention is paid to manufacturing of calcium orthophosphate cements [686] and multiphase [907] mixtures mimicking as closely as possible the mineral component of biological apatite. A work along the ecological ways of synthesis of calcium orthophosphates might be of a great importance as well [909]. A deeper study of the fascinating growth rate of deer antlers and the ability of some animals, such as newts, to regenerate amputated limbs might provide new and unexpected approaches to the bone-healing concept, as well as this will be important for further development of both biomimetics and biomineralization fields. Unfortunately, no currently available grafting biomaterials can substitute the bones' mechanical function, illustrating yet unmet medical need that would entirely substitute and regenerate a damaged tissue or organ. In a close future, the foreseeable application of calcium orthophosphates will be as a component of the third generation biomaterials [881,898], where they will support cells and/or other biologically active substances (peptides, growth factors, hormones, drugs, etc.) to guide regeneration of hard tissues [631,842,910-915]. To finalize this comprehensive review, one should note that, in spite of a long history of the calcium orthophosphate research and many important discoveries, still many gaps remain in our knowledge to be investigated in future.

\section{References and Notes}

1. Berzelius, J. Ueber basische phosphorsaure kalkerde. Ann. Chem. Pharma. 1845, 53, 286-288. 
2. Cameron, F.K.; Seidell, A. The phosphates of calcium. I. J. Am. Chem. Soc. 1905, 27, 1503-1512.

3. Cameron, F.K.; Bell, J.M. The phosphates of calcium. II. J. Am. Chem. Soc. 1905, 27, 1512-1514.

4. Cameron, F.K.; Bell, J.M. The phosphates of calcium, III; Superphosphate. J. Am. Chem. Soc. 1906, 28, 1222-1229.

5. Cameron, F.K.; Bell, J.M. The phosphates of calcium. IV. J. Am. Chem. Soc. 1910, 32, 869-873.

6. Bassett, H., Jr. Beiträge zum Studium der Calciumphosphate. I. Die Hydrate der CalciumHydroorthophosphate. Z. Anorg. Chem. 1907, 53, 34-48.

7. Bassett, H., Jr. Beiträge zum Studium der Calciumphosphate. II. Die Einwirkung von Ammoniakgas auf Calcium-Hydroorthophosphate. Z. Anorg. Chem. 1907, 53, 49-62.

8. Bassett, H., Jr. Beiträge zum Studium der Calciumphosphate. III. Das System $\mathrm{CaO}-\mathrm{P}_{2} \mathrm{O}_{5}-$ $\mathrm{H}_{2}$ O. Z. Anorg. Chem. 1908, 59, 1-55.

9. Bassett, H., Jr. The phosphates of calcium. Part IV. The basic phosphates. J. Chem. Soc. 1917, $111,620-642$.

10. As a mineral species, apatite was first recognized by the father of German geology Abraham Gottlob Werner $(1750$ - 1817) in 1786 and named by him from the ancient Greek $\alpha \pi \alpha \tau \alpha \dot{\omega} \omega$ (apatao) - "to mislead" or "to deceive", because it had previously been mistaken for other minerals, such as beryl, tourmaline, chrysolite, amethyst, fluorite, etc.

11. Hausen, H. Die Apatite, deren chemische zusammensetzung, und ihrer Verhältnis zu physikalischen und morphologischen Eigenschaften. Acta Acad. Abo. Ser. B: Mat. Phys. Mat. Natur. Teknik. 1929, 5, 62-65.

12. Lide, D.R. The CRC handbook of chemistry and physics, $86^{\text {th }}$ Ed.; CRC Press: Boca Raton, Florida, USA, 2005; p. 2544.

13. LeGeros, R.Z. Calcium phosphates in oral biology and medicine; Karger: Basel, Switzerland, 1991; p. 201

14. Elliot, J.C. Structure and chemistry of the apatites and other calcium orthophosphates. Stud. Inorg. Chem. 1994, 18, 389.

15. Amjad, Z., Ed. Calcium phosphates in biological and industrial systems; Kluwer Academic Publishers: Boston, MA, USA, 1997; p. 529.

16. Cantelar, E.; Lifante, G.; Calderón, T.; Meléndrez, R.; Millán, A.; Alvarez, M.A.; BarbozaFlores, M. Optical characterisation of rare earths in natural fluorapatite. J. Alloys Compd. 2001, 323-324, 851-854.

17. Ribeiro, H.B.; Guedes, K.J.; Pinheiro, M.V.B.; Greulich-Weber, S.; Krambrock, K. About the blue and green colours in natural fluorapatite. Phys. Status Solidi C 2005, 2, 720-723.

18. Dorozhkin, S.V.; Epple, M. Biological and medical significance of calcium phosphates. Angew. Chem. Int. Ed. Engl. 2002, 41, 3130-3146.

19. McConnell, D. Apatite: its crystal chemistry, mineralogy, utilization, and geologic and biologic occurrences; Springer-Verlag: Vienna and New York, USA, 1973; p.111.

20. Becker, P. Phosphates and phosphoric acid: raw materials technology and economics of the wet process, $2^{\text {nd }}$ Ed. In Fertilizer science and technology series; Marcel Dekker: New York, USA, $1989 ;$ p.760. 
21. Smith, D.K. Calcium phosphate apatites in nature. In Hydroxyapatite and related materials; Brown, P.W., Constantz, B. Eds.; CRC Press Inc.: Boca Raton, FL, USA, 1994; pp. 29-44.

22. Angelov, A.I.; Levin, B.V.; Chernenko, Yu.D. Phosphate ore, A reference book. (in Russian); Nedra Busyness Centre: Moscow, Russia, 2000; p. 120.

23. Phosphate deposits of the world: phosphate rock resources; Cook, P.J.; Shergold, J.H.; Davidson, D.F., Eds.; Cambridge University Press: Cambridge, MA, USA, 2005; Volume 2, p. 600 .

24. Ford, A.K. A remarkable crystal of apatite from Mt. Apatite, Auburn, Maine. Am. J. Sci. 1917, 44, 245-246.

25. Hogarth, D.D. The discovery of apatite on the Lievre River, Quebec. Mineral. Rec. 1974, 5, 178-182.

26. van Velthuizen, J. Giant fluorapatite crystals: a question of locality. Mineral. Rec. 1992, 23, 459-463.

27. Pan, Y.; Fleet, M.E. Compositions of the apatite-group minerals: substitution mechanisms and controlling factors. In Phosphates: geochemical, geobiological and materials importance, Series: Reviews in Mineralogy and Geochemistry. Vol. 48; Hughes; J.M., Kohn, M., Rakovan, J., Eds.; Mineralogical Society of America: Washington, D.C., USA, 2002; pp. 13-49.

28. Zanin, Yu.N. The classification of calcium phosphates of phosphorites. Lithol. Miner. Resour. 2004, 39, 281-282.

29. Rogers, A.F. Collophane, a much neglected mineral. Am. J. Sci. 1922, 3, 269-276.

30. http://www.mindat.org/min-10072.html, accessed April 2009.

31. Elorza, J.; Astibia, H.; Murelaga, X.; Pereda-Suberbiola, X. Francolite as a diagenetic mineral in dinosaur and other upper cretaceous reptile bones (Lano, Iberian peninsula): microstructural, petrological and geochemical features. Cretaceous Res. 1999, 20, 169-187.

32. Hubert, B.; Álvaro, J.J.; Chen, J.Y. Microbially mediated phosphatization in the Neoproterozoic Doushantuo Lagerstätte, South China. Bull. Soc. Géol. Fr. 2005, 176, 355-361.

33. Chakhmouradian, A.R.; Medici, L. Clinohydroxylapatite: a new apatite-group mineral from northwestern Ontario (Canada), and new data on the extent of Na-S substitution in natural apatites. Eur. J. Mineral. 2006, 18, 105-112.

34. http://www.mindat.org/gallery.php?min = 9293, accessed April 2009.

35. Klein, C. Brushite from the island of Mona (between Haiti and Puerto Rico). Sitzber. K. Preuss. Aka. 1901, 720-725.

36. Merrill, G.P. On the calcium phosphate in meteoric stones. Am. J. Sci. 1917, 43, 322-324.

37. Tyrrell, G.W. Apatite, nepheline, and rare-earth mining in the Kola Peninsula. Nature 1938, 141, 354-355.

38. Trueman, N.A. Substitutions for phosphate ions in apatite. Nature 1966, 210, 937-938.

39. White, T.; Ferraris, C.; Kim, J.; Madhavi, S. Apatite - an adaptive framework structure. In Micro- and mesoporous mineral phases, Series: Reviews in Mineralogy and Geochemistry. Vol. 57; Ferraris, G., Merlino S., Eds.; Mineralogical Society of America: Washington, D.C., USA, 2005; pp. 307-401.

40. Jacob, K.D.; Reynolds, D.S. Reduction of tricalcium phosphate by carbon. Ind. Eng. Chem. 1928, 20, 1204-1210. 
41. Copson, R.L.; Newton, R.H.; Lindsay, J.D. Superphosphate manufacture - mixing phosphate rook with concentrated phosphoric acid. Ind. Eng. Chem. 1936, 28, 923-927.

42. Newton, R.H.; Copson, R.L. Superphosphate manufacture - composition of superphosphate made from phosphate rock and concentrated phosphoric acid. Ind. Eng. Chem. 1936, 28, 1182-1186.

43. Magda, A.; Pode, V.; Niculescu, M.; Muntean, C.; Bandur, G.; Iovi, A. Studies on process of obtaining the fertilizers based on ammonium phosphates with addition of boric acid. Rev. Chim. (Bucharest) 2008, 59, 1340-1344.

44. Omelon, S.J.; Grynpas, M.D. Relationships between polyphosphate chemistry, biochemistry and apatite biomineralization. Chem. Rev. 2008, 108, 4694-4715.

45. Rey, C.; Combes, C.; Drouet, C.; Sfihi, H. Chemical diversity of apatites. Adv. Sci. Technol. 2006, 49, 27-36.

46. O'Neill, W.C. The fallacy of the calcium - phosphorus product. Kidney Int. 2007, 72, 792-796.

47. LeGeros, R.Z. Formation and transformation of calcium phosphates: relevance to vascular calcification. Z Kardiol. 2001, 90, Suppl. 3, III116-III125.

48. Becker, A.; Epple, M.; Müller, K.M.; Schmitz, I. A comparative study of clinically wellcharacterized human atherosclerotic plaques with histological, chemical, and ultrastructural methods. J. Inorg. Biochem. 2004, 98, 2032-2038.

49. Wopenka, B.; Pasteris, J.D. A mineralogical perspective on the apatite in bone. Mater. Sci. Eng., C 2005, 25, 131-143.

50. Pasteris, J.D.; Wopenka, B.; Valsami-Jones, E. Bone and tooth mineralization: why apatite? Elements 2008, 4, 97-104.

51. Sun, Y.; Hanley, E.N., Jr. Calcium-containing crystals and osteoarthritis. Curr. Opin. Orthoped. 2007, 18, 472-478.

52. Occasionally "biological apatite" is called "bioapatite" [53-55].

53. Danil'chenko, S.N.; Kulik, A.N.; Bugai, A.N.; Pavlenko, P.A.; Kalinichenko, T.G.; Ul'yanchich, N.V.; Sukhodub, L.F. Thermally activated diffusion of magnesium from bioapatite crystals. $J$. Appl. Spectrosc. 2005, 72, 899-905.

54. Passey, B.H.; Robinson, T.F.; Ayliffe, L.K.; Cerling, T.E.; Sphonheimer, M.; Dearing, M.D.; Roeder, B.L.; Ehleringer, J.R. Carbon isotopic fractionation between diet, breath and bioapatite in different mammals. J. Arch. Sci. 2005, 32, 1459-1470.

55. Meneghini, C.; Dalconi, M.C.; Nuzzo, S.; Mobilio, S.; Wenk, R.H. Rietveld refinement on X-ray diffraction patterns of bioapatite in human fetal bones. Biophys. J. 2003, 84, 2021-2029.

56. There are reports that dahllite belongs to the francolite group. Natural dahllite might be a rock forming mineral [57]. For example, it was found in some phosphorite concretions of Podolia [58, 59]. In addition, it was found in both massive and accretionary crustal phosphorites [28].

57. Rogers, A.F. Dahllite from Tonopah, Nevada; Voelckerite, a new basic calcium phosphate; comments on the chemical composition of apatite and phosphorite. Z. Krystallogr. Mineral. 1912, 52, 209-217.

58. Schaller, W.T. The probable identity of podolite with dahllite. Am. J. Sci. 1910, 30, 309-310.

59. Schaller, W.T. On the likely identity of podolite and dahllite. Z. Krystallogr. Mineral. 1910, 48, 559-561. 
60. Collagens are fibrous, insoluble proteins found in the connective tissues, including skin, bone, ligaments and cartilage.

61. Skinner, H.C.W. Biominerals. Mineral. Mag. 2005, 69, 621-641.

62. Daculsi, G. Physicochemical and ultrastructural analysis of bone bioactive interface. Biomater. Tissue Int. 1992, 10, 296-304.

63. Daculsi, G.; Bouler, J.M.; LeGeros, R.Z. Adaptive crystal formation in normal and pathological calcifications in synthetic calcium phosphate and related biomaterials. Int. Rev. Cytology 1997, 172, 129-191.

64. Driessens, F.C.M.; Verbeeck, R.M.H. Biominerals; CRC Press: Boca Raton, FL, USA, 1990; p. 440.

65. Clark, N.A. The system $\mathrm{P}_{2} \mathrm{O}_{5}-\mathrm{CaO}-\mathrm{H}_{2} \mathrm{O}$ and the recrystallization of monocalcium phosphate. $J$. Phys. Chem. 1931, 35, 1232-1238.

66. Brown, P.W. Phase relationships in the ternary system $\mathrm{CaO}-\mathrm{P}_{2} \mathrm{O}_{5}-\mathrm{H}_{2} \mathrm{O}$ at $25^{\circ} \mathrm{C} . \mathrm{J}$. Am. Ceram. Soc. 1992, 75, 17-22.

67. Martin, R.I.; Brown, P.W. Phase equilibria among acid calcium phosphates. J. Am. Ceram. Soc. 1997, 80, 1263-1266.

68. In literature occasionally one might find notes on the $12^{\text {th }}$ calcium orthophosphate, namely oxyapatite $\left(\mathrm{Ca}_{10}\left(\mathrm{PO}_{4}\right)_{6} \mathrm{O}\right)$. A mixture of oxyapatite and $\mathrm{HA}$ might be prepared by dehydration of $\mathrm{HA}$ at temperatures exceeding $\sim 900^{\circ} \mathrm{C}$ (e.g., during plasma-spray of HA) only in the absence of water vapor $[14,15,69,70]$. It also might be crystallized in glass-ceramics [71]. Computer modeling techniques have been employed to qualitatively and quantitatively investigate the dehydration of HA to oxyapatite [72]. Oxyapatite has the hexagonal space group symmetry $\mathrm{P}^{\overline{6}}$ (174) of cesanite type [73], while the space group symmetry for partially dehydrated HA was found to change from hexagonal $\mathrm{P} 63 / \mathrm{m}$ to triclinic $\mathrm{P} \overline{1}$ when more than ca. $35 \%$ of the structurally bound water had been removed [70]. Oxyapatite is very reactive and transforms to HA in contact with water vapor [69]. Oxyapatite is still very poorly known; however, the following data on the solubility constant $\left(\mathrm{K}_{\mathrm{s}} \sim 10^{-69}\right.$ at $\left.25^{\circ} \mathrm{C}\right)$ are available [14].

69. Gross, K.A.; Berndt, C.C.; Dinnebier, R.; Stephens, P. Oxyapatite in hydroxyapatite coatings, $J$. Maert. Sci. Mater. Med. 1998, 33, 3985-3991.

70. Alberius-Henning, P.; Adolfsson, E.; Grins, J.; Fitch, A. Triclinic oxy-hydroxyapatite. J. Mater. Sci. 2001, 36, 663-668.

71. van't Hoen, C.; Rheinberger, V.; Höland, W.; Apel, E. Crystallization of oxyapatite in glassceramics. J. Eur. Ceram. Soc. 2007, 27, 1579-1584.

72. de Leeuw, N.H.; Bowe, J.R.; Rabone, J.A.L. A computational investigation of stoichiometric and calcium-deficient oxy- and hydroxy-apatites. Faraday Disc. 2007, 134, 195-214.

73. White, T.J.; Dong, Z.L. Structural derivation and crystal chemistry of apatites. Acta Crystallogr., Sect. B: Struc. Sci. 2003, B59, 1-16.

74. Mathew, M.; Takagi, S. Structures of biological minerals in dental research. J. Res. Natl. Inst. Stand. Technol. 2001, 106, 1035-1044.

75. Hughes, J.M.; Rakovan, J. The crystal structure of apatite, $\mathrm{Ca}_{5}\left(\mathrm{PO}_{4}\right)_{3}(\mathrm{~F}, \mathrm{OH}, \mathrm{Cl})$. In Phosphates: geochemical, geobiological and materials importance, Series: Reviews in Mineralogy and 
Geochemistry. Vol. 48; Hughes; J.M., Kohn, M., Rakovan, J., Eds.; Mineralogical Society of America: Washington, D.C., USA, 2002; pp. 1-12.

76. Wang, L.; Nancollas, G.H. Calcium orthophosphates: crystallization and dissolution. Chem. Rev. 2008, 108, 4628-4669.

77. Lynn, A.K.; Bonfield, W. A novel method for the simultaneous, titrant-free control of $\mathrm{pH}$ and calcium phosphate mass yield. Acc. Chem. Res. 2005, 38, 202-207.

78. Fernández, E.; Gil, F.J.; Ginebra, M.P.; Driessens, F.C.M.; Planell, J.A.; Best, S.M. Calcium phosphate bone cements for clinical applications. Part I: solution chemistry. J. Mater. Sci. Mater. Med. 1999, 10, 169-176.

79. McDowell, H.; Gregory, T.M.; Brown, W.E. Solubility of $\mathrm{Ca}_{5}\left(\mathrm{PO}_{4}\right)_{3} \mathrm{OH}$ in the system $\mathrm{Ca}(\mathrm{OH})_{2}-$ $\mathrm{H}_{3} \mathrm{PO}_{4}-\mathrm{H}_{2} \mathrm{O}$ at 5, 15, 25, and 37 degree. C. J. Res. Natl. Bur. Stand. Sect. A Phys. Chem. 1977, 81A, 273-281.

80. Pan, H.B.; Darvell, B.W. Calcium phosphate solubility: the need for re-evaluation. Cryst. Growth Des. 2009, 9, 639-645.

81. Biocompatibility is the ability of a material to perform with an appropriate host response in a specific application [82].

82. Williams, D.F. The Williams dictionary of biomaterials; Liverpool University Press: Liverpool, UK, 1999; p.368.

83. Köster, K.; Heide, H.; König, R. Resorbierbare Calciumphosphatkeramik im Tierexperiment unter Belastung. Langenbecks Arch. Chir. 1977, 343, 173-181.

84. Bermúdez, O.; Boltong, M.G.; Driessens, F.C.M.; Planell, J.A. Optimization of a calcium orthophosphate cement formulation occurring in the combination of monocalcium phosphate monohydrate with calcium oxide. J. Mater. Sci. Mater. Med. 1994, 5, 67-71.

85. Bermúdez, O.; Boltong, M.G.; Driessens, F.C.M.; Planell, J.A. Development of some calcium phosphate cements from combinations of $\alpha$-TCP, MCPM and CaO. J. Mater. Sci. Mater. Med. 1994, $5,160-163$.

86. Driessens, F.C.M.; Boltong, M.G.; Bermúdez, O.; Planell, J.A.; Ginebra, M.P.; Fernández, E. Effective formulations for the preparation of calcium phosphate bone cements. J. Mater. Sci. Mater. Med. 1994, 5, 164-170.

87. Huan, Z.; Chang, J. Novel bioactive composite bone cements based on the $\beta$-tricalcium phosphate - monocalcium phosphate monohydrate composite cement system. Acta. Biomater. 2009, 5, 1253-1264.

88. The Merck Index: An encyclopedia of chemicals, drugs, and biologicals, $12^{\text {th }}$ Ed.; Budavari, S.; O’Neil, M.J.; Smith, A.; Heckelman, P.E.; Kinneary, J.F., Eds.; Chapman \& Hall: USA, 1996; p.1741.

89. Stein, H.H.; Kadzere, C.T.; Kim, S.W.; Miller, P.S. Influence of dietary phosphorus concentration on the digestibility of phosphorus in monocalcium phosphate by growing pigs. $J$. Animal Sci. 2008, 86, 1861-1867.

90. To honor Prof. George Jarvis Brush (1831-1912), an American mineralogist, Yale University, New Haven, Connecticut, USA.

91. Arsic, J.; Kaminski, D.; Poodt, P.; Vlieg, E. Liquid ordering at the brushite- $\{010\}$-water interface. Phys. Rev. B 2004, 69, 245406 (4 pages). 
92. Qiu, S.R.; Orme, C.A. Dynamics of biomineral formation at the near-molecular level. Chem. Rev. 2008, 108, 4784-4822.

93. Kurashina, K.; Kurita, H.; Hirano, M.; Kotani, A.; Klein, C.P.; de Groot, K. In vivo study of calcium phosphate cements: implantation of an $\alpha$-tricalcium phosphate / dicalcium phosphate dibasic / tetracalcium phosphate monoxide cement paste. Biomaterials 1997, 18, 539-543.

94. Driessens, F.C.M.; Planell, J.A.; Boltong, M.G.; Khairoun, I.; Ginebra, M.P. Osteotransductive bone cements. Proc. Inst. Mech. Eng., H: J. Eng. Med. 1998, 212, 427-435.

95. Takagi, S.; Chow, L.C.; Ishikawa, K. Formation of hydroxyapatite in new calcium phosphate cements. Biomaterials 1998, 19, 1593-1599.

96. Yamamoto, H.; Niwa, S.; Hori, M.; Hattori, T.; Sawai, K.; Aoki, S.; Hirano, M.; Takeuchi, H. Mechanical strength of calcium phosphate cement in vivo and in vitro. Biomaterials 1998, 19, 1587-1591.

97. Crall, J.J.; Bjerga, J.M. Effects of DCPD / APF application and prolonged exposure to fluoride on caries-like lesion formation in vitro. J. Oral Pathol. Med. 1987, 16, 488-491.

98. Wefel, J.S.; Harless, J.D. The use of saturated DCPD in remineralization of artificial caries lesions in vitro. J. Dent. Res. 1987, 66, 1640-1643.

99. Hoppenbrouwers, P.M.; Groenendijk, E.; Tewarie, N.R.; Driessens, F.C.M. Improvement of the Caries Resistance of human dental roots by a two-step conversion of the root mineral into fluoridated hydroxylapatite. J. Dent. Res. 1988, 67, 1254-1256.

100. Gaffar, A.; Blake-Haskins, J.; Mellberg, J. In vivo studies with a dicalcium phosphate / MFP system for caries prevention. Int. Dent. J. 1993, 43 (Suppl. 1), 81-88.

101. Sullivan, R.J.; Charig, A.; Blake-Haskins, J.; Zhang, Y.P.; Miller, S.M.; Strannick, M.; Gaffar, A.; Margolis, H.C. In vivo detection of calcium from dicalcium phosphate dihydrate dentifrices in demineralized human enamel and plaque. Adv. Dent. Res. 1997, 11, 380-387.

102. Mostashari, S.M.; Haddadi, H.; Hashempoor, Z. Effect of deposited calcium hydrogen phosphate dihydrate on the flame retardancy imparted to cotton fabric. Asian J. Chem. 2006, 18, 2388-2390.

103. Powditch, H.I.; Bosworth, A.W. Studies on infant feeding IX. The availability of dicalcium phosphate when present as a constituent of infant's food. Boston Med. Surg. J. 1917, 177, 864-867.

104. For Moneta (now Monito) Island (archipelago of Puerto Rico), which contains a notable occurrence.

105. Eshtiagh-Hosseini, H.; Houssaindokht, M.R.; Chahkandhi, M.; Youssefi, A. Preparation of anhydrous dicalcium phosphate, DCPA, through sol-gel process, identification and phase transformation evaluation. J. Non-Cryst. Solids 2008, 354, 3854-3857.

106. Fukase, Y.; Eanes, E.D.; Takagi, S.; Chow, L.C.; Brown, W.E. Setting reactions and compressive strengths of calcium phosphate cements. J. Dent. Res. 1990, 69, 1852-1856.

107. TenHuisen, K.S.; Brown, P.W. The formation of hydroxyapatite-ionomer cements at 38 degrees C. J. Dent. Res. 1994, 73, 598-606.

108. Fernández, E.; Ginebra, M.P.; Boltong, M.G.; Driessens, F.C.M.; J. Ginebra, de Maeyer, E.A.; Verbeeck, R.M.H.; Planell, J.A. Kinetic study of the setting reaction of a calcium phosphate bone cement. J. Biomed. Mater. Res. 1996, 32, 367-374. 
109. Fernández, E.; Gil, F.J.; Best, S.M.; Ginebra, M.P.; Driessens, F.C.M.; Planell, J.A. The cement setting reaction in the $\mathrm{CaHPO}_{4}-\alpha-\mathrm{Ca}_{3}\left(\mathrm{PO}_{4}\right)_{2}$ system: an X-ray diffraction study. J. Biomed. Mater. Res. 1998, 42, 403-406.

110. Fernández, E.; Gil, F.J.; Ginebra, M.P.; Driessens, F.C.M.; Planell, J.A.; Best, S.M. Production and characterization of new calcium phosphate bone cements in the $\mathrm{CaHPO}_{4}-\alpha-\mathrm{Ca}_{3}\left(\mathrm{PO}_{4}\right)_{2}$ system: pH, workability and setting times. J. Mater. Sci. Mater. Med. 1999, 10, 223-230.

111. LeGeros, R.Z. Preparation of octacalcium phosphate (OCP): a direct fast method. Calcif. Tissue Int. 1985, 37, 194-197.

112. Bigi, A.; Boanini, E.; Borghi, M.; Cojazzi, G.; Panzavolta, S.; Roveri, N. Synthesis and hydrolysis of octacalcium phosphate: effect of sodium polyacrylate. J. Inorg. Biochem. 1999, 75, 145-151.

113. Nakahira, A.; Aoki, S.; Sakamoto, K.; Yamaguchi, S. Synthesis and evaluation of various layered octacalcium phosphates by wet-chemical processing. J. Mater. Sci. Mater. Med. 2001, 12, 793-800.

114. Shelton, R.M.; Liu, Y.; Cooper, P.R.; Gbureck, U.; German, M.J.; Barralet, J.E. Bone marrow cell gene expression and tissue construct assembly using octacalcium phosphate microscaffolds. Biomaterials 2006, 27, 2874-2881.

115. Miyatake, N.; Kishimoto, K.N.; Anada, T.; Imaizumi, H.; Itoi, E.; Suzuki, O. Effect of partial hydrolysis of octacalcium phosphate on its osteoconductive characteristics. Biomaterials 2009, 30, 1005-1014.

116. Arellano-Jiménez, M.J.; García-García, R.; Reyes-Gasga, J. Synthesis and hydrolysis of octacalcium phosphate and its characterization by electron microscopy and X-ray diffraction. $J$. Phys. Chem. Solids 2009, 70, 390-395.

117. Brown, W.E.; Mathew, M.; Tung, M.S. Crystal chemistry of octacalcium phosphate. Prog. Cryst. Growth Charact. 1981, 4, 59-87.

118. LeGeros, R.Z. Variations in the crystalline components of human dental calculus: I. crystallographic and spectroscopic methods of analysis. J. Dent. Res. 1974, 53, 45-50.

119. Schroeder, H. Formation and inhibition of dental calculus. J. Periodontol. 1969, 40, 643-646.

120. Octacalcium phosphate; Chow, L.C.; Eanes, E.D. Eds.; Karger: Basel, Switzerland, 2001; p. 167.

121. Brown, W.E. Octacalcium phosphate and hydroxyapatite: crystal structure of octacalcium phosphate. Nature 1962, 196, 1048-1050.

122. Brown, W.E.; Smith, J.P.; Lehr, J.R.; Frazier, A.W. Octacalcium phosphate and hydroxyapatite: crystallographic and chemical relations between octacalcium phosphate and hydroxyapatite. Nature 1962, 196, 1050-1055.

123. Brown, W.E. Crystal growth of bone mineral. Clin. Orthop. Relat. Res. 1966, 44, 205-220.

124. Nelson, D.G.A.; Wood, G.J.; Barry, J.C.; Featherstone, J.D.B. The structure of (100) defects in carbonated apatite crystallites: a high-resolution electron microscope study. Ultramicroscopy 1986, 19, 253-265.

125. Iijima, M.; Nelson, D.G.A.; Pan, Y.; Kreinbrink, A.T.; Adachi, M.; Goto, T.; Moriwaki, Y. Fluoride analysis of apatite crystals with a central planar OCP inclusion: concerning the role of $\mathrm{F}^{-}$ions on apatite / OCP / apatite structure formation. Calcif. Tissue Int. 1996, 59, 377-384. 
126. Bodier-Houllé, P.; Steuer, P.; Voegel, J.C.; Cuisinier, F.J.G. First experimental evidence for human dentine crystal formation involving conversion of octacalcium phosphate to hydroxyapatite. Acta Crystallogr.,Sect D: Biol. Crystallogr. 1998, 54, 1377-1381.

127. Aoba, T.; Komatsu, H.; Shimazu, Y.; Yagishita, H.; Taya, Y. Enamel mineralization and an initial crystalline phase. Connect. Tissue Res. 1998, 38, 129-137.

128. Tomazic, B.B.; Brown, W.E.; Shoen, F.J. Physicochemical properties of calcific deposits isolated from porcine bioprosthetic heart valves removed from patients following 2-13 years function. $J$. Biomed. Mater. Res. 1994, 28, 35-47.

129. Nancollas, G.H.; Wu, W. Biomineralization mechanisms: a kinetics and interfacial energy approach. J. Cryst. Growth 2000, 211, 137-142.

130. Kamakura, S.; Sasano, Y.; Homma, H.; Suzuki, O.; Kagayama, M.; Motegi, K. Implantation of octacalcium phosphate (OCP) in rat skull defects enhances bone repair. J. Dent. Res. 1999, 78, 1682-1687.

131. Kamakura, S.; Sasano, Y.; Homma, H.; Suzuki, O.; Kagayama, M.; Motegi, K. Implantation of octacalcium phosphate nucleates isolated bone formation in rat skull defects. Oral Dis. 2001, 7, 259-265.

132. Sargolzaei-Aval, F.; Sobhani, A.; Arab, M.R.; Sarani, S.A.; Heydari, M.H. The efficacy of implant of octacalcium phosphate in combination with bone matrix gelatin (BMG) on bone regeneration in skull defects in rat. Iran. J. Med. Sci. 2004, 29, 124-129.

133. Suzuki, O.; Kamakura, S.; Katagiri, T.; Nakamura, M.; Zhao, B.; Honda, Y.; Kamijo, R. Bone formation enhanced by implanted octacalcium phosphate involving conversion into Ca-deficient hydroxyapatite. Biomaterials 2006, 27, 2671-2681.

134. Suzuki, O.; Imaizumi, H.; Kamakura, S.; Katagiri, T. Bone regeneration by synthetic octacalcium phosphate and its role in biological mineralization. Cur. Med. Chem. 2008, 15, 305-313.

135. Kikawa, T.; Kashimoto, O.; Imaizumi, H.; Kokubun, S.; Suzuki, O. Intramembranous bone tissue response to biodegradable octacalcium phosphate implant. Acta Biomater. 2009, (early view).

136. In 1941, to honor Mr. Herbert Percy Whitlock (1868 - 1948), an American mineralogist, the curator of the American Museum of Natural History, New York City, New York, USA, the term whitlockite was coined as a synonym for $\beta$-TCP identified by its X-ray diffraction pattern in phosphate rocks [137-139]. Therefore, strictly speaking, $\beta$-TCMP should be called as a "magnesium whitlokite". Its solubility is less than that of $\beta$-TCP [140]. An iron-containing whitlockite with chemical formula $\mathrm{Ca}_{9}\left(\mathrm{Mg}, \mathrm{Fe}^{2+}\right)\left(\mathrm{PO}_{4}\right)_{6}\left(\mathrm{PO}_{3}, \mathrm{OH}\right)$ exists in nature: is a relatively rare natural mineral but is found in granitic pegmatite and has also been found in meteorites. It can form small, but distinct and well-formed crystals [141, 142].

137. Jensen, A.T.; Rowles, S.L. Magnesium whitlockite, a major constituent of dental calculus. Acta Odont. Scand. 1957, 16, 121-139.

138. Frondel, C. Whitlockite: a new calcium phosphate, $\mathrm{Ca}_{3}\left(\mathrm{PO}_{4}\right)_{2}$. Am. Mineral. 1941, 26, 145-152.

139. Frondel, C. Mineralogy of the calcium phosphates in insular phosphate rock. Am. Mineral. 1943, 28, 215-232.

140. Li, X.; Ito, A.; Sogo, Y.; Wang, X.; LeGeros, R.Z. Solubility of Mg-containing $\beta$-tricalcium phosphate at $25^{\circ} \mathrm{C}$. Acta Biomater. 2009, 5, 508-517. 
141. Calvo, C.; Gopal, R. The crystal structure of whitlockite from the Palermo Quarry. Am. Mineral. 1975, 60, 120-133.

142. http://rruff.geo.arizona.edu/doclib/hom/whitlockite.pdf, accessed April 2009.

143. Kodaka, T.; Debari, K.; Higashi, S. Magnesium-containing crystals in human dental calculus. $J$. Electron Microsc. (Tokyo) 1988, 37, 73-80.

144. Mirtchi, A.A.; Lemaître J.; Munting, E. Calcium phosphate cements: study of the $\beta$-tricalcium phosphate - dicalcium phosphate - calcite cements. Biomaterials 1990, 11, 83-88.

145. Mirtchi, A.A.; Lemaître J.; Munting, E. Calcium phosphate cements: effect of fluorides on the setting and hardening of $\beta$-tricalcium phosphate - dicalcium phosphate - calcite cements. Biomaterials 1991, 12, 505-510.

146. Lemaître J.; Munting, E.; Mirtchi, A.A. Setting, hardening and resorption of calcium phosphate ionic cements. Rev. Stomatol. Chir. Maxillofac. 1992, 93, 163-165.

147. Ohura, K.; Bohner, M.; Hardouin, P.; Lemaître, J.; Pasquier, G.; Flautre, B. Resorption of, and bone formation from, new $\beta$-tricalcium phosphate-monocalcium phosphate cements: an in vivo study. J. Biomed. Mater. Res. 1996, 30, 193-200.

148. The term biphasic calcium phosphate (BCP) was first used by Nery et. al. [149] to describe the bioceramic, that consisted of a mixture of HA and $\beta$-TCP, based on the X-ray diffraction analysis which showed that the "tricalcium phosphate" preparation material used in their early publication [150] was in fact a mixture of $\sim 20 \% \mathrm{HA}$ and $\sim 80 \% \beta$-TCP.

149. Ellinger, R.F.; Nery, E.B.; Lynch, K.L. Histological assessment of periodontal osseous defects following implantation of hydroxyapatite and biphasic calcium phosphate ceramics: a case report. Int. J. Periodont. Restor. Dent. 1986, 3, 22-33.

150. Nery, E.B.; Lynch, K.L.; Hirthe, W.M.; Mueller, K.H. Bioceramic implants in surgically produced infrabony defects. J. Periodontol. 1975, 46, 328-347.

151. Lecomte, A.; Gautier, H.; Bouler, J.M.; Gouyette, A.; Pegon, Y.; Daculsi, G.; Merle, C. Biphasic calcium phosphate: a comparative study of interconnected porosity in two ceramics. J. Biomed. Mater. Res. B Appl. Biomater. 2008, 84B, 1-6.

152. Tancret, F.; Bouler, J.M.; Chamousset, J.; Minois, L.M. Modelling the mechanical properties of microporous and macroporous biphasic calcium phosphate bioceramics. J. Eur. Ceram. Soc. 2006, 26, 3647-3656.

153. Bouler, J.M.; Trecant, M.; Delecrin, J.; Royer, J.; Passuti, N.; Daculsi, G. Macroporous biphasic calcium phosphate ceramics: Influence of five synthesis parameters on compressive strength. $J$. Biomed. Mater. Res. 1996, 32, 603-609.

154. Wang, J.; Chen, W.; Li, Y.; Fan, S.; Weng, J.; Zhang, X. Biological evaluation of biphasic calcium phosphate ceramic vertebral laminae. Biomaterials 1998, 19, 1387-1392.

155. Daculsi, G. Biphasic calcium phosphate concept applied to artificial bone, implant coating and injectable bone substitute. Biomaterials 1998, 19, 1473-1478.

156. Daculsi, G.; Weiss, P.; Bouler, J.M.; Gauthier, O.; Millot, F.; Aguado, E. Biphasic calcium phosphate / hydrosoluble polymer composites: a new concept for bone and dental substitution biomaterials. Bone 1999, 25 (Suppl. 2), 59S-61S. 
157. LeGeros, R.Z. Lin, S.; Rohanizadeh, R.; Mijares, D.; LeGeros, J.P. Biphasic calcium phosphate bioceramics: preparation, properties and applications. J. Mater. Sci. Mater. Med. 2003, 14, 201-209.

158. Daculsi, G.; Laboux, O.; Malard, O.; Weiss, P. Current state of the art of biphasic calcium phosphate bioceramics. J. Mater. Sci. Mater. Med. 2003, 14, 195-200.

159. Alam, I.; Asahina, I.; Ohmamiuda, K.; Enomoto, S. Comparative study of biphasic calcium phosphate ceramics impregnated with rhBMP-2 as bone substitutes. J. Biomed. Mater. Res. 2001, 54, 129-138.

160. Daculsi, G. Biphasic calcium phosphate granules concept for injectable and mouldable bone substitute. Adv. Sci. Technol. 2006, 49, 9-13.

161. Metsger, D.S.; Driskell, T.D.; Paulsrud, J.R. Tricalcium phosphate ceramic - a resorbable bone implant: review and current status. J. Am. Dent. Assoc. 1982, 105, 1035-1038.

162. Nurse, R.W.; Welch, J.B.; Gun, W. High-temperature phase equilibria in the system dicalcium silicate - tricalcium phosphate. J. Chem. Soc. 1959, 1077-1083.

163. Langstaff, S.D.; Sayer, M.; Smith, T.J.N.; Pugh, S.M.; Hesp, S.A.M.; Thompson, W.T. Resorbable bioceramics based on stabilized calcium phosphates. Part I: Rational design, sample preparation and material characterization. Biomaterials 1999, 20, 1727-1741.

164. Langstaff, S.D.; Sayer, M.; Smith, T.J.N.; Pugh, S.M. Resorbable bioceramics based on stabilized calcium phosphates. Part II: Evaluation of biological response. Biomaterials 2001, 22, 135-150.

165. Sayer, M.; Stratilatov, A.D.; Reid, J.W.; Calderin, L.; Stott, M.J.; Yin, X.; MacKenzie, M.; Smith, T.J.N.; Hendry, J.A.; Langstaff, S.D. Structure and composition of silicon-stabilized tricalcium phosphate. Biomaterials 2003, 24, 369-382.

166. Reid, J.W.; Pietak, A.M.; Sayer, M.; Dunfield, D.; Smith, T.J.N. Phase formation and evolution in the silicon substituted tricalcium phosphate / apatite system. Biomaterials 2005, 26, 2887-2897.

167. Reid, J.W.; Tuck, L.; Sayer, M.; Fargo, K.; Hendry, J.A. Synthesis and characterization of singlephase silicon substituted $\alpha$-tricalcium phosphate. Biomaterials 2006, 27, 2916-2925.

168. Astala, R.; Calderin, L.; Yin, X.; Stott, M.J. Ab initio simulation of Si-doped hydroxyapatite. Chem. Mater. 2006, 18, 413-422.

169. Yin, X.; Stott, M.J.; Rubio, A. $\alpha$ - and $\beta$-tricalcium phosphate: a density functional study. Phys. Rev. B 2003, 68, 205205 (7 pages).

170. Constantz, B.R.; Ison, I.C.; Fulmer, M.T.; Poser, R.D.; Smith, S.T.; Vanwagoner, M.; Ross, J.; Goldstein, S.A.; Jupiter, J.B.; Rosenthal, D.I. Skeletal repair by in situ formation of the mineral phase of bone. Science 1995, 267, 1796-1799.

171. Oda, M.; Takeuchi, A.; Lin, X.; Matsuya, S.; Ishikawa, K. Effects of liquid phase on basic properties of $\alpha$-tricalcium phosphate-based apatite cement. Dent. Mater. J. 2008, 27, 672-677.

172. Yin, X.; Stott, M.J. Theoretical insights into bone grafting Si-stabilized $\alpha$-tricalcium phosphate. J. Chem. Phys. 2005, 122, 024709 (9 pages).

173. Yin, X.; Stott, M.J. Surface and adsorption properties of $\alpha$-tricalcium phosphate. J. Chem. Phys. 2006, 124, 124701 (9 pages). 
174. Termine, J.D.; Eanes, E.D. Comparative chemistry of amorphous and apatitic calcium phosphate preparations. Calcif. Tissue Res. 1972, 10, 171-197.

175. Eanes, E.D.; Termine, J.D.; Nylen, M.U. An electron microscopic study of the formation of amorphous calcium phosphate and its transformation to crystalline apatite. Calcif. Tissue Res. 1973, 12, 143-158.

176. Meyer, J.L.; Eanes, E.D. A thermodynamic analysis of the amorphous to crystalline calcium phosphate transformation. Calcif. Tissue Res. 1978, 28, 59-68.

177. Meyer, J.L.; Eanes, E.D. A thermodynamic analysis of the secondary transition in the spontaneous precipitation of calcium phosphate. Calcif. Tissue Res. 1978, 28, 209-216.

178. Wuthier, R.E.; Rice, G.S.; Wallace, J.E.; Weaver, R.L.; LeGeros, R.Z. Eanes, E.D. In vitro precipitation of calcium phosphate under intracellular conditions: formation of brushite from an amorphous precursor in the absence of ATP. Calcif. Tissue Int. 1985, 37, 401-410.

179. Sinyaev, V.A.; Shustikova, E.S.; Levchenko, L.V.; Sedunov, A.A. Synthesis and dehydration of amorphous calcium phosphate. Inorg. Mater. 2001, 37, 619-622.

180. Termine, J.D.; Peckauskas, R.A.; Posner, A.S. Calcium phosphate formation in vitro. II. Effects of environment on amorphous-crystalline transformation. Arch. Biochem. Biophys. 1970, 140, 318-325.

181. Elliot, J.C. Recent studies of apatites and other calcium orthophosphates. In Les matériaux en phosphate de calcium. Aspects fondamentaux. / Calcium phosphate materials. Fundamentals; Brès, E., Hardouin, P., Eds.; Sauramps Medical: Montpellier, France, 1998; pp. 25-66.

182. Li, Y.; Weng, W. In vitro synthesis and characterization of amorphous calcium phosphates with various $\mathrm{Ca} / \mathrm{P}$ atomic ratios. J. Mater. Sci. Mater. Med. 2007, 18, 2303-2308.

183. Tadic, D.; Peters, F.; Epple, M. Continuous synthesis of amorphous carbonated apatites. Biomaterials 2002, 23, 2553-2559.

184. Boskey, A.L.; Posner, A.S. Conversion of amorphous calcium phosphate to microcrystalline hydroxyapatite. A pH-dependent, solution-mediated, solid-solid conversion. J. Phys. Chem. 1973, 77, 2313-2317.

185. Posner, A.S.; Betts, F. Synthetic amorphous calcium phosphate and its relation to bone mineral structure. Acc. Chem. Res. 1975, 8, 273-281.

186. Harries, J.E.; Hukins, D.W.L.; Hasnain, S.S. Analysis of the EXAFS spectrum of hydroxyapatite. J. Phys. C: Solid State Phys. 1986, 19, 6859-6872.

187. Harries, J.E.; Hukins, D.W.L.; Holt, C.; Hasnain, S.S. Conversion of amorphous calcium phosphate into hydroxyapatite investigated by EXAFS spectroscopy. J. Cryst. Growth 1987, 84, 563-570.

188. Taylor, M.G.; Simkiss, K.; Simmons, J.; Wu, L.N.Y.; Wuthier, R.E. Structural studies of a phosphatidyl serine-amorphous calcium phosphate complex. Cell. Mol. Life Sci. 1998, 54, 192-202.

189. Peters, F.; Schwarz, K.; Epple, M. The structure of bone studied with synchrotron X-ray diffraction, X-ray absorption spectroscopy and thermal analysis. Thermochim. Acta 2000, 361, 131-138.

190. Posner, A.S.; Betts, F.; Blumenthal, N.C. Formation and structure of synthetic and bone hydroxyapatite. Progr. Cryst. Growth Char. 1980, 3, 49-64. 
191. Boskey, A.L. Amorphous calcium phosphate: the contention of bone. J. Dent. Res. 1997, 76, $1433-1436$.

192. Onuma, K.; Ito, A. Cluster growth model for hydroxyapatite. Chem. Mater. 1998, 10, 3346-3351.

193. Skrtic, D.; Hailer, A.W.; Takagi, S.; Antonucci, J.M.; Eanes, E.D. Quantitative assessment of the efficacy of amorphous calcium phosphate / methacrylate composites in remineralizing caries-like lesions artificially produced in bovine enamel. J. Dent. Res. 1996, 75, 1679-1686.

194. Skrtic, D.; Antonucci, J.M.; Eanes, E.D. Improved properties of amorphous calcium phosphate fillers in remineralizing resin composites. Dent. Mater. 1996, 12, 295-301.

195. Skrtic, D.; Antonucci, J.M.; Eanes, E.D. Amorphous calcium phosphate-based bioactive polymeric composites for mineralized tissue regeneration. J. Res. Natl. Inst. Stand. Technol. 2003, 108, 167-182.

196. Skrtic, D.; Antonucci, J.M.; Eanes, E.D.; Eichmiller, F.C.; Schumacher, G.E. Physicochemical evaluation of bioactive polymeric composites based on hybrid amorphous calcium phosphates. $J$. Biomed. Mater. Res. B Appl. Biomater. 2000, 53, 381-391.

197. Schiller, C.; Siedler, M.; Peters, F.; Epple, M. Functionally graded materials of biodegradable polyesters and bone-like calcium phosphates for bone replacement. Ceram. Transact. 2001, 114, 97-108.

198. Linhart, W.; Peters, F.; Lehmann, W.; Schilling, A.F.; Schwarz, K.; Amling, M.; Rueger, J.M.; Epple, M. Biologically and chemically optimized composites of carbonated apatite and polyglycolide as bone substitution materials. J. Biomed. Mater. Res. 2001, 54, 162-171.

199. Tadic, D.; Beckmann, F.; Schwarz, K.; Epple, M. A novel method to produce hydroxylapatite objects with interconnecting porosity that avoids sintering. Biomaterials 2004, 25, 3335-3340.

200. Tadic, D.; Epple, M. Amorphous calcium phosphates as bone substitution materials. Eur. J. Trauma 2002, 28, 136-137.

201. Eanes, E.D. Amorphous calcium phosphate. In Octacalcium phosphate; Chow, L.C., Eanes, E.D., Eds.; Karger: Basel, Switzerland, 2001; pp. 130-147.

202. In some research papers, CDHA is defined as "precipitated HA" [203-205].

203. Knowles, J.C.; Callcut, S.; Georgiou, G. Characterisation of the rheological properties and zeta potential of a range of hydroxyapatite powders. Biomaterials 2000, 21, 1387-1392.

204. Kumar, R.; Prakash, K.H.; Cheang, P.; Khor, K.A. Temperature driven morphological changes of chemically precipitated hydroxyapatite nanoparticles. Langmuir 2004, 20, 5196-5200.

205. Sung, Y.M.; Lee, J.C.; Yang, J.W. Crystallization and sintering characteristics of chemically precipitated hydroxyapatite nanopowder. J. Cryst. Growth 2004, 262, 467-472.

206. Brès, E.F.; Duhoo, T.; Leroy, N.; Lemaitre, J. Evidence of a transient phase during the hydrolysis of calcium-deficient hydroxyapatite. Zeitschrift fuer Metallkunde / Mater. Res. Adv. Tech. 2005, 96, 503-506

207. Dorozhkina, E.I.; Dorozhkin, S.V. Mechanism of the solid-state transformation of a calciumdeficient hydroxyapatite (CDHA) into biphasic calcium phosphate (BCP) at elevated temperatures. Chem. Mater. 2002, 14, 4267-4272.

208. Dorozhkin, S.V. Mechanism of solid-state conversion of non-stoichiometric hydroxyapatite to diphase calcium phosphate. Russ. Chem. Bull. Int. Ed. 2003, 52, 2369-2375. 
209. Rodríguez-Lorenzo, L. Studies on calcium deficient apatites structure by means of MAS-NMR spectroscopy. J. Mater. Sci. Mater. Med. 2005, 16, 393-398.

210. Wilson, R.M.; Elliott, J.C.; Dowker, S.E.P. Formate incorporation in the structure of Ca-deficient apatite: Rietveld structure refinement. J. Solid State Chem. 2003, 174, 132-140.

211. Zahn, D.; Hochrein, O. On the composition and atomic arrangement of calcium-deficient hydroxyapatite: an ab-initio analysis. J. Solid State Chem. 2008, 181, 1712-1716.

212. Brown, P.W.; Martin, R.I. An analysis of hydroxyapatite surface layer formation. J. Phys. Chem. $B$ 1999, 103, 1671-1675.

213. Honghui, Z.; Hui, L.; Linghong, G. Molecular and crystal structure characterization of calciumdeficient apatite. Key Eng. Mater. 2007, 330-332, 119-122.

214. Mortier, A.; Lemaitre, J.; Rodrique, L.; Rouxhet, P.G. Synthesis and thermal behavior of wellcrystallized calcium-deficient phosphate apatite. J. Solid State Chem. 1989, 78, 215-219.

215. Jeanjean, J.; McGrellis, S.; Rouchaud, J.C.; Fedoroff, M.; Rondeau, A.; Perocheau, S.; Dubis, A. A crystallographic study of the sorption of cadmium on calcium hydroxyapatites: incidence of cationic vacancies. J. Solid State Chem. 1996, 126, 195-201.

216. Wilson, R.M.; Elliott, J.C.; Dowker, S.E.P.; Rodriguez-Lorenzo, L.M. Rietveld refinements and spectroscopic studies of the structure of Ca-deficient apatite. Biomaterials 2005, 26, 1317-1327.

217. Ivanova, T. I.; Frank-Kamenetskaya, O.V.; Kol'tsov, A.B.; Ugolkov, V.L. Crystal structure of calcium-deficient carbonated hydroxyapatite thermal decomposition. J. Solid State Chem. 2001, 160, 340-349.

218. Matsunaga, K. Theoretical investigation of the defect formation mechanism relevant to nonstoichiometry in hydroxyapatite. Phys. Rev. B 2008, 77, 104106 (14 pages).

219. Tsuchida, T.; Yoshioka, T.; Sakuma, S.; Takeguchi, T.; Ueda, W. Synthesis of biogasoline from ethanol over hydroxyapatite catalyst. Ind. Eng. Chem. Res. 2008, 47, 1443-1452.

220. It is worth noting that the chemically correct name would be hydroxylapatite (perhaps, hydroxidapatite would be even better because it relates to calcium hydroxide) while by the medical and material communities it is usually called as hydroxyapatite.

221. Elliott, J.C.; Mackie, P.E.; Young, R.A. Monoclinic hydroxyapatite. Science 1973, 180, 1055-1057.

222. Rangavittal, N.; Landa-Cánovas, A.R.; González-Calbet, J.M.; Vallet-Regi, M. Structural study and stability of hydroxyapatite and $\beta$-tricalcium phosphate: two important bioceramics. $J$. Biomed. Mater. Res. 2000, 51, 660-668.

223. Kim, J.Y.; Fenton, R.R.; Hunter, B.A.; Kennedy, B.J. Powder diffraction studies of synthetic calcium and lead apatites. Austr. J. Chem. 2000, 53, 679-686.

224. Kay, M.I.; Young, R.A.; Posner, A.S. Crystal structure of hydroxyapatite. Nature 1964, 204, 1050-1052.

225. Treboux, G.; Layrolle, P.; Kanzaki, N.; Onuma, K.; Ito, A. Existence of Posner's cluster in vacuum. J. Phys. Chem. A 2000, 104, 5111-5114.

226. Calderin, L.; Stott, M.J.; Rubio, A. Electronic and crystallographic structure of apatites. Phys. Rev. B, 2003, 67, 134106 (6 pages).

227. Rulis, P.; Ouyang, L.; Ching, W.Y. Electronic structure and bonding in calcium apatite crystals: hydroxyapatite, fluorapatite, chlorapatite and bromapatite. Phys. Rev. B 2004, 70, 155104 (8 pages). 
228. Treboux, G.; Layrolle, P.; Kanzaki, N.; Onuma, K.; Ito, A. Symmetry of Posner's cluster. J. Am. Chem. Soc. 2000, 122, 8323-8324.

229. Yin, X.; Stott, M.J. Biological calcium phosphates and Posner's cluster. J. Chem. Phys. 2003, 118, 3717-3723.

230. Kanzaki, N.; Treboux, G.; Onuma, K.; Tsutsumi, S.; Ito, A. Calcium phosphate clusters. Biomaterials 2001, 22, 2921-2929.

231. Calderin, L.; Dunfield, D.; Stott, M.J. Shell-model study of the lattice dynamics of hydroxyapatite. Phys. Rev. B 2005, 72, 224304 (12 pages).

232. Briak-Ben, El, Abdeslam, H.; Ginebra, M.P.; Vert, M.; Boudeville, P. Wet or dry mechanochemical synthesis of calcium phosphates? Influence of the water content on DCPD $\mathrm{CaO}$ reaction kinetics. Acta Biomater. 2008, 4, 378-386.

233. LeGeros, R.Z.; LeGeros, J.P. Dense hydroxyapatite. In An introduction to bioceramics; Hench, L.L., Wilson, J., Eds.; World Scientific: London, UK, 1993; pp. 139-180.

234. Rodriguez-Lorenzo, L.M.; Vallet-Regi, M. Controlled crystallization of calcium phosphate apatites. Chem. Mater. 2000, 12, 2460-2465.

235. Cazalbou, S.; Combes, C.; Eichert, D.; Rey, C. Adaptive physico-chemistry of bio-related calcium phosphates. J. Mater. Chem. 2004, 14, 2148-2153.

236. Markovic, M.; Fowler, B.O.; Tung, M.S. Preparation and comprehensive characterization of a calcium hydroxyapatite reference material. J. Res. Natl. Inst. Stand. Technol. 2004, 109, 553-568.

237. Ioku, K.; Kawachi, G.; Sasaki, S.; Fujimori, H.; Goto, S. Hydrothermal preparation of tailored hydroxyapatite. J. Mater. Sci. 2006, 41, 1341-1344.

238. Layrolle, P.; Lebugle, A. Characterization and reactivity of nanosized calcium phosphates prepared in anhydrous ethanol. Chem. Mater. 1994, 6, 1996-2004.

239. Layrolle, P.; Lebugle, A. Synthesis in pure ethanol and characterization of nanosized calcium phosphate fluoroapatite. Chem. Mater. 1996, 8, 134-144.

240. Yeong, B.; Junmin, X.; Wang, J. Mechanochemical synthesis of hydroxyapatite from calcium oxide and brushite. J. Am. Ceram. Soc. 2001, 84, 465-467.

241. Roy, D.M.; Linnehan, S.K. Hydroxyapatite formed from coral skeletal carbonate by hydrothermal exchange. Nature 1974, 247, 220-222.

242. Ben-Nissan, B. Natural bioceramics: from coral to bone and beyond. Curr. Opin. Solid State Mater. Sci. 2003, 7, 283-288.

243. Ben-Nissan, B.; Milev, A.; Vago, R. Morphology of sol-gel derived nano-coated coralline hydroxyapatite. Biomaterials 2004, 25, 4971-4975.

244. Elliott, J.C.; Young, R.A. Conversion of single crystals of chlorapatite into single crystals of hydroxyapatite. Nature 1967, 214, 904-906.

245. Tao, J.; Jiang, W.; Pan, H.; Xu, X.; Tang, R. Preparation of large-sized hydroxyapatite single crystals using homogeneous releasing controls. J. Cryst. Growth 2007, 308, 151-158.

246. Vallet-Regi, M.; Gutièrez Rios, M.T.; Alonso, M.P.; de Frutos, M.I.; Nicolopoulos, S. Hydroxyapatite particles synthesized by pyrolysis of an aerosol. J. Solid State Chem. 1994, 112, 58-64. 
247. Montero, M.L.; Sáenz, A.; Rodríguez, J.G.; Arenas, J.; Castaño, V.M. Electrochemical synthesis of nanosized hydroxyapatite. J. Mater. Sci. 2006, 41, 2141-2144.

248. Kumar, A.R.; Kalainathan, S. Growth and characterization of nano-crystalline hydroxyapatite at physiological conditions. Crystal Res. Technol. 2008, 43, 640-644.

249. Kalita, S.J.; Bhardwaj, A.; Bhatt, H.A. Nanocrystalline calcium phosphate ceramics in biomedical engineering. Mater. Sci. Eng., C 2007, 27, 441-449.

250. Melikhov, I.V.; Komarov, V.F.; Severin, A.V.; Bozhevolnov, V.E.; Rudin, V.N. Twodimensional crystalline hydroxyapatite. Doklady Phys. Chem. 2000, 373, 125-128.

251. Suvorova, E.I.; Buffat, P.A. Electron diffraction and HRTEM characterization of calcium phosphate precipitation from aqueous solutions under biomineralization conditions. Eur. Cell Mater. 2001, 1, 27-42.

252. Suvorova, E.I.; Buffat, P.A. Model of the mechanism of Ca loss by bones under microgravity and earth conditions. J. Biomed. Mater. Res. 2002, 63, 424-432.

253. Uematsu, K.; Takagi, M.; Honda, T.; Uchida, N.; Saito, K. Transparent hydroxyapatite prepared by hot isostatic pressing of filter cake. J. Am. Ceram. Soc. 1989, 72, 1476-1478.

254. Takikawa, K.; Akao, M. Fabrication of transparent hydroxyapatite and application to bone marrow derived cell / hydroxyapatite interaction observation in vivo. J. Mater. Sci. Mater. Med. 1996, 7, 439-445.

255. Watanabe, Y.; Ikoma, T.; Monkawa, A.; Suetsugu, Y.; Yamada, H.; Tanaka, J.; Moriyoshi, Y. Fabrication of transparent hydroxyapatite sintered body with high crystal orientation by pulse electric current sintering. J. Am. Ceram. Soc. 2005, 88, 243-245.

256. Kotobuki, N.; Ioku, K.; Kawagoe, D.; Fujimori, H.; Goto, S.; Ohgushi, H. Observation of osteogenic differentiation cascade of living mesenchymal stem cells on transparent hydroxyapatite ceramics. Biomaterials 2005, 26, 779-785.

257. Perloff, A.; Posner, A.S. Preparation of pure hydroxyapatite crystals. Science 1956, 124, 583-584.

258. LeGeros, R.Z.; LeGeros, J.P.; Daculsi, G.; Kijkowska, R. Calcium phosphate biomaterials: preparation, properties and biodegradation. In Encyclopedic handbook of biomaterials and bioengineering, Part A: Materials. Vol. 2; Wise, D.L., Trantolo, D.J., Altobelli, D.E., Yaszemski, M.J., Gresser, J.D., Schwartz, E.R., Eds.; Marcel Dekker: New York, USA, 1995; pp. 1429-1463.

259. Narasaraju, T.S.B.; Phebe, D.E. Some physico-chemical aspects of hydroxylapatite. J. Mater. Sci. 1996, 31, 1-21.

260. Orlovskii, V.P.; Barinov, S.M. Hydroxyapatite and hydroxyapatite-matrix materials: a survey. Russ. J. Inorg. Chem. 2001, 46 (Suppl. 2), S129-S149.

261. Orlovskii, V.P.; Komlev, V.S.; Barinov, S.M. Hydroxyapatite and hydroxyapatite-based ceramics. Inorg. Mater. 2002, 38, 973-984.

262. Peňa, J.; Vallet-Regi, M. Hydroxyapatite, tricalcium phosphate and biphasic materials prepared by a liquid mix technique. J. Eur. Ceram. Soc. 2003, 23, 1687-1696.

263. Koutsopoulos, S. Synthesis and characterization of hydroxyapatite crystals: a review study on the analytical methods. J. Biomed. Mater. Res. 2002, 62, 600-612.

264. Rakovan, J. Growth and surface properties of apatite. In Phosphates: geochemical, geobiological and materials importance, Series: Reviews in Mineralogy and Geochemistry. Vol. 48; Hughes, 
J.M., Kohn, M., Rakovan, J., Eds.; Mineralogical Society of America: Washington, D.C., USA, 2002; pp. 51-86.

265. Dorozhkin, S.V. A review on the dissolution models of calcium apatites. Prog. Cryst. Growth Charact. Mater. 2002, 44, 45-61.

266. Suchanek, W.; Yoshimura, M. Processing and properties of hydroxyapatite-based biomaterials for use as hard tissue replacement implants. J. Mater. Res. 1998, 13, 94-117.

267. Willmann, G. Coating of implants with hydroxyapatite - material connections between bone and metal. Adv. Eng. Mater. 1999, 1, 95-105.

268. Sun, L.; Berndt, C.C.; Gross, K.A.; Kucuk, A. Review: material fundamentals and clinical performance of plasma sprayed hydroxyapatite coatings. J. Biomed. Mater. Res. B Appl. Biomater. 2001, 58, 570-592.

269. Ong, J.L.; Chan, D.C.N. Hydroxyapatites and their use as coatings in dental implants: a review. Crit. Rev. Biomed. Eng. 1999, 28, 667-707.

270. Geesink, R.G. Osteoconductive coatings for total joint arthroplasty. Clin. Orthop. Rel. Res. 2002, 395, 53-65.

271. Hench, L.L. Bioceramics: from concept to clinic. J. Am. Ceram. Soc. 1991, 74, 1487-1510.

272. Hench, L.L. Bioceramics. J. Am. Ceram. Soc. 1998, 81, 1705-1728.

273. Mangano, C.; Piattelli, A.; Perrotti, V.; Iezzi, G. Dense hydroxyapatite inserted into postextraction sockets: a histologic and histomorphometric 20-year case report. J. Periodontol. 2008, 79, 929-933.

274. Dickinson, W. Chromatography of insulin on calcium phosphate columns. Nature, 1956, 178, 994-995.

275. Bernardi, G. Chromatography of nucleic acids on hydroxyapatite. Nature 1965, 206, 779-783.

276. Xia, Z.; Duan, X.; Locklin, R.M.; Quijano, M.; Dobson, R.L.; Triffitt, J.T.; Ebetino, F.H.; Russell, G.R. Evaluation of the relative mineral-binding affinities of clinically-relevant bisphosphonates by using hydroxyapatite-column chromatography and adsorption isotherms combined with mass spectrometric analysis. Bone 2008, 42 (Supp. 1), S90-S91.

277. Brand, M.; Rampalli, S.; Chaturvedi, C.P.; Dilworth, F.J. Analysis of epigenetic modifications of chromatin at specific gene loci by native chromatin immunoprecipitation of nucleosomes isolated using hydroxyapatite chromatography. Nat. Protoc. 2008, 3, 398-409.

278. Yoshitake, T.; Kobayashi, S.; Ogawa, T.; Okuyama, T. Hydroxyapatite chromatography of guanidine denatured proteins: 1. Guanidine containing phosphate buffer system. Chromatography 2006, 27, 19-26.

279. Smith, G.P.; Gingrich, T.R. Hydroxyapatite chromatography of phage-display virions. Biotechniques 2005, 39, 879-884.

280. Jungbauer, A.; Hahn, R.; Deinhofer, K.; Luo, P. Performance and characterization of a nanophased porous hydroxyapatite for protein chromatography. Biotechnol. Bioeng. 2004, 87, 364-375.

281. Doonan, S. Chromatography on hydroxyapatite. Methods Mol. Biol. 2004, 244, 191-194.

282. Liu, T.Y.; Chen, S.Y.; Liu, D.M.; Liou, S.C. On the study of BSA-loaded calcium-deficient hydroxyapatite nano-carriers for controlled drug delivery. J. Control. Release 2005, 107, 112-121. 
283. Palazzo, B.; Sidoti, M.C.; Roveri, N.; Tampieri, A.; Sandri, M.; Bertolazzi, L.; Galbusera, F.; Dubini, G.; Vena, P.; Contro, R. Controlled drug delivery from porous hydroxyapatite grafts: an experimental and theoretical approach. Mater. Sci. Eng., C 2005, 25, 207-213.

284. Pietrasik, J.; Szustakiewicz, K.; Zaborski, M.; Haberko, K. Hydroxyapatite: an environmentally friendly filler for elastomers. Mol. Cryst. Liq. Cryst. 2008, 483, 172-178.

285. Corami, A.; Mignardi, S.; Ferrini, V. Cadmium removal from single- and multi-metal (Cd plus $\mathrm{Pb}$ plus $\mathrm{Zn}$ plus $\mathrm{Cu}$ ) solutions by sorption on hydroxyapatite. J. Colloid Interface Sci. 2008, 317, 402-408.

286. Phonthammachai, N.; Ziyi, Z.; Jun, G.; Fan, H.Y.; White, T.J. Synthesis of high performance hydroxyapatite-gold catalysts for CO oxidation. Gold Bull. 2008, 41, 42-50.

287. Chen, W.; Huang, Z.L.; Liu, Y.; He, Q.J. Preparation and characterization of a novel solid base catalyst hydroxyapatite loaded with strontium. Catal. Commun. 2008, 9, 516-521.

288. de Groot, K.; Wolke, J.G.C.; Jansen, J.A. Calcium phosphate coatings for medical implants. Proc. Inst. Mech. Eng. Part H: J. Eng. Med. 1998, 212, 137-147.

289. Gross, K.A.; Berndt C.C. Biomedical application of apatites. In Phosphates: geochemical, geobiological and materials importance, Series: Reviews in Mineralogy and Geochemistry. Vol. 48; Hughes, J.M., Kohn, M., Rakovan, J., Eds.; Mineralogical Society of America: Washington, D.C., USA, 2002; pp. 631-672.

290. Ferraz, M.P.; Monteiro, F.J.; Manuel, C.M. Hydroxyapatite nanoparticles: a review of preparation methodologies. J. Appl. Biomater. Biomech. 2004, 2, 74-80.

291. Damien, E.; Revell, P.A. Coralline hydroxyapatite bone graft substitute: a review of experimental studies and biomedical applications. J. Appl. Biomater. Biomech. 2004, 2, 65-73.

292. Aoki, H. Science and medical applications of hydroxyapatite; JAAS: Tokyo, Japan, 1991; p.245.

293. Barinov, S.M.; Komlev, V.S. Calcium phosphate based bioceramics for bone tissue engineering, Materials Science Foundations (monograph series), Vol. 48; Trans Tech Publ.: Switzerland, 2008; p.170.

294. Kniep, R.; Busch, S. Biomimetic growth and self-assembly of fluorapatite aggregates by diffusion into denatured collagen matrices. Angew. Chem. Int. Ed. Engl. 1996, 35, 2624-2626.

295. Busch, S.; Dolhaine, H.; Duchesne, A.; Heinz, S.; Hochrein, O.; Laeri, F.; Podebrad, O.; Vietze, U.; Weiland, T.; Kniep, R. Biomimetic morphogenesis of fluorapatite-gelatin composites: fractal growth, the question of intrinsic electric fields, core / shell assemblies, hollow spheres and reorganization of denatured collagen. Eur. J. Inorg. Chem. 1999, 1643-1653.

296. GÖBEL, C.; Simon, P.; Buder, J.; Tlatlik, H.; Kniep, R. Phase formation and morphology of calcium phosphate-gelatine-composites grown by double diffusion technique: the influence of fluoride. J. Mater. Chem. 2004, 14, 2225-2230.

297. Prymak, O.; Sokolova, V.; Peitsch, T.; Epple, M. The crystallization of fluoroapatite dumbbells from supersaturated aqueous solution. Cryst. Growth Des. 2006, 6, 498-506.

298. Tlatlik, H.; Simon, P.; Kawska, A.; Zahn, D.; Kniep, R. Biomimetic fluorapatite-gelatine nanocomposites: pre-structuring of gelatine matrices by ion impregnation and its effect on form development. Angew. Chem. Int. Ed. Engl. 2006, 45, 1905-1910. 
299. Simon, P.; Zahn, D.; Lichte, H.; Kniep, R. Intrinsic electric dipole fields and the induction of hierarchical form developments in fluorapatite-gelatine nanocomposites: a general principle for morphogenesis of biominerals? Angew. Chem. Int. Ed. Engl. 2006, 45, 1911-1915.

300. Dorozhkin, S.V. A hierarchical structure for apatite crystals. J. Mater. Sci. Mater. Med. 2007, 18, 363-366.

301. Mehmel, M. On the structure of apatite: I. Z. Kristallogr. 1930, 75, 323-331.

302. Naray-Szabo, S. The structure of apatite $(\mathrm{CaF}) \mathrm{Ca}_{4}\left(\mathrm{PO}_{4}\right)_{3}$. Z. Kristallogr. 1930, 75, 387-398.

303. Sudarsanan, K.; Mackie, P.E.; Young, R.A. Comparison of synthetic and mineral fluorapatite, $\mathrm{Ca}_{5}\left(\mathrm{PO}_{4}\right)_{3} \mathrm{~F}$, in crystallographic detail. Mater. Res. Bull. 1972, 7, 1331-1337.

304. Barinov, S.M.; Shvorneva, L.I.; Ferro, D.; Fadeeva, I.V.; Tumanov, S.V. Solid solution formation at the sintering of hydroxyapatite-fluorapatite ceramics. Sci. Technol. Adv. Mater. 2004, 5, 537-541.

305. Nikcevic, I.; Jokanovic, V.; Mitric, M.; Nedic, Z.; Makovec, D.; Uskokovic, D. Mechanochemical synthesis of nanostructured fluorapatite / fluorhydroxyapatite and carbonated fluorapatite / fluorhydroxyapatite. J. Solid State Chem. 2004, 177, 2565-2574.

306. Cheng, K.; Weng, W.; Qu, H.; Du, P.; Shen, G.; Han, G.; Yang, J.; Ferreira, J.M.F. Sol-gel preparation and in vitro test of fluorapatite / hydroxyapatite films. J. Biomed. Mater. Res. B Appl.Biomater. 2004, 69B, 33-37.

307. Rodriguez-Lorenzo, L.M.; Hart, J.N.; Gross, K.A. Influence of fluorine in the synthesis of apatites. Synthesis of solid solutions of hydroxy-fluorapatite. Biomaterials 2003, 24, 3777-3785.

308. Wei, M.; Evans, J.H.; Bostrom, T.; Grondahl, L. Synthesis and characterization of hydroxyapatite, fluoride-substituted hydroxyapatite and fluorapatite. J. Mater. Sci. Mater. Med.; 2003, 14, 311-320.

309. Daculsi, G.; Kerebel, L.M. Ultrastructural study and comparative analysis of fluoride content of enameloid in sea-water and fresh-water sharks. Arch. Oral Biol. 1980, 25, 145-151.

310. Daculsi, G.; Kerebel, L.M.; Kerebel, B. Effects of fluoride on human enamel and selachian enameloid in vitro: a high-resolution TEM and electron diffraction study. Calcif. Tissue Int. 1981, 33, 9-13.

311. Lowenstam, H.A.; Weiner, S. On biomineralization; Oxford University Press: Oxford, UK, 1989; p. 324.

312. Weiner, S.; Dove, P.M. An overview of biomineralization processes and the problem of the vital effect. In Biomineralization, Series: Reviews in Mineralogy and Geochemistry. Vol. 54; Dove, P.M., de Yoreo, J.J., Weiner, S., Eds.; Mineralogical Society of America: Washington, D.C., USA, 2003: pp. 1-29.

313. Dahm, S.; Risnes, S. A comparative infrared spectroscopic study of hydroxide and carbonate absorption bands in spectra of shark enameloid, shark dentin, and a geological apatite. Calcif. Tissue Int. 1999, 65, 459-465.

314. Carr, A.; Kemp, A.; Tibbetts, I.; Truss, R.; Drennan, J. Microstructure of pharyngeal tooth enameloid in the parrotfish Scarus rivulatus (Pisces: Scaridae). J. Microscopy 2006, 221, 8-16.

315. Leveque, I.; Cusack, M.; Davis, S.A.; Mann, S. Promotion of fluorapatite crystallization by soluble-matrix proteins from Lingula Anatina shells. Angew. Chem. Int. Ed. Engl. 2004, 43, 885-888. 
316. The amount of fluorides on the very surface of dental enamel might be increased by using fluoride-containing toothpastes and mouthwashes [317-320]. Fluoride-containing toothpastes and mouthwashes are widely used in practice due to the well-known anti-cariogenic effect of fluorides that is related to the solubility decreasing [321,322].

317. Fonteles, C.S.R.; Zero, D.T.; Moss, M.E.; Fu, J. Fluoride concentrations in enamel and dentin of primary teeth after pre- and postnatal fluoride exposure. Caries Res. 2005, 39, 505-508.

318. Wiegand, A.; Krieger, C.; Attin, R.; Hellwig, E.; Attin, T. Fluoride uptake and resistance to further demineralisation of demineralised enamel after application of differently concentrated acidulated sodium fluoride gels. Clin. Oral. Investig. 2005, 9, 52-57.

319. Waszkiel, D.; Opalko, K.; Lagocka, R.; Chlubek, D. Fluoride and magnesium content in superficial enamel layers of teeth with erosions. Fluoride 2004, 37, 271-277.

320. Vieira, A.P.G.F.; Hancock, R.; Dumitriu, M.; Schwartz, M.; Limeback, H.; Grynpas, M.D. How does fluoride affect dentin microhardness and mineralization? J. Dental Res. 2005, 84, 951-957.

321. Driessens, F.C.M. Relation between apatite solubility and anti-cariogenic effect of fluoride. Nature 1973, 243, 420-421.

322. Moreno, E.C.; Kresak, M.; Zahradnik, R.T. Fluoridated hydroxyapatite solubility and caries formation. Nature 1974, 247, 64-65.

323. Heling, L.; Heindel, R.; Merin, B. Calcium-fluorapatite. A new material for bone implants. $J$. Oral Implantol. 1981, 9, 548-555.

324. Bibby, J.K.; Bubb, N.L.; Wood, D.J.; Mummery, P.M. Fluorapatite-mullite glass sputter coated Ti6Al4V for biomedical applications. J. Mater. Sci. Mater. Med. 2005, 16, 379-385.

325. Yoon, B.H.; Kim, H.W.; Lee, S.H.; Bae, C.J.; Koh, Y.H.; Kong, Y.M.; Kim, H.E. Stability and cellular responses to fluorapatite-collagen composites. Biomaterials 2005, 26, 2957-2963.

326. Gineste, L.; Gineste, M.; Ranz, X.; Ellefterion, A.; Guilhem, A.; Rouquet, N.; Frayssinet, P. Degradation of hydroxylapatite, fluorapatite and fluorhydroxyapatite coatings of dental implants in dogs. J. Biomed. Mater. Res. 1999, 48, 224-234.

327. Bhadang, K.A.; Gross, K.A. Influence of fluorapatite on the properties of thermally sprayed hydroxyapatite coatings. Biomaterials 2004, 25, 4935-4945.

328. Gross, K.A.; Bhadang, K.A. Sintered hydroxyfluorapatites. Part III: Sintering and resultant mechanical properties of sintered blends of hydroxyapatite and fluorapatite. Biomaterials 2004, 25, 1395-1405.

329. Barinov, S.M.; Rustichelli, F.; Orlovskii, V.P.; Lodini, A.; Oscarsson, S.; Firstov, S.A.; Tumanov, S.V.; Millet, P.; Rosengren, A. Influence of fluorapatite minor additions on behavior of hydroxyapatite ceramics. J. Mater. Sci. Mater. Med.; 2004, 15, 291-296.

330. Agathopoulos, S.; Tulyaganov, D.U.; Marques, P.A.A.P.; Ferro, M.C.; Fernandes, M.H.; Correia, R.N. The fluorapatite - anorthite system in biomedicine. Biomaterials 2003, 24, 1317-1331.

331. Qu, H.; Wei, M. The effect of fluoride contents in fluoridated hydroxyapatite on osteoblast behavior. Acta Biomater. 2006, 2, 113-119.

332. Theiszova, M.; Jantova, S.; Letasiova, S.; Palou, M.; Cipak, L. Cytotoxicity of hydroxyapatite, fluorapatite and fluor-hydroxyapatite: a comparative in vitro study. Neoplasma 2008, 55, 312-316. 
333. To honor Gustav Hilgenstock (1844-1913), a German metallurgist, who first discovered it in Thomas slags nearly 120 years ago [334,335].

334. Hilgenstock, G. Eine neue Verbindung von $\mathrm{P}_{2} \mathrm{O}_{5}$ und CaO. Stahl Eisen 1883, 3, 498.

335. Hilgenstock, G. Das vierbasische Kalkphosphat und die Basicitätsstufe des Silicats in der Thomas-Schlacxke. Stahl Eisen 1887, 7, 557-560.

336. Brown, W.E.; Epstein, E.F. Crystallography of tetracalcium phosphate. J. Res. Nat. Bur. Stand. A 1965, 69A, 547-551.

337. Romeo, H.E.; Fanovich, M.A. Synthesis of tetracalcium phosphate from mechanochemically activated reactants and assessment as a component of bone cements. J. Mater. Sci. Mater. Med. 2008, 19, 2751-2760.

338. Fernández, E.; Gil, F.J.; Ginebra, M.P.; Driessens, F.C.M.; Planell, J.A.; Best, S.M. Calcium phosphate bone cements for clinical applications. Part II: precipitate formation during setting reactions. J. Mater. Sci. Mater. Med. 1999, 10, 177-183.

339. McConnell, D.; Posner, A.S.; Carbonate in apatites. Science 1961, 134, 213-215.

340. LeGeros, R.Z. Effect of carbonate on the lattice parameters of apatite. Nature 1965, 206, 403-404.

341. LeGeros, R.Z.; Trautz, O.R.; LeGeros, J,P.; Klein, E.; Shirra, W.P. Apatite crystallites: effects of carbonate on morphology. Science 1967, 155, 1409-1411.

342. Astala, R.; Stott, M.J.; First principles investigation of mineral component of bone: $\mathrm{CO}_{3}$ substitutions in hydroxyapatite. Chem. Mater. 2005, 17, 4125-4133.

343. Lafon, J.P.; Champion, E.; Bernache-Assollant, D. Processing of AB-type carbonated hydroxyapatite $\mathrm{Ca}_{10-\mathrm{x}}\left(\mathrm{PO}_{4}\right)_{(6-\mathrm{x})}\left(\mathrm{CO}_{3}\right)_{(\mathrm{x})}(\mathrm{OH})_{(2-\mathrm{x}-2 \mathrm{y})}\left(\mathrm{CO}_{3}\right)_{(\mathrm{y})}$ ceramics with controlled composition. J. Eur. Ceram. Soc. 2008, 28, 139-147.

344. Kannan, S.; Rebelo, A.; Lemos, A.F.; Barba, A.; Ferreira, J.M.F. Synthesis and mechanical behaviour of chlorapatite and chlorapatite / $\beta$-TCP composites. J. Eur. Ceram. Soc. 2007, 27, 2287-2294.

345. Teshima, K.; Yubuta, K.; Ooi, S.; Suzuki, T.; Shishido, T.; Oishi, S. Environmentally friendly growth of calcium chlorapatite whiskers from a sodium chloride flux. Cryst. Growth Des. 2006, 6, 2538-2542.

346. Kannan, S.; Goetz-Neunhoeffer, F.; Neubauer, J.; Ferreira, J.M.F. Ionic substitutions in biphasic hydroxyapatite and $\beta$-tricalcium phosphate mixtures: structural analysis by Rietveld refinement. J. Am. Ceram. Soc. 2008, 91, 1-12.

347. Pushpakanth, S.; Srinivasan, B.; Sastry, T.P.; Mandal, A.B. Biocompatible and antibacterial properties of silver-doped hydroxyapatite. J. Biomed. Nanotechnol. 2008, 4, 62-66.

348. Kim, T.N.; Feng, Q.L.; Kim, J.O.; Wu, J.; Wang, H.; Chen, G.C.; Cui, F.Z. Antimicrobial effects of metal ions $\left(\mathrm{Ag}^{+}, \mathrm{Cu}^{2+}, \mathrm{Zn}^{2+}\right)$ in hydroxyapatite. J. Mater. Sci. Mater. Med. 1998, 9, 129-134.

349. Thomas, S.; Assi, P.; Marycel, B.; Correa, M.; Liberato, W.; Brito, V. Yttrium 90hydroxyapatite, a new radioisotope for chronic synovitis in hemophilia. Haemophilia 2008, 14, 77.

350. Chinol, M.; Vallabhajosula, S.; Goldsmith, S.J.; Klein, M.J.; Deutsch, K.F.; Chinen, L.K.; Brodack, J.W.; Deutsch, E.A.; Watson, B.A.; Tofe, A.J. Chemistry and biological behavior of 
samarium-153 and rhenium-186-labeled hydroxyapatite particles: potential radiopharmaceuticals for radiation synovectomy. J. Nucl. Med. 1993, 34, 1536-1542.

351. Argüelles, M.G.; Berlanga, I.S.L.; Torres, E.A. Preparation of ${ }^{153} \mathrm{Sm}$-particles for radiosynovectomy. J. Radioanal. Nucl. Chem. 1999, 240, 509-511.

352. O’Duffy, E.; Clunie, G.; Lui, D.; Edwards, J.; Ell, P. Double blind glucocorticoid controlled trial of samarium-153 particulate hydroxyapatite radiation synovectomy for chronic knee synovitis. Ann. Rheum. Dis. 1999, 58, 554-558.

353. Palmer, L.C.; Newcomb, C.J.; Kaltz, S.R.; Spoerke, E.D.; Stupp, S.I. Biomimetic systems for hydroxyapatite mineralization inspired by bone and enamel. Chem. Rev. 2008, 108, 4754-4783.

354. Boskey, A.L. Assessment of bone mineral and matrix using backscatter electron imaging and FTIR imaging. Curr. Osteoporos. Rep. 2006, 4, 71-75.

355. Vallet-Regi, M.; González-Calbet, J.M. Calcium phosphates as substitution of bone tissues. Progr. Solid State Chem. 2004, 32, 1-31.

356. Holt, L.E.; la Mer, V.K.; Chown, H.B. Studies in calcification. I. The solubility product of secondary and tertiary calcium phosphate under various conditions. J. Biol. Chem. 1925, 64, 509-565.

357. Holt, L.E.; la Mer, V.K.; Chown, H.B. Studies in calcification. II. Delayed equilibrium between the calcium phosphates and its biological significance. J. Biol. Chem. 1925, 64, 567-578.

358. Gassmann, T. The preparation of a complex salt corresponding to apatite-typus and its relations to the constitution of bones. H.-S. Z. Physiol. Chem. 1913, 83, 403-408.

359. de Jong, W.F. La substance minérale dans les os. Recl. Trav. Chim. Pays-Bas 1926, 45, 445-449.

360. Bredig, M.A. The apatite structure of inorganic bone and tooth substance. H.-S. Z. Physiol. Chem. 1933, 216, 239-243.

361. Taylor, N.W.; Sheard, C. Microscopic and X-ray investigations on the calcification of tissue. $J$. Biol. Chem. 1929, 81, 479-493.

362. Weiner, S.; Wagner, H.D. Material bone: structure-mechanical function relations. Ann. Rev. Mater. Sci. 1998, 28, 271-298.

363. Weiner, S.; Traub, W.; Wagner, H.D. Lamellar bone: structure-function relations. J. Struct. Biol. 1999, 126, 241-255.

364. Limeback, H. Molecular mechanisms in dental hard tissue mineralization. Curr. Opin. Dent. 1991, $1,826-835$.

365. Matkovic, V. Calcium metabolism and calcium requirements during skeletal modeling and consolidation of bone mass. Am. J. Clin. Nutr. 1991, 54, 245S-260S.

366. Power, M.L.; Heaney, R.P.; Kalkwarf, H.J.; Pitkin, R.M.; Repke, J.T.; Tsang, R.C.; Schulkin, J. The role of calcium in health and disease. Am. J. Obstetrics Gynecol. 1999, 181, 1560-1569.

367. Elliott, J.C. Calcium phosphate biominerals. In Phosphates: geochemical, geobiological and materials importance, Series: Reviews in Mineralogy and Geochemistry. Vol. 48; Hughes, J.M., Kohn, M., Rakovan, J., Eds.; Mineralogical Society of America: Washington, D.C., USA, 2002; pp. 13-49.

368. Jones, F.H. Teeth and bones: application of Surface Science to dental materials and related biomaterials. Surf. Sci. Rep. 2001, 42, 75-205.

369. Loveridge, N. Bone: more than a stick. J. Anim. Sci. 1999, 77 (Suppl. 2), 190-196. 
370. Nightingale, J.P.; Lewis, D. Pole figures of the orientation of apatite in bones. Nature 1971, 232, 334-335.

371. Currey, J.D. Bones: structure and mechanics; Princeton Univercity Press: Princeton, USA, 2002; p. 456.

372. Rho, J.Y.; Kuhn-Spearing, L.; Zioupos, P. Mechanical properties and the hierarchical structure of bone. Med. Eng. Phys. 1998, 20, 92-102.

373. Mann, S. Biomimetic materials chemistry;VCH, Weinheim, Germany, 1996; p. 400.

374. Hancox, N.M. Biology of bone; Cambridge University Press: Cambridge, MA, USA, 1972; p. 199.

375. Martin, R.B. Bone as a ceramic composite material. Mater. Sci. Forum 1999, 7, 5-16.

376. Tzaphlidou, M. Bone architecture: collagen structure and calcium / phosphorus maps. J. Biol. Phys. 2008, 34, Spec. Iss. 1-2, 39-49.

377. Davison, K.S.; Siminoski, K.; Adachi, J.D.; Hanley, D.A.; Goltzman, D.; Hodsman, A.B.; Josse, R.; Kaiser, S.; Olszynski, W.P.; Papaioannou, A.; Ste-Marie, L.G.; Kendler, D.L.; Tenenhouse, A.; Brown, J.P. Bone strength: the whole is greater than the sum of its parts. Semin. Arthritis Rheum. 2006, 36, 22-31.

378. Turner, C.H.; Burr, D.B. Basic biomechanical measurements of bone: a tutorial. Bone 1993, 14, 595-608.

379. Currey, J.D. Tensile yield in compact bone is determined by strain, post-yield behaviour by mineral content. J. Biomech. 2004, 37, 549-556.

380. Currey, J.D.; Brear, K.; Zioupos, P. Notch sensitivity of mammalian mineralized tissues in impact. Proc. R. Soc. London, Ser. B 2004, 217, 517-522.

381. Anderson, J.C.; Eriksson, C. Piezoelectric properties of dry and wet bone. Nature 1970, 227, 491-492.

382. Lang, S.B. Pyroelectric effect in bone and tendon. Nature 1966, 212, 704-705.

383. Haynes, V. Radiocarbon: analysis of inorganic carbon of fossil bone and enamel. Science 1968, 161, 687-688.

384. Rensberger, J.M.; Watabe, M. Fine structure of bone in dinosaurs, birds and mammals. Nature 2000, 406, 619-622.

385. Kolodny, Y.; Luz, B.; Sander, M.; Clemens, W.A. Dinosaur bones: fossils or pseudomorphs? The pitfalls of physiology reconstruction from apatitic fossils. Palaeo 1996, 126, 161-171.

386. Trueman, C.N.; Tuross, N. Trace elements in recent and fossil bone apatite, In Phosphates: geochemical, geobiological and materials importance, Series: Reviews in Mineralogy and Geochemistry. Vol. 48; Hughes, J.M., Kohn, M., Rakovan, J., Eds.; Mineralogical Society of America: Washington, D.C., USA, 2002; pp. 489-522.

387. Currey, J.D.; Brear, K. Hardness, Young's modulus and yield stress in mammalian mineralized tissues. J. Mater. Sci. Mater. Med. 1990, 1, 14-20.

388. Brown, W.E.; Chow, L.C. Chemical properties of bone mineral. Ann. Rev. Mater. Sci. 1976, 6, 213-236.

389. Lakes, R. Materials with structural hierarchy. Nature 1993, 361, 511-515.

390. Meyers, M.A.; Lin, A.Y.M.; Seki, Y.; Chen, P.Y.; Kad, B. K.; Bodde, S. Structural biological composites: an overview. JOM 2006, 58, 36-43. 
391. Wahl, D.A.; Czernuszka, J.T. Collagen - hydroxyapatite composites for hard tissue repair. Eur. Cell Mater. 2006, 11, 43-56.

392. Watt, J.C. The deposition of calcium phosphate and calcium carbonate in bone and in areas of calcification. Arch. Surg. Chicago 1925, 10, 983-990.

393. Olszta, M.J.; Cheng, X.; Jee, S.S.; Kumar, R.; Kim, Y.Y.; Kaufman, M.J.; Douglas, E.P.; Gower, L.B. Bone structure and formation: a new perspective. Mater. Sci. Eng. R 2007, 58, 77-116.

394. Boskey, A.L. Mineralization of bones and teeth. Elements 2007, 3, 385-391.

395. Glimcher, M.J. Bone: nature of the calcium phosphate crystals and cellular, structural and physical chemical mechanisms in their formation. In Medical Mineralogy and Geochemistry, Series: Reviews in Mineralogy and Geochemistry. Vol. 64; Sahai, N., Schoonen M.A.A., Eds.; Mineralogical Society of America: Washington, D.C., USA, 2006; pp. 223-282.

396. Boskey, A.L.; Roy, R. Cell culture systems for studies of bone and tooth mineralization. Chem. Rev. 2008, 108, 4716-4733.

397. McKee, M.D.; Addison, W.N.; Kaartinen, M.T. Hierarchies of extracellular matrix and mineral organization in bone of the craniofacial complex and skeleton. Cell Tiss. Organ 2005, 181, 176-188.

398. Currey, J.D. Hierarchies in biomineral structures. Science 2005, 309, 253-254.

399. Fantner, G.E.; Rabinovych, O.; Schitter, G.; Thurner, P.; Kindt, J.H.; Finch, M.M.; Weaver, J.C.; Golde, L.S.; Morse, D.E.; Lipman, E.A.; Rangelow, I.W.; Hansma, P.K. Hierarchical interconnections in the nano-composite material bone: fibrillar cross-links resist fracture on several length scales. Composite Sci. Technol. 2006, 66, 1202-1208.

400. Meyers, M.A.; Chen, P.Y.; Lin, A.Y.M.; Seki, Y. Biological materials: structure and mechanical properties. Prog. Mater. Sci. 2008, 53, 1-206.

401. Athanasiou, K.A.; Zhu, C.; Lanctot, D.R.; Agrawal, C.M.; Wang, X. Fundamentals of biomechanics in tissue engineering of bone. Tissue Eng. 2000, 6, 361-381.

402. Nikolov, S.; Raabe, D. Hierarchical modeling of the elastic properties of bone at submicron scales: the role of extrafibrillar mineralization. Biophys. J. 2008, 94, 4220-4232.

403. Gupta, H.S.; Wagermaier, W.; Zickler, G.A.; Aroush, D.R.B.; Funari, S.S.; Roschger, P.; Wagner, H.D.; Fratzl, P. Nanoscale deformation mechanisms in bone. Nano Lett. 2005, 5, 2108-2111.

404. Peterlik, H.; Roschger, P.; Klaushofer, K.; Fratzl, P. From brittle to ductile fracture of bone, Nature Mater. 2006, 5, 52-55.

405. Ruppel, M.E.; Miller, L.M.; Burr, D.B. The effect of the microscopic and nanoscale structure on bone fragility. Osteop. Int. 2008, 19, 1251-1265.

406. Fratzl, P.; Gupta, H.S.; Paschalis, E.P.; Roschger, P. Structure and mechanical quality of the collagen-mineral nano-composite in bone. J. Mater. Chem. 2004, 14, $2115-2123$.

407. Marino, A.A.; Becker, R.O. Evidence for direct physical bonding between the collagen fibres and apatite crystals in bone. Nature 1967, 213, 697-698.

408. Eppell, S.J.; Tong, W.; Katz, J.L.; Kuhn, L.; Glimcher, M.J. Shape and size of isolated bone mineralites measured using atomic force microscopy. J. Orthop. Res. 2001, 19, 1027-1034.

409. Clark, S.M.; Iball, J. Orientation of apatite crystals in bone. Nature 1954, 174, 399-400. 
410. Rubin, M.A.; Jasiuk, I.; Taylor, J.; Rubin, J.; Ganey, T.; Apkarian, R.P. TEM analysis of the nanostructure of normal and osteoporotic human trabecular bone. Bone 2003, 33, 270-282.

411. Su, X.; Sun, K.; Cui, F.Z.; Landis, W.J. Organization of apatite crystals in human woven bone. Bone 2003, 32; 150-162.

412. Due to the nanoscopic dimensions, biological apatite is occasionally called "nano-apatite" [362].

413. Self-assembling is the autonomous organization of components into patterns or structures without human intervention. It is considered that self-assembling processes are common throughout nature and technology [414].

414. Whitesides, G.M.; Grzybowski, B. Self-assembly at all scales. Science 2002, 295, 2418-2421.

415. Fratzl, P.; Fratzl-Zelman, N.; Klaushofer, K.; Vogl, G.; Koller, K. Nucleation and growth of mineral crystals in bone studied by small-angle X-ray scattering. Calcif. Tissue Int. 1991, 48, 407-413.

416. Landis, W.J.; Hodgens, K.J.; Arena, J.; Song, M.J.; McEwen, B.F. Structural relations between collagen and mineral in bone as determined by high voltage electron microscopic tomography. Microsc. Res. Techn. 1996, 33, 192-202.

417. Rosen, V.B.; Hobbs, L.W.; Spector, M. The ultrastructure of anorganic bovine bone and selected synthetic hyroxyapatites used as bone graft substitute materials. Biomaterials 2002, 23, 921-928.

418. Cui, F.Z.; Li, Y.; Ge, J. Self-assembly of mineralized collagen composites. Mater. Sci. Eng. $R$ 2007, 57, 1-27.

419. Sato, K. Inorganic-organic interfacial interactions in hydroxyapatite mineralization processes. Topics Curr. Chem. 2006, 270, 127-153.

420. Hartgerink, J.D.; Beniash, E.; Stupp, S.I. Self-assembly and mineralization of peptide-amphiphile nanofibers. Science 2001, 294, 1684-1688.

421. Burger, C.; Zhou, H.; Wang, H.; Sics, I.; Hsiao, B.S.; Chu, B.; Graham, L.; Glimcher, M. Lateral packing of mineral crystals in bone collagen fibrils. Biophys. J. 2008, 95, 1985-1992.

422. George, A.; Veis, A. Phosphorylated proteins and control over apatite nucleation, crystal growth, and inhibition. Chem. Rev. 2008, 108, 4670-4693.

423. Cartilage: structure, function and biochemistry; Hall, B.K., Ed.; Academic Press: New York, USA, 1983; p. 385.

424. Robins, S.P.; Bilezikian, J.P.; Seibel. M.J. Dynamics of bone and cartilage metabolism; Academic Press: New York, USA, 1999; p. 672.

425. Bones and cartilage: developmental skeletal biology; Hall, B.K., Ed.; Academic Press: New York, USA, 2005; p. 792.

426. Marino, A.A.; Becker, R.O. Evidence for epitaxy in the formation of collagen and apatite. Nature 1970, 226, 652-653.

427. Jodaikin, A.; Weiner, S.; Talmon, Y.; Grossman, E.; Traub, W. Mineral-organic matrix relations in tooth enamel. Int. J. Biol. Macromol. 1988, 10, 349-352.

428. Fincham, A.G.; Moradian-Oldak, J.; Diekwisch, T.G.H.; Lyaruu, D.M.; Wright, J.T.; Bringas, P.; Slavkin, H.C. Evidence for amelogenin "nanospheres" as functional components of secretorystage enamel matrix. J. Struct. Biol. 1995, 115, 50-59.

429. LeGeros, R.Z.; Pan, C.M.; Suga, S.; Watabe, N. Crystallo-chemical properties of apatite in atremate brachiopod shells. Calcif. Tissue Int. 1985, 37, 98-100. 
430. Iijima, M.; Moriwaki, Y. Orientation of apatite and organic matrix in Lingula unguis shell. Calcif. Tissue Int. 1990, 47, 237-242.

431. Williams, A.; Cusack, M.; Buckman, J.O.; Stachel, T. Siliceous tablets in the larval shells of apatitic discinid Brachiopods. Science 1998, 297, 2094-2096.

432. Rohanizadeh, R.; LeGeros, R.Z. Mineral phase in linguloid brachiopod shell: Lingula adamsi. Lethaia 2007, 40, 61-68.

433. Nakano, T.; Ishimoto, T.; Lee, J.W.; Umakoshi, Y. Preferential orientation of biological apatite crystallite in original, regenerated and diseased cortical bones. J. Ceram. Soc. Jpn. 2008, 116, 313-315.

434. Nakano, T.; Ishimoto, T.; Umakoshi, Y.; Tabata, Y. Variation in bone quality during regenerative process. Mater. Sci. Forum 2007, 539-543, 675-680.

435. Suvorova, E.I.; Petrenko, P.P.; Buffat, P.A.; Scanning and transmission electron microscopy for evaluation of order / disorder in bone structure. Scanning 2007, 29, 162-170.

436. Stock, S.R.; Blackburn, D.; Gradassi, M.; Simon, H.G. Bone formation during forelimb regeneration: a microtomography (microct) analysis. Dev. Dyn. 2003, 226, 410-417.

437. Teitelbaum, S.L. Bone resorption by osteoclasts. Science 2000, 289, 1504-1508.

438. Rodan, G.A.; Martin, T.J. Therapeutic approaches to bone diseases. Science 2000, 289, 1508-1514.

439. Schilling, A.F.; Filke, S.; Brink, S.; Korbmacher, H.; Amling, M.; Rueger, J.M. Osteoclasts and biomaterials. Eur. J. Trauma 2006, 32, 107-113.

440. Bonar, L.C.; Shimizu, M.; Roberts, J.E.; Griffin, R.G.; Glimcher, M.J. Structural and composition studies on the mineral of newly formed dental enamel: a chemical, X-ray diffraction, and ${ }^{31} \mathrm{P}$ and proton nuclear magnetic resonance study. J. Bone Miner. Res. 1991, 6, 1167-1176.

441. Biltz, R.M.; Pellegrino, E.D. The hydroxyl content of calcified tissue mineral. Calcif. Tissue Res. 1971, 7, 259-263.

442. Rey, C.; Renugopalakrishnan, V.; Collins, B.; Glimcher, M.J. Fourier transform infrared spectroscopic study of the carbonate ions in bone mineral during aging. Calcif. Tissue Int. 1991, 49, 251-258.

443. Rey, C.; Miquel, J.L.; Facchini, L.; Legrand, A.P.; Glimcher, M.J. Hydroxyl groups in bone mineral. Bone 1995, 16, 583-586.

444. Loong, C.K.; Rey, C.; Kuhn, L.T.; Combes, C.; Wu, Y.; Chen, S.H.; Glimcher, M.J.; Evidence of hydroxyl-ion deficiency in bone apatites: an inelastic neutron scattering study. Bone 2000, 26, 599-602.

445. Cho, G.; Wu, Y.; Ackerman, J.L. Detection of hydroxyl ions in bone mineral by solid-state NMR spectroscopy. Science 2003, 300, 1123-1127.

446. Grynpas, M.D.; Omelon, S. Transient precursor strategy or very small biological apatite crystals? Bone 2007, 41, 162-164.

447. Tung, M.S.; Brown, W.E. An intermediate state in hydrolysis of amorphous calcium phosphate. Calcif. Tissue Int. 1983, 35, 783-790.

448. Tung, M.S.; Brown, W.E. The role of octacalcium phosphate in subcutaneous heterotopic calcification. Calcif. Tissue Int. 1985, 37, 329-331. 
449. Brown, W.E.; Eidelman, N.; Tomazic, B.B. Octacalcium phosphate as a precursor in biomineral formation. Adv. Dent. Res. 1987, 1, 306-313.

450. Siew, C.; Gruninger, S.E.; Chow, L.C.; Brown, W.E. Procedure for the study of acidic calcium phosphate precursor phases in enamel mineral formation. Calcif. Tissue Int. 1992, 50, 144-148.

451. Crane, N.J.; Popescu, V.; Morris, M.D.; Steenhuis, P.; Ignelzi, J.M.A. Raman spectroscopic evidence for octacalcium phosphate and other transient mineral species deposited during intramembranous mineralization. Bone 2006, 39, 434-442.

452. Tseng, Y.H.; Mou, C.Y.; Chan, J.C.C. Solid-state NMR study of the transformation of octacalcium phosphate to hydroxyapatite: a mechanistic model for central dark line formation. $J$. Am. Chem. Soc. 2006, 128, 6909-6918.

453. Eanes, E.D.; Gillessen, I.H.; Posner, A.S. Intermediate states in the precipitation of hydroxyapatite. Nature 1965, 208, 365-367.

454. Termine, J.D.; Posner, A.S. Infrared analysis of rat bone: age dependency of amorphous and crystalline mineral fractions. Science 1966, 153, 1523-1525.

455. Termine, J.D.; Posner, A.S. Infra-red determination of the percentage of crystallinity in apatitic calcium phosphates. Nature 1966, 211, 268-270.

456. Harper, R.A.; Posner, A.S. Measurement of non-crystalline calcium phosphate in bone mineral. Proc. Soc. Exptl. Biol. Med. 1966, 122, 137-142.

457. Posner, A.S. Crystal chemistry of bone mineral. Physiol. Rev. 1969, 49, 760-792.

458. Posner, A.S. Bone mineral on the molecular level. Fed. Proc. 1973, 32, 1933-1937.

459. Boskey, A.L.; Posner, A.S. Formation of hydroxyapatite at low supersaturation. J. Phys. Chem. 1976, 80, 40-44.

460. Posner, A.S. The chemistry of bone mineral. Bull. Hosp. Joint Dis. 1978, 39, 126-144.

461. Glimcher, M.J.; Bonar, L.C.; Grynpas, M.D.; Landis, W.J.; Roufosse, A.H. Recent studies of bone mineral: is the amorphous calcium phosphate theory valid? J. Cryst. Growth 1981, 53, 100-119.

462. Meyer, J.L.; Eanes, E.D. A thermodynamic analysis of the amorphous to crystalline calcium phosphate transformation. Calcif. Tissue Res. 1978, 25, 59-68.

463. Meyer, J.L.; Eanes, E.D. A thermodynamic analysis of the secondary transition in the spontaneous precipitation of calcium phosphate. Calcif. Tissue Res. 1978, 25, 209-216.

464. Politi, Y.; Arad, T.; Klein, E.; Weiner, S.; Addadi, L. Sea urchin spine calcite forms via a transient amorphous calcium carbonate phase. Science 2004, 306, 1161-1164.

465. Weiner, S.; Sagi, I.; Addadi, L. Choosing the crystallization path less traveled. Science 2005, 309, 1027-1028.

466. Weiner, S. Transient precursor strategy in mineral formation of bone. Bone 2006, 39, 431-433.

467. Pekounov, Y.; Petrov, O.E. Bone resembling apatite by amorphous-to-crystalline transition driven self-organisation. J. Mater. Sci. Mater. Med. 2008, 19, 753-759.

468. Gower, L.B. Biomimetic model systems for investigating the amorphous precursor pathway and its role in biomineralization. Chem. Rev. 2008, 108, 4551-4627.

469. Mahamid, J.; Sharir, A.; Addadi, L.; Weiner, S. Amorphous calcium phosphate is a major component of the forming fin bones of zebrafish: indications for an amorphous precursor phase. Proc. Natl. Acad. Sci. USA 2008, 105, 12748-12753. 
470. Sahar, N.D.; Hong, S.I.; Kohn, D.H. Micro- and nano-structural analyses of damage in bone. Micron 2005, 36, 617-629.

471. Bilezikian, J.P.; Raisz, L.G.; Martin, T.J. Principles of Bone Biology, $3^{\text {rd }}$ Ed.; Academic Press: New York, USA, 2008; p. 1900.

472. Burnell, J.M.; Teubner, E.J.; Miller, A.G. Normal maturational changes in bone matrix, mineral, and crystal size in the rat. Calcif. Tissue Int. 1980, 31, 13-19.

473. Weiner, S.; Traub, W. Organization of hydroxyapatite crystals within collagen fibrils. FEBS Lett. 1986, 206, 262-266.

474. Pellegrino, E.D.; Blitz, R.M. Mineralization in the chick embryo I. Monohydrogen phosphate and carbonate relationships during maturation of the bone crystal complex. Calcif. Tissue Res. 1972, 10, 128-135.

475. LeGeros, R.Z.; Balmain, N.; Bonel, G. Age-related changes in mineral of rat and bovine cortical bone. Calcif. Tissue Int. 1987, 41, 137-144.

476. Rey, C.; Hina, A.; Tofighi, A.; Glimcher, M.J. Maturation of poorly crystalline apatites: chemical and structural aspect in vivo and in vitro behavior. Cell Mater. 1995, 5, 345-356.

477. Verdelis, K.; Lukashova, L.; Wright, J.T.; Mendelsohn, R.; Peterson, M.G.E.; Doty, S.; Boskey, A.L. Maturational changes in dentin mineral properties. Bone 2007, 40, 1399-1407.

478. Plate, U.; Tkotz, T.; Wiesmann, H.P.; Stratmann, U.; Joos, U.; Höhling, H.J. Early mineralization of matrix vesicles in the epiphyseal growth plate. J. Microsc. 1996, 183, 102-107.

479. Stratmann, U.; Schaarschmidt, K.; Wiesmann, H.P.; Plate, U.; Höhling, H.J. Mineralization during matrix-vesicle-mediated mantle dentine formation in molars of albino rats: a microanalytical and ultrastructural study. Cell Tiss. Res. 1996, 284, 223-230.

480. Jahnen-Dechent, W.; Schinke, T.; Trindl, A.; Muller-Esterl, W.; Sablitzky, F.; Kaiser, S.; Blessing, M. Cloning and targeted deletion of the mouse fetuin gene. J. Biol. Chem. 1997, 272, 31496-31503.

481. Schinke, T.; McKnee, M.D.; Karsenty, G. Extracellular matrix calcification: where is the action? Nat.Genet. 1999, 21, 150-151.

482. Jahnen-Dechent, W.; Schäfer, G.; Heiss, A.; Grötzinger, J. Systemic inhibition of spontaneous calcification by the serum protein $\mathrm{a}_{2}$-HS glycoprotein / fetuin. Z. Kardiol. 2001, 90 (Suppl. 3), III/47-III/56.

483. Avery, J.K. Oral development and histology, $3^{\text {rd }}$ Ed.; Thieme Medical Publishers Inc.: New York, USA, 2001; p. 435.

484. ten Cate, A.R. Oral histology: development, structure, and function, $5^{\text {th }}$ Ed.; Mosby-Year Book: Saint Louis, USA, 1998; p. 497.

485. Xue, J.; Zhang, L.; Zou, L.; Liao, Y.; Li, J.; Xiao, L.; Li, W. High-resolution X-ray microdiffraction analysis of natural teeth. J. Synchrotron Rad. 2008, 15, 235-238.

486. Gaft, M.; Shoval, S.; Panczer, G.; Nathan, Y.; Champagnon, B.; Garapon, C. Luminescence of uranium and rare-earth elements in apatite of fossil fish teeth. Palaeogeogr. Palaeocl. 1996, 126, 187-193.

487. Huang, C.M.; Zhang, Q.; Bai, S.; Wang, C.S. FTIR and XRD analysis of hydroxyapatite from fossil human and animal teeth in Jinsha Relict, Chengdu. Spectrosc. Spect. Anal. 2007, 27, 2448-2452. 
488. Ho, S.P.; Yu, B.; Yun, W.; Marshall, G.W.; Ryder, M.I.; Marshall, S.J. Structure, chemical composition and mechanical properties of human and rat cementum and its interface with root dentin. Acta Biomater. 2009, 5, 707-718.

489. Strictly speaking, there are some differences among these biological materials. For example, the hardness of live dentin is less than that of enamel but is greater than that of bone or cementum [488]. When pulp of the tooth dies or is removed by a dentist, the properties of dentin change: it becomes brittle, liable to fracture and looses a reparative capability.

490. Margolis, H.C.; Beniash, E.; Fowler, C.E. Role of macromolecular assembly of enamel matrix proteins in enamel formation. J. Dent. Res. 2006, 86, 775-793.

491. Vieira, A.; Hancock, R.; Limeback, H.; Schwartz, M.; Grynpas, M.D. How does fluoride concentration in the tooth affect apatite crystal size? J. Dent. Res. 2003, 82, 909-913.

492. Cui, F.Z.; Ge, J. New observations of the hierarchical structure of human enamel, from nanoscale to microscale. J. Tissue Eng. Regener. Med. 2007, 1, 185-191.

493. Jandt, K.D. Probing the future in functional soft drinks on the nanometre scale - towards tooth friendly soft drinks. Trends Food Sci. Technol. 2006, 17, 263-271.

494. Chen, H.; Chen, Y.; Orr, B.G.; Banaszak-Holl, M.; Majoros, I.; Clarkson, B.H. Nanoscale probing of the enamel nanorod surface using polyamidoamine dendrimers. Langmuir 2004, 20, 4168-4171.

495. Rönnholm, E. The amelogenesis of human teeth as revealed by electron microscopy. II. The development of the enamel crystallites. J. Ultrastruct. Res. 1962, 6, 249-303.

496. Nylen, M.U.; Evans, E.D.; Omnel, K.A. Crystal growth in rat enamel. J. Cell. Biol. 1963, 18, 109-123.

497. Miake, Y.; Shimoda, S.; Fukae, M.; Aoba, T. Epitaxial overgrowth of apatite crystals on the thinribbon precursor at early stages of porcine enamel mineralization. Calcif. Tissue Int. 1993, 53, 249-256.

498. Daculsi, G.; Menanteau, J.; Kerebel, L.M.; Mitre, D. Length and shape of enamel crystals. Calcif. Tissue Int. 1984, 36, 550-555.

499. Jodaikin, A.; Traub, W.; Weiner, S.; Enamel rod relations in the developing rat incisor. $J$. Ultrastruct. Res. 1984, 89, 324-332.

500. Bres, E.F.; Hutchison, J.L. Surface structure study of biological calcium phosphate apatite crystals from human tooth enamel. J. Biomed. Mater. Res. 2002, 63, 433-440.

501. Schroeder, I.; Frank, R.M. High-resolution transmission electron microscopy of adult human peritubular dentine. Cell Tissue Res. 1985, 242, 449-451.

502. Brès, E.F.; Voegel, J.C.; Frank, R.M. High-resolution electron microscopy of human enamel crystals. J. Microsc. 1990, 160, 183-201.

503. Robinson, C.; Connell, S.; Kirkham, J.; Shorea, R.; Smith, A. Dental enamel - a biological ceramic: regular substructures in enamel hydroxyapatite crystals revealed by atomic force microscopy. J. Mater. Chem. 2004, 14, 2242-2248.

504. Warf, R.D.; Watson, R.R. Calcium phosphate - nutrition in prevention of early childhood dental caries. In Wild-type food in health promotion and disease prevention: the Columbus concept; de Meester, F., Watson, R.R., Eds.; Humana Press: Totowa, NJ, USA, 2008; pp. 343-353. 
505. Simmer, J.P.; Fincham, A.G. Molecular mechanisms of dental enamel formation. Crit. Rev. Oral Biol. Med. 1995, 6, 84-108.

506. Diekwisch, T.G.; Berman, B.J.; Genters, S.; Slavkin, H.C. Initial enamel crystals are not spatially associated with mineralized dentine. Cell Tissue Res. 1995, 279, 149-167.

507. Aoba, T. Recent observations on enamel crystal formation during mammalian amelogenesis. Anat. Rec. 1996, 245, 208-218.

508. Smith, C.E. Cellular and chemical events during enamel maturation. Crit. Rev. Oral. Biol. Med. 1998, 9, 128-161.

509. Sydney-Zax, M.; Mayer, I.; Deutsch, D. Carbonate content in developing human and bovine enamel. J. Dent. Res. 1991, 70, 913-916.

510. Rey, C.; Renugopalakrishnan, V.; Shimizu, M.; Collins, B.; Glimcher, M.J. A resolutionenhanced Fourier Transform Infrared spectroscopic study of the environment of the $\mathrm{CO}_{3}{ }^{2-}$ ion in the mineral phase of enamel during its formation and maturation. Calcif. Tissue Int. 1991, 49, 259-268.

511. Takagi, T.; Ogasawara, T.; Tagami, J.; Akao, M.; Kuboki, Y.; Nagai, N.; LeGeros, R.Z. pH and carbonate levels in. developing enamel. Connect. Tissue Res. 1998, 38, 181-187.

512. Lowenstam, H.A.; Weiner, S. Transformation of amorphous calcium phosphate to crystalline dahillite in the radular teeth of chitons. Science 1985, 227, 51-53.

513. Selvig, K.A.; Periodic lattice images of hydroxyapatite crystals in human bone and dental hard tissues. Calcif. Tissue Res. 1970, 6, 227-238.

514. Selvig, K.A.; Electron microscopy of dental enamel: analysis of crystal lattice images. Cell Tissue Res. 1973, 137, 271-280.

515. Cuisinier, F.J.G.; Steuer, P.; Senger, B.; Voegel, J.C.; Frank, R.M. Human amelogenesis: high resolution electron microscopy of nanometer-sized particles. Cell Tissue Res. 1993, 273, 175-182.

516. Cuisinier, F.J.G.; Steuer, P.; Brisson, A.; Voegel, J.C. High resolution electron microscopy study of crystal growth mechanisms in chicken bone composites. J. Cryst. Growth 1995, 156, 443-453.

517. Houllé, P.; Voegel, J.C.; Schultz, P.; Steuer, P.; Cuisinier, F.J.G. High resolution electron microscopy: structure and growth mechanisms of human dentin crystals. J. Dent. Res. 1997, 76, 895-904.

518. Mann, S. Molecular tectonics in biomineralization and biomimetic materials chemistry. Nature 1993, 365, 499-505.

519. Kirkham, J.; Zhang, J.; Brookes, S.J.; Shore, R.C.; Wood, S.R.; Smith, D.A.; Wallwork, M.L.; Ryu, O.H.; Robinson, C. Evidence for charge domains on developing enamel crystal surfaces. J. Dent. Res. 2000, 79, 1943-1947.

520. Smith, T.M.; Tafforeau, P. New visions of dental tissue research: tooth development, chemistry, and structure. Evol. Anthropol. 2008, 17, 213-226.

521. Warshawsky, H.; Nanci, A. Stereo electron microscopy of enamel crystallites. J. Dent. Res. 1982, 61, 1504-1514.

522. Warshawsky, H. Organization of crystals in enamel. Anat. Rec. 1989, 224, 242-262.

523. Xu, C.; Yao, X.; Walker, M.P.; Wang, Y. Chemical / molecular structure of the dentin-enamel junction is dependent on the intratooth location. Calcif. Tiss. Int. 2009, 84, 221-228. 
524. Arsenault, A.L.; Robinson, B.W. The dentino-enamel junction: a structural and microanalytical study of early mineralization. Calcif. Tissue Int. 1989, 45, 111-121.

525. Hayashi, Y. High resolution electron microscopy in the dentino-enamel junction. J. Electron Microsc. (Tokyo) 1992, 41, 387-391.

526. Hayashi, Y. High resolution electron microscopic study on the human dentine crystal. J. Electron Microsc. (Tokyo) 1993, 42, 141-146.

527. Bodier-Houllé, P.; Steuer, P.; Meyer, J.M.; Bigeard, L.; Cuisinier, F.J.G.; High-resolution electron-microscopic study of the relationship between human enamel and dentin crystals at the dentino-enamel junction. Cell Tissue Res. 2000, 301, 389-395.

528. Takano, Y.; Hanaizumi, Y.; Oshima, H. Occurrence of amorphous and crystalline mineral deposits at the epithelial-mesenchymal interface of incisors in the calcium-loaded rat: Implication of novel calcium binding domains. Anat. Rec. 1996, 245, 174-185.

529. Dong, W.; Warshawsky, H. Lattice fringe continuity in the absence of crystal continuity in enamel. Adv. Dent. Res. 1996, 10, 232-237.

530. Wang, R.; Hu, Y.; Ng, C. Microstructure and interfacial fracture at the cementum-enamel junctions in equine and bovine teeth. J. Mater. Res. 2006, 21, 2146-2155.

531. Ho, S.P.; Goodis, H.; Balooch, M.; Nonomura, G.; Marshall, S.J.; Marshall, G.W. The effect of sample preparation technique on determination of structure and nanomechanical properties of human cementum hard tissue. Biomaterials 2004, 25, 4847-4857.

532. Paine, M.L.; White, S.N.; Luo, W.; Fong, H.; Sarikaya, M.; Snead, M.L. Regulated gene expression dictates enamel structure and tooth function. Matrix Biol. 2001, 20, 273-292.

533. Finke, M.; Parker, D.M.; Jandt, K.D. Influence of soft drinks on the thickness and morphology of in situ acquired pellicle layer on enamel. J. Colloid Interface Sci. 2002, 251, 263-270.

534. Barbour, M.E.; Parker, D.M.; Jandt, K.D. Enamel dissolution as a function of solution degree of saturation with respect to hydroxyapatite: a nanoindentation study. J. Colloid Interface Sci. 2003, 265, 9-14.

535. Lippert, F.; Parker, D.M.; Jandt, K.D. Susceptibility of deciduous and permanent enamel to dietary acid-induced erosion studied with atomic force microscopy nanoindentation. Eur. J. Oral Sci. 2004, 112, 61-66.

536. Barbour, M.E.; Parker, D.M.; Allen, G.C.; Jandt, K.D. Human enamel erosion in constant composition citric acid solutions as a function of degree of saturation with respect to hydroxyapatite. J. Oral Rehabil. 2005, 32, 16-21.

537. LeGeros, R.Z. Calcium phosphates in demineralization and remineralization processes. J. Clin. Dent. 1999, 10, 65-73.

538. Walker, G.; Cai, F.; Shen, P.; Reynolds, C.; Ward, B.; Fone, C.; Honda, S.; Koganei, M.; Oda, M.; Reynolds, E. Increased remineralization of tooth enamel by milk containing added casein phosphopeptide-amorphous calcium phosphate. J. Dairy Res. 2006, 73, 74-78.

539. Lippert, F.; Parker, D.M.; Jandt, K.D. In situ remineralisation of surface softened human enamel studied with AFM nanoindentation. Surface Sci. 2004, 553, 105-114.

540. Lippert, F.; Parker, D.M.; Jandt, K.D. In vitro demineralization / remineralization cycles at human tooth enamel surfaces investigated by AFM and nanoindentation. J. Colloid Interface Sci. 2004, 280, 442-448. 
541. Lippert, F.; Parker, D.M.; Jandt, K.D. Toothbrush abrasion of surface softened enamel studied with tapping mode AFM and AFM nanoindentation. Caries Res. 2004, 38, 464-472.

542. Onuma, K.; Yamagishi, K.; Oyane, A. Nucleation and growth of hydroxyapatite nanocrystals for nondestructive repair of early caries lesions. J. Cryst. Growth 2005, 282, 199-207.

543. Cochrane, N.J.; Saranathan, S.; Cai, F.; Cross, K.J.; Reynolds, E.C. Enamel subsurface lesion remineralisation with casein phosphopeptide stabilised solutions of calcium, phosphate and fluoride. Caries Res. 2008, 42, 88-97.

544. McClendon, J.F. Fluorapatite and teeth. Science 1966, 151, 151.

545. Price, J.; Faucheux, C.; Allen, S. Deer antlers as a model of mammalian regeneration. Curr. Top. Dev. Biol. 2005, 67, 2-49.

546. Yue, Z.; Deng, X.; Feng, H. The mechanisms of deer antlers development and regeneration. $J$. Econ. Animal 2005, 9, 46-49.

547. Zhao, L.; Yue, Z.; Zhang, X.; Deng, X. The deer antlers endochondral ossification and its regulation mechanisms. J. Econ. Animal 2006, 10, 238-241.

548. Landete-Castilleijos, T.; Garcia, A.; Gallego, L. Body weight, early growth and antler size influence antler bone mineral composition of Iberian Red Deer (Cervus elaphus hispanicus). Bone 2007, 40, 230-235.

549. Huxley, J. The relative size of antlers of deer. Proc. Zool. Soc. London 1931, 72, 819-864.

550. Chen, P.Y.; Stokes, A.G.; McKittrick, J. Comparison of the structure and mechanical properties of bovine femur bone and antler of the North American elk (Cervus elaphus canadensis). Acta Biomater. 2009, 5, 693-706.

551. Zioupos, P.; Wang, X.T.; Currey, J.D. Experimental and theoretical quantification of the development of damage in fatigue tests of bone and antler. J. Biomech. 1996, 29, 989-1002.

552. Landete-Castilleijos, T.; Currey, J.D.; Estevez, J.A.; Gaspar-Lopez, E.; Garcia, A.; Gallego, L. Influence of physiological effort of growth and chemical composition on antler bone mechanical properties. Bone 2007, 41, 794-803.

553. Evans, L.A.; McCutcheon, A.L.; Dennis, G.R.; Mulley, R.C.; Wilson, M.A. Pore size analysis of fallow deer (Dama dama) antler bone. J. Mater. Sci. 2005, 40, 5733-5739.

554. Akhtar, R.; Daymond, M. R.; Almer, J. D.; Mummery, P. M. Elastic strains in antler trabecular bone determined by synchrotron X-ray diffraction. Acta Biomater. 2008, 4, 1677-1687.

555. Goss, R.J. Deer antlers regeneration, function and evolution; Academic Press: New York, USA, $1983 ;$ p. 316.

556. Horns, pronghorns, and antlers: evolution, morphology, physiology, and social significance; Bubenik, G.A.; Bubenik, A.B., Eds.; Springer: New York, USA, 1990; p. 562.

557. Kierdorf, U.; Kierdorf, H. Antlers as biomonitors of environmental pollution by lead and fluoride: a review. Eur. J. Wildlife Res. 2005, 51, 137-150.

558. Barling, P.M.; Gupta, D.K.; Lim, C.E.L. Involvement of phosphodiesterase I in mineralization: histochemical studies using antler from red deer (Cervus elaphus) as a model. Calcif. Tissue Int. 1999, 65, 384-389.

559. Barling, P.M.; Chong, K.W. The involvement of phosphohydrolases in mineralization: studies on enzymatic activities extracted from red deer antler. Calcif. Tissue Int. 1999, 65, 232-236. 
560. Kierdorf, U.; Kierdorf, H. The fluoride content of antlers as an indicator of fluoride exposure in red deer (Cervus elaphus): a historical biomonitoring study. Fluoride 2000, 33, 92-94.

561. Pathak, N.N.; Pattanaik, A.K.; Patra, R.C.; Arora, B.M. Mineral composition of antlers of three deer species reared in captivity. Small Rumin. Res. 2001, 42, 61-65.

562. Yuxia, Y.; Rui, D.; Wang, Y.; Wang, S. Calcium and phosphors contents of three-branched and two-branched antler and ossificational antler from sika deer. J. Econ. Animal 2002, 6, 6-8.

563. Kim, H.Y.; Rhyu, M.R. Sectional composition of minerals in domestic deer antler. Korean $J$. Food Sci. Technol. 2000, 32, 31-36.

564. Li, C.; Suttie, J.M.; Clarck, D.E. Histological examination of antler regeneration in red deer (Cervus elaphus). Anat. Rec. 2005, 282A, 163-174.

565. Meister, W. Changes in biological structure of the long bones of white-tailed deer during the growth of antlers. Anat. Rec. 1956, 124, 709-721.

566. Muir, P.D.; Sykes, A.R.; Barrell, G.K. Calcium metabolism in red deer (Cervus elaphus) offered herbages during antlerogenesis: kinetic and stable balance studies. J. Agric. Sci. Camb. 1987, 109, 357-364.

567. Baxter, B.J.; Andrews, R.N.; Barrell, G.K. Bone turnover associated with antler growth in red deer (Cervus elaphus). Anat. Rec. 1999, 256, 14-19.

568. Landete-Castilleijos, T.; Estevez, J.A.; Martinez, A.; Ceacero, F.; Garcia, A.; Gallego, L. Does chemical composition of antler bone reflect the physiological effort made to grow it? Bone 2007, 40, 1095-1102.

569. Baciut, M.; Baciut, G.; Simon, V.; Albon, C.; Coman, V.; Prodan, P.; Florian, S.; Bran, S. Investigation of deer antler as a potential bone regenerating biomaterial. J. Optoelectronics Adv. Mater. 2007, 9, 2547-2550.

570. Block, G.A.; Hulbert-Shearon, T.E.; Levin, N.W.; Port, F.K. Association of serum phosphorus and calcium $\mathrm{x}$ phosphate product with mortality risk in chronic hemodialysis patients: a national study. Am. J. Kidney Dis. 1998, 31, 607-617.

571. Kazama, J.J.; Amizuka, N.; Fukagawa, M. Ectopic calcification as abnormal biomineralization. Ther. Apher. Dial. 2006, 10 (Suppl. 1), S34-S38.

572. Mackarell, W.W.; Moore, B.; Thomas, W.T. On the presence of insoluble salts of calcium (oxalate and phosphate) in renal calculi in large amount in a preponderating number of cases, and the bearing of this finding upon calcium metabolism in gout and allied conditions. Biochem. $J$. 1911, 5, 161-180.

573.Frondel, C.; Prien, E.L. Carbonate-apatite and hydroxylapatite in urinary calculi. Science 1942, $95,431$.

574. Frondel, C.; Prien, E.L. Deposition of calcium phosphates accompanying senile degeneration and disease. Science 1946, 103, 326.

575. Brancaccio, D.; Cozzolino, M. The mechanism of calcium deposition in soft tissues. Contrib. Nephrol. 2005, 149, 279-286.

576. Goff, A.K.; Reichard, R. A soft-tissue calcification: differential diagnosis and pathogenesis. $J$. Forensic Sci. 2006, 51, 493-497.

577. Bittmann, S.; Gunther, M.W.; Ulus, H. Tumoral calcinosis of the gluteal region in a child: case report with overview of different soft-tissue calcifications. J. Pediatric Surg. 2003, 38, E4-E7. 
578. Molloy, E.S.; McCarthy, G.M. Basic calcium phosphate crystals: pathways to joint degeneration. Curr. Opin. Rheumatol. 2006, 18, 187-192.

579. Giachelli, C.M. Vascular calcification mechanisms. J. Am. Soc. Nephrol. 2004, 15, 2959-2964.

580. Kazama, J.J.; Amizuka, N.; Fukagawa, M. The making of a bone in blood vessels: from the soft shell to the hard bone. Kidney Int. 2007, 72, 533-534.

581. Achilles, W. Crystallization in gel matrices: a new experimental model of calcium stone formation. Contrib. Nephrol. 1987, 58, 59-64.

582. Achilles, W.; Jockel, U.; Schaper, A.; Burk, M.; Riedmiller, H. In vitro formation of "urinary stones": generation of spherulites of calcium phosphate in gel and overgrowth with calcium oxalate using a new flow model of crystallization. Scanning Microsc.1995, 9, 577-585; discussion 585-586.

583. Ross, A.E.; Handa, S.; Lingeman, J.E.; Matlaga, B.R. Kidney stones during pregnancy: an investigation into stone composition. Urol. Res. 2008, 36, 99-102.

584. Ringdén, I.; Tiselius, H.G. Composition and clinically determined hardness of urinary tract stones. Scand. J. Urol. Nephrol. 2007, 41, 316-323.

585. Le May, O.; Kaqueler, J.C.; Kodaka, T. Electron probe micro-analysis of human dental pulp stones. Scan. Microscc. 1993, 7, 267-272.

586. Kodaka, T.; Hirayama, A.; Mori, R.; Sano, T. Spherulitic brushite stones in the dental pulp of a cow. J. Electron Microsc. 1998, 47, 57-65.

587. Hayashizaki, J.; Ban, S.; Nakagaki, H.; Okumura, A.; Yoshii, S.; Robinson, C. Site specific mineral composition and microstructure of human supra-gingival dental calculus. Arch. Oral Biol. 2008, 53, 168-174.

588. Zelentsov, E.L.; Moroz, T.N.; Kolmogorov, Yu.P.; Tolmachev, V.E.; Dragun, G.N.; Palchik, N.A.; Grigorieva, T.N. The elemental SRXRF analysis and mineral composition of human salivary stones. Nucl. Instrum. Methods Phys. Res., Sect. A 2001, 470, 417-421.

589. Ortlepp, J.R.; Schmitz, F.; Mevissen, V.; Weiß, S.; Huster, J.; Dronskowski, R.; Langebartels, G.; Autschbach, R.; Zerres, K.; Weber, C.; Hanrath, P.; Hoffmann, R. The amount of calciumdeficient hexagonal hydroxyapatite in aortic valves is influenced by gender and associated with genetic polymorphisms in patients with severe calcific aortic stenosis. Eur. Heart J. 2004, 25, 514-522.

590. Kim, K.M. Cellular mechanism of calcification and its prevention in glutaraldehyde treated vascular tissue. Z. Kardiol. 2001, 90 (Suppl. 3), III99-III105.

591. Tomazic, B.B. Physicochemical principles of cardiovascular calcification. Z. Kardiol. 2001, 90 (Suppl. 3), III68-III80.

592. Marra, S.P.; Daghlian, C.P.; Fillinger, M.F.; Kennedy, F.E. Elemental composition, morphology and mechanical properties of calcified deposits obtained from abdominal aortic aneurysms. Acta Biomater. 2006, 2, 515-520.

593. Fitzpatrick, L.A.; Turner, R.T.; Ritman, E.R. Endochondral bone formation in the heart: a possible mechanism of coronary calcification. Endocrinology 2003, 144, 2214-2219.

594. Suvorova, E.I.; Buffat, P.A. Pathological mineralization of cardiac valves: causes and mechanism. J. Long Term Eff. Med. Implants 2005, 15, 355-367. 
595. Giachelli, C. Ectopic calcification: new concepts in cellular regulation. Z. Kardiol. 2001, 90 (Suppl. 3), III31-III37.

596. Glasmacher, B.; Nellen, E.; Reul, H.; Rau, G. In vitro hemocompatibility testing of new materials for mechanical heart valves. Mat.-Wiss. u. Werkstofftech. 1999, 30, 806-808.

597. Deiwick, M.; Glasmacher, B.; Pettenazzo, E.; Hammel, D.; Castellon, W.; Thiene, G.; Reul, H.; Berendes, E.; Scheld, H.H. Primary tissue failure of bioprostheses: new evidence from in vitro tests. Thorac. Cardiovasc. Surg. 2001, 49, 78-83.

598. Pettenazzo, E.; Deiwick, M.; Thiene, G.; Molin, G.; Glasmacher, B.; Martignago, F.; Bottio, T.; Reul, H.; Valente, M. Dynamic in vitro calcification of bioprosthetic porcine valves: evidence of apatite crystallization. J. Thorac. Cardiovasc. Surg. 2001, 121, 500-509.

599. Schoen, F.J.; Levy, R.J. Calcification of tissue heart valve substitutes: progress toward understanding and prevention. Ann. Thorac. Surg. 2005, 79, 1072-1080.

600. Sensui, K.; Saitoh, S.; Kametani, K.; Makino, K.; Ohira, M.; Kimura, T.; Cheng, G.A.; Hata, Y. Property analysis of ectopic calcification in the carpal tunnel identification of apatite crystals: a case report. Arch. Orthop. Trauma Surg. 2003, 123, 442-445.

601. Kim, C.J.; Choi, S.K. Analysis of aqueous humor calcium and phosphate from cataract eyes with and without diabetes mellitus. KJO 2007, 21, 90-94.

602. McCarty, D.J.; Hogan, H.M.; Gatter, R.A.; Grossmann, M. Studies on pathological calcifications in human cartilage. J. Bone Joint Surg. 1966, 48, 309-325.

603. Laird, D.F.; Mucalo, M.R.; Yokogawa, Y. Growth of calcium hydroxyapatite (Ca-HAp) on cholesterol and cholestanol crystals from a simulated body fluid: a possible insight into the pathological calcifications associated with atherosclerosis. J. Colloid Interface Sci. 2006, 295, 348-363.

604. Stock, S.R.; Ignatiev, K.; Lee, P.L.; Abbott, K.; Pachman, L.M. Pathological calcification in juvenile dermatomyositis (JDM): microCT and synchrotron X-ray diffraction reveal hydroxyapatite with varied microstructures. Connect. Tissue Res. 2004, 45, 248-256.

605. Pachman, L.M.; Boskey, A.L. Clinical manifestations and pathogenesis of hydroxyapatite crystal deposition in juvenile dermatomyositis. Curr. Rheumatol. Rep. 2006, 8, 236-243.

606. Hale, E.K. Metastatic calcification. Dermatology Online J. 2003, 9, 2. (http://dermatology.cdlib.org/94/NYU/Nov2001/3.html) - accessed in April 2009.

607. Grech, P.; Ell, P.J.; Martin, T.J.; Barrington, N.A.; Martin, T.J. Diagnosis in metabolic bone disease; Hodder Arnold H\&S: USA, 1998, p. 300.

608. Mohr, W. Apatite diseases. The pathological substrate in dependence of tissue processing and in consideration of pathogenesis. Aktuel Rheumatol. 2003, 28, 53-58.

609. Tomazic, B.B. Characterization of mineral phases in cardiovascular calcification. In Hydroxyapatite and related materials; Brown, P.W., Constantz, B., Eds.; CRC Press: Boca Raton, FL, USA, 1994; pp. 93-116.

610. Lee, R.S.; Kayser, M.V.; Ali, S.Y. Calcium phosphate microcrystal deposition in the human intervertebral disc. J. Anat. 2006, 208, 13-19.

611. Rosenthal, A.K. Update in calcium deposition diseases. Curr. Opin. Rheumatol. 2007, 19, 158-162. 
612. Lagier, R.; Baud, C.A. Magnesium whitlockite, a calcium phosphate crystal of special interest in pathology. Pathol. Res. Pract. 2003, 199, 329-335.

613. Wesson, J.A.; Ward, M.D. Pathological biomineralization of kidney stones. Elements 2007, 3, 415-421.

614. LeGeros, R.Z; Orly, I.; LeGeros, J.P.; Gomez, C.; Kazimiroff, J.; Tarpley, T.; Kerebel, B. Scanning electron microscopy and electron probe microanalyses of the crystalline components of human and animal dental calculi. Scan. Microsc. 1988, 2, 345-356.

615. Kirsch, T. Determinants of pathological mineralization. Curr. Opin. Rheumatol. 2006, 18, 174-180.

616. Giachelli, C.M. Ectopic calcification: gathering hard facts about soft tissue mineralization. Am. J. Pathol. 1999, 154, 671-675.

617. Kirsch, T. Physiological and pathological mineralization: a complex multifactorial process. Curr. Opin. Orthop. 2007, 18, 425-427.

618. Speer, M.Y.; Giachelli, C.M. Regulation of cardiovascular calcification. Cardiovasc. Pathol. 2004, 13, 63-70.

619. Giachelli, C.M. Inducers and inhibitors of biomineralization: lessons from pathological calcification. Orthod. Craniofac. Res. 2005, 8, 229-231.

620. Giachelli, C.M.; Speer, M.Y.; Li, X.; Rajachar, R.M.; Yang, H. Regulation of vascular calcification: roles of phosphate and osteopontin. Circ. Res. 2005, 96, 717-722.

621. Schmitt, C.P.; Odenwald, T.; Ritz, E. Calcium, calcium regulatory hormones, and calcimimetics: impact on cardiovascular mortality. J. Am. Soc. Nephrol. 2006, 17, 78-80.

622. Azari, F.; Vali, H.; Guerquin-Kern, J.L.; Wu, T.D.; Croisy, A.; Sears, S.K.; Tabrizian, M.; McKee, M.D. Intracellular precipitation of hydroxyapatite mineral and implications for pathologic calcification. J. Struct. Biology 2008, 162, 468-479.

623. Stayton, P.S.; Drobny, G.P.; Shaw, W.J.; Long, J.R.; Gilbert, M. Molecular recognition at the protein-hydroxyapatite interface. Crit. Rev. Oral. Biol. Med. 2003, 14, 370-376.

624. Doherty, T.M.; Fitzpatrick, L.A.; Inoue, D.; Qiao, J.H.; Fishbein, M.C.; Detrano, R.C.; Shah, P.K. Rajavashisth, T.B. Molecular, endocrine and genetic mechanisms of arterial calcification. Endocr. Rev. 2004, 25, 629-672.

625. Lamas, G.A.; Ackermann, A. Clinical evaluation of chelation therapy: is there any wheat amidst the chaff? Am. Heart J. 2000, 140, 4-5.

626. Knudtson, M.L.; Wyse, D.G.; Galbraith, P.D.; Brant, R.; Hildebrand, K.; Paterson, D.; Richardson, D.; Burkart, C.; Burgess, E. Chelation therapy for ischemic heart disease: a randomized controlled trial. JAMA 2002, 287, 481-486.

627. Ehrlich, H.; Koutsoukos, P.G.; Demadis, K.D.; Pokrovsky, O.S. Principles of demineralization: modern strategies for the isolation of organic frameworks. Part I. Common definitions and history. Micron 2008, 39, 1062-1091.

628. Ehrlich, H.; Koutsoukos, P.G.; Demadis, K.D.; Pokrovsky, O.S. Principles of demineralization: modern strategies for the isolation of organic frameworks. Part II. Decalcification. Micron 2009, 40, 169-193.

629. Best, S.M.; Porter, A.E.; Thian, E.S.; Huang, J. Bioceramics: past, present and for the future. J. Eur. Ceram. Soc. 2008, 28, 1319-1327. 
630. Jandt, K.D. Evolutions, revolutions and trends in biomaterials science - a perspective. Adv. Eng. Mater. 2007, 9, 1035-1050.

631. Salinas, A.J.; Vallet-Regí, M. Evolution of ceramics with medical applications. Z. Anorg. Allg. Chem. 2007, 633, 1762-1773.

632. Ring, M.E. Dentistry: an illustrated history; Harry N. Abrams, Inc.: New York, USA, 1992; p. 320.

633. Albee, F.H. Studies in bone growth - triple calcium phosphate as stimulus to osteogenesis. Ann. Surg. 1920, 71, 32-39.

634. Balazsi, C.; Weber, F.; Kover, Z.; Horvath, E.; Nemeth, C. Preparation of calcium-phosphate bioceramics from natural resources. J. Eur. Ceram. Soc. 2007, 27, 1601-1606.

635. Murugan, R.; Ramakrishna, S. Crystallographic study of hydroxyapatite bioceramics derived from various sources. Cryst. Growth Des. 2005, 5, 111-112.

636. Kokubo, T.; Kim, H.M.; Kawashita, M. Novel bioactive materials with different mechanical properties. Biomaterials 2003, 24, 2161-2175.

637. Bioceramics and their clinical applications; Kokubo, T., Ed.; Woodhead Publishing Ltd.: Abington, Cambridge, MA, USA, 2008; p. 784.

638. Greenspan, D.C. Bioactive ceramic implant materials. Curr. Opin. Solid State Mater. Sci. 1999, 4, 389-393.

639. Blokhuis, T.J.; Termaat, M.F.; den Boer, F.C.; Patka, P.; Bakker, F.C.; Haarman, H.J.T.M. Properties of calcium phosphate ceramics in relation to their in vivo behavior. J. Trauma 2000, 48, 179-189.

640. Kim, H.M. Bioactive ceramics: challenges and perspectives. J. Ceram. Soc. Jpn. 2001, 109, S49-S57.

641. Cao, W.; Hench, L.L. Bioactive materials. Ceram. Intern. 1996, 22, 493-507.

642. Okuda, T.; Ioku, K.; Yonezawa, I.; Minagi, H.; Gonda, Y.; Kawachi, G.; Kamitakahara, M.; Shibata, Y.; Murayama, H.; Kurosawa, H.; Ikeda, T. The slow resorption with replacement by bone of a hydrothermally synthesized pure calcium-deficient hydroxyapatite. Biomaterials 2008, 29, 2719-2728.

643. Seeley, Z.; Bandyopadhyay, A.; Bose, S. Tricalcium phosphate based resorbable ceramics: influence of $\mathrm{NaF}$ and $\mathrm{CaO}$ addition. Mater. Sci. Eng., C 2008, 28, 11-17.

644. Cushnie, E.K.; Khan, Y.M.; Laurencin, C.T. Amorphous hydroxyapatite-sintered polymeric scaffolds for bone tissue regeneration: physical characterization studies. J. Biomed. Mater. Res. A 2008, $84 A$, 54-62.

645. Linhart, W.; Briem, D.; Amling, M.; Rueger, J.M.; Windolf, J. Mechanical failure of porous hydroxyapatite ceramics 7.5 years after implantation in the proximal tibial. Unfallchirurg. 2004, 107, 154-157.

646. Burger, E.L.; Patel, V. Calcium phosphates as bone graft extenders. Orthopedics 2007, 30, 939-942.

647. He, L.H.; Standard, O.C.; Huang, T.T.; Latella, B.A.; Swain, M.V. Mechanical behaviour of porous hydroxyapatite. Acta Biomater. 2008, 4, 577-586.

648. Norton, J.; Malik, K.R.; Darr, J.A.; Rehman, I. Recent developments in processing and surface modification of hydroxyapatite. Adv. Appl. Ceram. 2006, 105, 113-139. 
649. LeGeros, R.Z.; LeGeros, J.P. Calcium phosphate bioceramics: past, present, future. Key Eng. Mater. 2003, 240-242, 3-10.

650. Jones, A.C.; Arns, C.H.; Sheppard, A.P.; Hutmacher, D.W.; Milthorpe, B.K.; Knackstedt, M.A. Assessment of bone ingrowth into porous biomaterials using MICRO-CT. Biomaterials 2007, 28, 2491-2504.

651. McAfee, P.C.; Cunningham, B.W.; Orbegoso, D.O.; Sefter, J.C.; Dmitriev, A.E.; Fedder, I.L. Analysis of porous ingrowth in intervertebral disc prostheses. Spine 2003, 28, 332-340.

652. Mastrogiacomo, M.; Scaglione, S.; Martinetti, R.; Dolcini, L.; Beltrame, F.; Cancedda, R.; Quarto, R. Role of scaffold internal structure on in vivo bone formation in macroporous calcium phosphate bioceramics. Biomaterials 2006, 27, 3230-3237.

653. Okamoto, M.; Dohi, Y.; Ohgushi, H.; Shimaoka, H.; Ikeuchi, M.; Matsushima, A.; Yonemasu, $\mathrm{K}$.; Hosoi, H. Influence of the porosity of hydroxyapatite ceramics on in vitro and in vivo bone formation by cultured rat bone marrow stromal cells. J. Mater. Sci. Mater. Med. 2006, 17, 327-336.

654. Takagi, S.; Chow, L.C. Formation of macropores in calcium phosphate cement implants. $J$. Biomed. Mater. Res. 2001, 12, 135-139.

655. Walsh, D.; Tanaka, J. Preparation of a bone-like apatite foam cement. J. Mater. Sci. Mater. Med. 2001, 12, 339-344.

656. Chevalier, E.; Chulia, D.; Pouget, C.; Viana, M. Fabrication of porous substrates: a review of processes using pore forming agents in the biomaterial field. J. Pharm. Sci. 2008, 97, 1135-1154.

657. Komlev, V.S.; Barinov, S.M. Porous hydroxyapatite ceramics of bi-modal pore size distribution. J. Mater. Sci. Mater. Med. 2002, 13, 295-299.

658. Hsu, Y.H.; Turner, I.G.; Miles, A.W. Mechanical characterization of dense calcium phosphate bioceramics with interconnected porosity. J. Mater. Sci. Mater. Med. 2007, 18, 2319-2329.

659. Ota, Y.; Kasuga, T.; Abe, Y. Preparation and compressive strength behaviour of porous ceramics with $\beta-\mathrm{Ca}_{3}\left(\mathrm{PO}_{3}\right)_{2}$ fiber skeletons. J. Am. Ceram. Soc. 1997, 80, 225-231.

660. von Doernberg, M.C.; von Rechenberg, B.; Bohner, M.; Grünenfelder, S.; van Lenthe, G.H.; Müller, R.; Gasser, B.; Mathys, R.; Baroud, G.; Auer, J. In vivo behavior of calcium phosphate scaffolds with four different pore sizes. Biomaterials 2006, 27, 5186-5198.

661. Walsh, D.; Hopwood, J.D.; Mann, S. Crystal tectonics: construction of reticulated calcium phosphate frameworks in bicontinuous reverse microemulsions. Science 1994, 264, 1576-1578.

662. Yao, X.; Tan, S.; Jiang, D. Improving the properties of porous hydroxyapatite ceramics by fabricating methods. J. Mater. Sci. 2005, 40, 4939-4942.

663. Zhang, J.; Fujiwara, M.; Xu, Q.; Zhu, Y.; Iwasa, M.; Jiang, D. Synthesis of mesoporous calcium phosphate using hybrid templates. Micropor. Mesopor. Mat. 2008, 111, 411-416.

664. Wang, H.; Zhai, L.; Li, Y.; Shi, T. Preparation of irregular mesoporous hydroxyapatite. Mater. Res. Bull. 2008, 43, 1607-1614.

665. Cyster, L.A.; Grant, D.M.; Howdle, S.M.; Rose, F.R.A.J.; Irvine, D.J.; Freeman, D.; Scotchford, C.A.; Shakesheff, K.M. The influence of dispersant concentration on the pore morphology of hydroxyapatite ceramics for bone tissue engineering. Biomaterials 2005, 26, 697-702. 
666. Lee, E.J.; Koh, Y.H.; Yoon, B.H.; Kim, H.E.; Kim, H.W. Highly porous hydroxyapatite bioceramics with interconnected pore channels using camphene-based freeze casting. Mater. Lett. 2007, 61, 2270-2273.

667. Jones, J.R.; Hench, L.L. Regeneration of trabecular bone using porous ceramics. Curr. Opin. Solid State Mater. Sci. 2003, 7, 301-307.

668. Tas, A.C. Preparation of porous apatite granules from calcium phosphate cement. J. Mater. Sci. Mater. Med. 2008, 19, 2231-2239.

669. Fu, Q.; Rahaman, M.N.; Dogan, F.; Bal, B.S. Freeze casting of porous hydroxyapatite scaffolds. I. Processing and general microstructure. J. Biomed. Mater. Res. B Appl. Biomater. 2008, 86B, 125-135.

670. Tang, Y.J.; Tang, Y.F.; Lv, C.T.; Zhou, Z.H. Preparation of uniform porous hydroxyapatite biomaterials by a new method. Appl. Surf. Sci. 2008, 254, 5359-5362.

671. Fu, Y.C.; Ho, M.L.; Wu, S.C.; Hsieh, H.S.; Wang, C.K. Porous bioceramic bead prepared by calcium phosphate with sodium alginate gel and PE powder. Mater. Sci. Eng., C 2008, 28, 11491158.

672. Hsu, Y.H.; Turner, I.G.; Miles, A.W. Fabrication of porous bioceramics with porosity gradients similar to the bimodal structure of cortical and cancellous bone. J. Mater. Sci. Mater. Med. 2007, 18, 2251-2256.

673. Khalil, K.A.; Kim, S.W.; Dharmaraj, N.; Kim, K.W.; Kim, H.Y. Novel mechanism to improve toughness of the hydroxyapatite bioceramics using high-frequency induction heat sintering. $J$. Mater. Process. Technol. 2007, 187-188, 417-420.

674. Bioactivity is defined as the property of the material to develop a direct, adherent and strong bonding with bone [271,272].

675. Yan, X.; Yu, C.; Zhou, X.; Tang, J.; Zhao, D. Highly ordered mesoporous bioactive glasses with superior in vitro bone-forming bioactivities. Angew. Chem. Int. Ed. Engl. 2004, 43, 5980-5984.

676. Izquierdo-Barba, I.; Ruiz-González, L.; Doadrio, J.C.; González-Calbet, J.M.; Vallet-Regí, M. Tissue regeneration: a new property of mesoporous materials. Solid State Sci. 2005, 7, 983-989.

677. da Silva, R.V.; Bertran, C.A.; Kawachi, E.Y.; Camilli, J.A. Repair of cranial bone defects with calcium phosphate ceramic implant or autogenous bone graft. J. Craniofac. Surg. 2007, 18, 281-286.

678. Jordan, D.R.; Gilberg, S.; Bawazeer, A. Coralline hydroxyapatite orbital implant (Bio-Eye): experience with 158 patients. Ophthal. Plast. Reconstr. Surg. 2004, 20, 69-74.

679. Yoon, J.S.; Lew, H.; Kim, S.J.; Lee, S.Y. Exposure rate of hydroxyapatite orbital implants a 15year experience of 802 cases. Ophthalmology 2008, 115, 566-572.

680. Schnettler, R.; Stahl, J.P.; Alt, V.; Pavlidis, T.; Dingeldein, E.; Wenisch, S. Calcium phosphatebased bone substitutes. Eur. J. Trauma 2004, 4, 219-229.

681. Zyman, Z.Z.; Glushko, V.; Dedukh, N.; Malyshkina, S.; Ashukina, N. Porous calcium phosphate ceramic granules and their behaviour in differently loaded areas of skeleton. J. Mater. Sci. Mater. Med. 2008, 19, 2197-2205.

682. Tadic, D.; Epple, M. A thorough physicochemical characterization of 14 calcium phosphatebased bone substitution materials in comparison to natural bone. Biomaterials 2004, 25, 987-994. 
683. LeGeros, R.Z. Properties of osteoconductive biomaterials: calcium phosphates. Clin. Orthop. Rel. Res. 2002, 395, 81-98.

684. Ruan, J.M.; Zou, J.P.; Zhou, J.N.; Hu, J.Z. Porous hydroxyapatite - tricalcium phosphate bioceramics. Powder Metall. 2006, 49, 66-69.

685. Bohner, M. Calcium orthophosphates in medicine: from ceramics to calcium phosphate cements. Injury 2000, 31 (Suppl. 4), D37-D47.

686. Dorozhkin, S.V. Calcium orthophosphate cements and concretes. Materials 2009, 2, 221-291.

687. Wilson, C.E.; Kruyt, M.C.; de Bruijn, J.; van Blitterswijk, C.A.; Oner, F.C.; Verbout, A.J.; Dhert, W.J.A. A new in vivo screening model for posterior spinal bone formation: comparison of ten calcium phosphate ceramic material treatments. Biomaterials 2006, 27, 302-314.

688. Weiss, D.D.; Sachs, M.A.; Woodard, C.R. Calcium phosphate bone cements: a comprehensive review. J. Long Term Eff. Med. Implants 2003, 13, 41-47.

689. Ambard, A.J.; Mueninghoff, L. Calcium phosphate cement: review of mechanical and biological properties. J. Prosthodont. 2006, 15, 321-328.

690. Costantino, P.D.; Friedman, C.D.; Jones, K.; Chow, L.C.; Pelzer, H.J.; Sisson, G.A. Hydroxyapatite cement. I. Basic chemistry and histologic properties. Arch. Otolaryngol. Head Neck Surg. 1991, 117, 379-384.

691. Costantino, P.D.; Friedman, C.D.; Jones, K.; Chow, L.C.; Pelzer, H.J.; Sisson, G.A. Hydroxyapatite cement. II. Obliteration and reconstruction of the cat frontal sinus. Arch. Otolaryngol. Head Neck Surg. 1991, 117, 385-389.

692. Hong, S.J.; Park, Y.K.; Kim, J.H.; Lee, S.H.; Ryu, K.N.; Park, C.M.; Kim, Y.S. The biomechanical evaluation of calcium phosphate cements for use in vertebroplasty. J. Neurosurg. Spine 2006, 4, 154-159.

693. Lin, J.; Zhang, S.; Chen, T.; Liu, C.; Lin, S.; Tian, X. Calcium phosphate cement reinforced by polypeptide copolymers. J. Biomed. Mater. Res. B Appl. Biomater. 2006, 76B, 432-439.

694. Iooss, P.; Leray, A.M.; Grimandi, G.; Daculsi, G.; Merle, C. A new injectable bone substitute

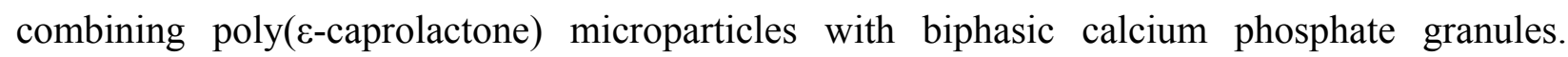
Biomaterials 2001, 22, 2785-2794.

695. Gauthier, O.; Goyenvalle, E.; Bouler, J.M.; Guicheux, J.; Pilet, P.; Weiss P.; Daculsi, G. Macroporous biphasic calcium phosphate ceramics versus injectable bone substitute: a comparative study 3 and 8 weeks after implantation in rabbit bone. J. Mater. Sci. Mater. Med. 2001, 12, 385-390.

696. Schmitt, M.; Weiss, P.; Bourges, X.; Amadordel-Valle, G.; Daculsi, G. Crystallization at the polymer / calcium-phosphate interface in a sterilized injectable bone substitute IBS. Biomaterials 2002, 23, 2789-2794.

697. Gauthier, O.; Khairoun, I.; Bosco, J.; Obadia, L.; Bourges, X.; Rau, C.; Magne, D.; Bouler, J.M.; Aguado, E.; Daculsi, G. Noninvasive bone replacement with a new injectable calcium phosphate biomaterial. J. Biomed. Mater. Res. A 2003, 66A, 47-54.

698. Trojani, C.; Boukhechba, F.; Scimeca, J.C.; Vandenbos, F.; Michiels, J.F.; Daculsi, G.; Boileau, P.; Weiss, P.; Carle, G.F.; Rochet, N. Ectopic bone formation using an injectable biphasic calcium phosphate / Si-HPMC hydrogel composite loaded with undifferentiated bone marrow stromal cells. Biomaterials 2006, 27, 3256-3264. 
699. Lerouxel, E.; Weiss, P.; Giumelli, B.; Moreau, A.; Pilet, P.; Guicheux, J.; Corre, P.; Bouler, J.M.; Daculsi, G.; Malard, O. Injectable calcium phosphate scaffold and bone marrow graft for bone reconstruction in irradiated areas: an experimental study in rats. Biomaterials 2006, 27, 4566-4572.

700. Blouin, S.; Moreau, M.F.; Weiss, P.; Daculsi, G.; Basle, M.F.; Chappard, D. Evaluation of an injectable bone substitute ( $\beta$-TCP / hydroxyapatite / hydroxy-propyl-methyl-cellulose) in severely osteopenic and aged rats. J. Biomed. Mater. Res. A 2006, 78A, 570-580.

701. Dorozhkin, S.V. Is there a chemical interaction between calcium phosphates and hydroxypropylmethylcellulose (HPMC) in organic / inorganic composites? J. Biomed. Mater. Res. 2001, 54, 247-255.

702. Chris Arts, J.J.; Verdonschot, N.; Schreurs, B.W.; Buma, P. The use of a bioresorbable nanocrystalline hydroxyapatite paste in acetabular bone impaction grafting. Biomaterials 2006, 27, 1110-1118.

703. Laschke, M.W.; Witt, K.; Pohlemann, T.; Menger, M.D. Injectable nanocrystalline hydroxyapatite paste for bone substitution: in vivo analysis of biocompatibility and vascularization. J. Biomed. Mater. Res. B Appl. Biomater. 2007, 82B, 494-505.

704. Huber, F.X.; Berger, I.; McArthur, N.; Huber, C.; Kock, H.P.; Hillmeier, J.; Meeder, P.J. Evaluation of a novel nanocrystalline hydroxyapatite paste and a solid hydroxyapatite ceramic for the treatment of critical size bone defects (CSD) in rabbits. J. Mater. Sci. Mater. Med. 2008, 19, 33-38.

705. Xu, H.H.; Weir, M.D.; Burguera, E.F.; Fraser, A.M. Injectable and macroporous calcium phosphate cement scaffold. Biomaterials 2006, 27, 4279-4287.

706. Kruyt, M.C.; Persson, C.; Johansson, G.; Dhert, W.J.; de Bruijn, J. Towards injectable cell-based tissue-engineered bone: the effect of different calcium phosphate microparticles and preculturing. Tissue Eng. 2006, 12, 309-317.

707. Trojani, C.; Boukhechba, F.; Scimeca, J.C.; Vandenbos, F.; Michiels, J.F.; Daculsi, G.; Boileau, P.; Weiss, P.; Carle, G.F.; Rochet, N. Ectopic bone formation using an injectable biphasic calcium phosphate / Si-HPMC hydrogel composite loaded with undifferentiated bone marrow stromal cells. Biomaterials 2006, 27, 3256-3264.

708. Zyman, Z.Z.; Ivanov, I.; Rochmistrov, D.; Glushko, V.; Tkachenko, N.; Kijko, S. Sintering peculiarities for hydroxyapatite with different degrees of crystallinity. J. Biomed. Mater. Res. 2001, 54, 256-263.

709. Willmann, G. Coating of implants with hydroxyapatite - material connections between bone and metal. Adv. Eng. Mater. 1999, 1, 95-105.

710. Epinette, J.A.M.D.; Geesink, R.G.T. Hydroxyapatite coated hip and knee arthroplasty; Elsevier: Amsterdam, The Netherlands, 1995; p. 394.

711. Schliephake, H.; Scharnweber, D.; Roesseler, S.; Dard, M.; Sewing, A.; Aref, A. Biomimetic calcium phosphate composite coating of dental implants. Int. J. Oral Max. Impl. 2006, 21, 738-746.

712. Yang, Y.; Kim, K.H.; Ong, J.L. A review on calcium phosphate coatings produced using a sputtering process - an alternative to plasma spraying. Biomaterials 2005, 26, 327-337. 
713. Oliveira, A.L.; Mano, J.F.; Reis, R.L. Nature-inspired calcium phosphate coatings: present status and novel advances in the science of mimicry. Curr. Opin. Solid State Mater. Sci. 2003, 7 , 309-318.

714. Kurella, A.; Dahotre, N.B. Surface modification for bioimplants: the role of laser surface engineering. J. Biomater. Appl. 2005, 20, 5-50.

715. Kuo, M.C.; Yen, S.K. The process of electrochemical deposited hydroxyapatite coatings on biomedical titanium at room temperature. Mater. Sci. Eng., C 2002, 20, 153-160.

716. Eliaz, N.; Sridhar, T.M.; Mudali, U.K.; Raj, B. Electrochemical and electrophoretic deposition of hydroxyapatite for orthopaedic applications. Surf. Eng. 2005, 21, 238-242.

717. Ma, M.; Ye, W.; Wang, X.X. Effect of supersaturation on the morphology of hydroxyapatite crystals deposited by electrochemical deposition on titanium. Mater. Lett. 2008, 62, 3875-3877.

718. Ong, J.L.; Appleford, M.; Oh, S.; Yang, Y.; Chen, W.H.; Bumgardner, J.D.; Haggard, W.O. The characterization and development of bioactive hydroxyapatite coatings. JOM 2006, 58, 67-69.

719. Qu, H.; Wei, M. The effect of temperature and initial $\mathrm{pH}$ on biomimetic apatite coating. $J$. Biomed. Mater. Res. B Appl. Biomater. 2008, 87, 204-212.

720. Narayanan, R.; Seshadri, S.K.; Kwon, T.Y.; Kim, K.H. Calcium phosphate-based coatings on titanium and its alloys. J. Biomed. Mater. Res. B Appl. Biomater. 2008, 85, 279-299.

721. Chang, J.K.; Chen, C.H.; Huang, K.Y.; Wang, G.J. Eight-year results of hydroxyapatite-coated hip arthroplasty. J. Arthroplasty 2006, 21, 541-546.

722. Slack, R.; Tindall, A.; Shetty, A.A.; James, K.D.; Rand, C. 15-year follow-up results of the hydroxyapatite ceramic-coated femoral stem. J. Orthop. Surg. 2006, 14, 151-154.

723. Buchanan, J.M. 17 year review of hydroxyapatite ceramic coated hip implants - a clinical and histological evaluation. Key Eng. Mater. 2006, 309-311, 1341-1344.

724. Buchanan, J.M.; Goodfellow, S. Nineteen years review of hydroxyapatite ceramic coated hip implants: a clinical and histological evaluation. Key Eng. Mater. 2008, 361-363, 1315-1318.

725. Binahmed, A.; Stoykewych, A.; Hussain, A.; Love, B.; Pruthi, V. Long-term follow-up of hydroxyapatite-coated dental implants - a clinical trial. Int. J. Oral Max. Impl. 2007, 22, 963-968.

726. Iezzi, G.; Scarano, A.; Petrone, G.; Piattelli, A. Two human hydroxyapatite-coated dental implants retrieved after a 14-year loading period: a histologic and histomorphometric case report. J. Periodontol. 2007, 78, 940-947.

727. Osteoconductivity is the ability to provide a scaffold or template for the formation of new bone on its surface by attachment, migration, proliferation, and differentiation of bone-forming cells [649].

728. Geesink, R.G.T. Osteoconductive coating for total joint arthroplasty. Clin. Orthop. Related Res. 2002, 395, 53-65.

729. Zheng, X.; Zhou, S.; Li, X.; Weng, J. Shape memory properties of poly(D,L-lactide) / hydroxyapatite composites. Biomaterials 2006, 27, 4288-4295.

730. Bonfield, W.; Grynpas, M.D.; Tully, A.E.; Bowman, J.; Abram, J. Hydroxyapatite reinforced polyethylene - a mechanically compatible implant material for bone replacement. Biomaterials 1981, 2, 185-186. 
731. Neumann, M.; Epple, M. Composites of calcium phosphate and polymers as bone substitution materials. Eur. J. Trauma 2006, 32, 125-131.

732. Mickiewicz, R.A.; Mayes, A.M.; Knaack, D. Polymer - calcium phosphate cement composites for bone substitutes. J. Biomed. Mater. Res. 2002, 61, 581-592.

733. Wei, G.; Ma, P.X. Structure and properties of nano-hydroxyapatite / polymer composite scaffolds for bone tissue engineering. Biomaterials 2004, 25, 4749-4757.

734. Sun, L.; Berndt, C.C.; Gross, K.A. Hydroxyapatite / polymer composite flame sprayed coatings for orthopedic application. J. Biomater. Sci. Polym. Ed. 2002, 13, 977-990.

735. Lewandrowski, K.U.; Bondre, S.P.; Shea, M.; Untch, C.M.; Hayes, W.C.; Hile, D.D.; Wise, D.L.; Trantolo, D.J. Composite resorbable polymer / hydroxylapatite composite screws for fixation of osteochondral osteotomies. Biomed. Mater. Eng. 2002, 12, 423-438.

736. Salernitano, E.; Migliares, C. Composite materials for biomedical applications: a review. J. Appl. Biomater. Biomech. 2003, 1, 3-18.

737. Kusmanto, F.; Walker, G.; Gan, Q.; Walsh, P.; Buchanan, F.; Dickson, G.; McCaigue, M.; Maggs, C.; Dring, M. Development of composite tissue scaffolds containing naturally sourced mircoporous hydroxyapatite. Chem. Eng. J. 2008, 139, 398-407.

738. Roeder, R.K.; Converse, G.L.; Kane, R.J.; Yue, W.M. Hydroxyapatite-reinforced polymer biocomposites for synthetic bone substitutes. JOM 2008, 60, 38-45.

739. O’Donnell, J.N.R.; Antonucci, J.M.; Skrtic, D. Amorphous calcium phosphate composites with improved mechanical properties. J. Bioact. Comp. Polym. 2006, 21, 169-184.

740. Baji, A.; Wong, S.C.; Srivatsan, T.S.; Njus, G.O.; Mathur, G. Processing methodologies for polycaprolactone-hydroxyapatite composites: a review. Mater. Manufac. Proc. 2006, 21, 211-218.

741. Ruhe, P.Q.; Hedberg-Dirk, E.L.; Padron, N.T.; Spauwen, P.H.; Jansen, J.A.; Mikos, A.G. Porous poly(D,L-lactic-co-glycolic acid) / calcium phosphate cement composite for reconstruction of bone defects. Tissue Eng. 2006, 12, 789-800.

742. Nath, S.; Basu, B. Designing materials for hard tissue replacement. J. Korean Ceram. Soc. 2008, $45,1-29$.

743. Dorozhkin, S.V. Calcium orthophosphate-based biocomposites and hybrid biomaterials. $J$. Mater. Sci. 2009, 44, 2343-2387.

744. Orly, I.; Gregoire, M.; Menanteau, J.; Heughebaert, M.; Kerebel, B. Chemical changes in hydroxyapatite biomaterial under in vivo and in vitro biological conditions. Calcif. Tissue Int. 1989, 45, 20-26.

745. LeGeros, R.Z. Calcium phosphate-based osteoinductive materials. Chem. Rev. 2008, 108, $4742-4753$.

746. The term "biomimetics" ("the mimicry of life") was coined by an American inventor, engineer and biophysicist Otto Herbert Schmitt (1913 - 1998) in the 1950-s.

747. Benyus, J.M. Biomimicry: innovation inspired by nature; William Morrow: New York, USA, 1997, p. 308.

748. Watt, J.C. The behavior of calcium phosphate and calcium carbonate (bone salts) precipitated in various media, with applications to bone formation. Biol. Bull. 1923, 44, 280-288. 
749. Dorozhkin, S.V.; Dorozhkina, E.I.; Epple, M. A model system to provide a good in vitro simulation of biological mineralization. Cryst. Growth Des. 2004, 4, 389-395.

750. Izquierdo-Barba, I.; Salinas, A.J.; Vallet-Regi, M. Effect of the continuous solution exchange on the in vitro reactivity of a $\mathrm{CaO}-\mathrm{SiO}_{2}$ sol-gel glass. J. Biomed. Mater. Res. 2000, 51, 191-199.

751. Vallet-Regi, M.; Pèrez-Pariente, J.; Izquierdo-Barba, I.; Salinas, A.J. Compositional variations in the calcium phosphate layer growth on gel glasses soaked in a simulated body fluid. Chem. Mater. 2000, 12, 3770-3775.

752. Koutsoukos, P.; Amjad, Z.; Tomson, M.B.; Nancollas, G.H. Crystallization of calcium phosphates: a constant composition study. J. Am. Chem. Soc. 1980, 102, 1553-1557.

753. Tomson, M.B.; Nancollas, G.H. Mineralization kinetics: a constant composition approach. Science 1978, 200, 1059-1060.

754. Manjubala, I.; Scheler, S.; Bössert, J.; Jandt, K.D. Mineralisation of chitosan scaffolds with nano-apatite formation by double diffusion technique. Acta Biomater. 2006, 2, 75-84.

755. Dorozhkin, S.V.; Dorozhkina, E.I. The influence of bovine serum albumin on the crystallization of calcium phosphates from a revised simulated body fluid. Colloids Surf., A 2003, 215, 191-199.

756. Dorozhkina, E.I.; Dorozhkin, S.V. In vitro crystallization of carbonateapatite on cholesterol from a modified simulated body fluid. Colloids Surf., A 2003, 223, 231-237.

757. Dorozhkin, S.V.; Dorozhkina, E.I.; Epple, M. Precipitation of carbonateapatite from a revised simulated body fluid in the presence of glucose. J. Appl. Biomater. Biomech. 2003, 1, 200-208.

758. Dorozhkin, S.V.; Dorozhkina, E.I. In vitro simulation of vascular calcification by the controlled crystallization of amorphous calcium phosphates onto porous cholesterol. J. Mater. Sci. 2005, 40, 6417-6422.

759. Dorozhkin, S.V. In vitro mineralization of silicon containing calcium phosphate bioceramics. $J$. Am. Ceram. Soc. 2007, 90, 244-249.

760. Becker, A.; Epple, M. A high-throughput crystallisation device to study biomineralisation in vitro. Mater. Res. Soc. Symp. Proc. 2005, 873E, K12.1.1-K12.1.10.

761. Krings, M.; Kanellopoulou, D.; Mavrilas, D.; Glasmacher, B. In vitro $\mathrm{pH}$-controlled calcification of biological heart valve prostheses. Mat.-Wiss. u. Werkstofftech. 2006, 37, 432-435.

762. Wang, L.J.; Guan, X.Y.; Yin, H.Y.; Moradian-Oldak, J.; Nancollas, G.H. Mimicking the selforganized microstructure of tooth enamel. J. Phys. Chem. C 2008, 112, 5892-5899.

763. Howland, J.; Kramer, B. Calcium and phosphorus in the serum in relation to rickets. Am. J. Dis. Child. 1921, 22, 105-119.

764. Tisdall, F.F. The effects of ultra violet rays on the calcium and inorganic phosphate content of the blood serum of rachitic infants. Can. Med. Assoc. J. 1922, 7, 536-538.

765. Hanks, J.H.; Wallace, R.E. Relation of oxygen and temperature in the preservation of tissues by refrigeration. Proc. Soc. Exp. Biol. Med. 1949, 71, 196-200.

766. Shibata, Y.; Takashima, H.; Yamamoto, H.; Miyazaki, T. Functionally gradient bonelike hydroxyapatite coating on a titanium metal substrate created by a discharging method in HBSS without organic molecules. Int. J. Oral Max. Impl. 2004, 19, 177-183.

767. Marques, P.A.A.P.; Serro, A.P.; Saramago, B.J.; Fernandes, A.C.; Magalhães, M.C.F.; Correia, R.N. Mineralisation of two phosphate ceramics in HBSS: role of albumin. Biomaterials 2003, 24, 451-460. 
768. Gopikrishna, V.; Baweja, P.S.; Venkateshbabu, N.; Thomas, T.; Kandaswamy, D. Comparison of coconut water, propolis, HBSS, and milk on PDL cell survival. J. Endod. 2008, 34, 587-589.

769. Hanawa, T.; Asami, K.; Asaoka, K. Repassivation of titanium and surface oxide film regenerated in simulated bioliquid. J. Biomed. Mater. Res. 1998, 40, 530-538.

770. Rocha, L.A.; Anza, E.; Costa, A.M.; Oliveira, F.J.; Silva, R.F. Electrochemical behavior of Ti / $\mathrm{Al}_{2} \mathrm{O}_{3}$ interfaces produced by diffusion bonding. Mater. Res. 2003, 6, 439-444.

771. Named after Harry Eagle (1905 - 1992), an American physician and pathologist.

772. Named after Renato Dulbecco (born February 22, 1914), an Italian virologist who won the 1975 Nobel Prize in Physiology or Medicine for his work on reverse transcriptase.

773. Meuleman, N.; Tondreau, T.; Delforge, A.; Dejeneffe, M.; Massy, M.; Libertalis, M.; Bron, D.; Lagneaux, L. Human marrow mesenchymal stem cell culture: serum-free medium allows better expansion than classical $\alpha$-MEM medium. Eur. J. Haematol. 2006, 76, 309-316.

774. Okazaki, Y.; Gotoh, E. Corrosion fatigue properties of metallic biomaterials in Eagle's medium. Mater. Trans. 2002, 43, 2949-2955.

775. Coelho, M.J.; Cabral, A.T.; Fernandes, M.H. Human bone cell cultures in biocompatibility testing. Part I: Osteoblastic differentiation of serially passaged human bone marrow cells cultured in $\alpha$-MEM and in DMEM. Biomaterials 2000, 21, 1087-1094.

776. Gao, Y.B.; Weng, W.J.; Deng, X.L.; Cheng, K.; Liu, X.G.; Du, P.Y.; Shen, G.; Han, G.R. Surface morphology variations of porous nano-calcium phosphate / poly(L-lactic acid) composites in PBS. Key Eng. Mater. 2006, 309-311, 569-572.

777. Lewis, A.C.; Kilburn, M.R.; Papageorgiou, I.; Allen, G.C.; Case, C.P. Effect of synovial fluid, phosphate-buffered saline solution, and water on the dissolution and corrosion properties of CoCrMo alloys as used in orthopedic implants. J. Biomed. Mater. Res. A 2005, 73A, 456-467.

778. Humphrey, S.P.; Williamson, R.T. A review of saliva: normal composition, flow, and function. $J$. Prosthet. Dent. 2001, 85, 162-169.

779. Preetha, A.; Banerjee, R. Comparison of artificial saliva substitutes. Trends Biomater. Artif. Organs 2005, 18, 178-186.

780. Kokubo, T.; Kushitani, H.; Sakka, S.; Kitsugi, T.; Yamamuro, T. Solutions able to reproduce in vivo surface-structure changes in bioactive glass-ceramic A-W3. J. Biomed. Mater. Res. 1990, 24, 721-734.

781. Lu, X.; Leng, Y. Theoretical analysis of calcium phosphate precipitation in simulated body fluid. Biomaterials 2005, 26, 1097-1108.

782. Tas, A.C. Synthesis of biomimetic Ca-hydroxyapatite powders at $37^{\circ} \mathrm{C}$ in synthetic body fluids. Biomaterials 2000, 21, 1429-1438.

783. Landi, E.; Tampieri, A.; Celotti, G.; Langenati, R.; Sandri, M.; Sprio, S. Nucleation of biomimetic apatite in synthetic body fluids: dense and porous scaffold development. Biomaterials 2005, 26, 2835-2845.

784. Jalota, S.; Bhaduri, S.B.; Tas, A.C. Using a synthetic body fluid (SBF) solution of $27 \mathrm{mM} \mathrm{HCO}_{3}{ }^{-}$ to make bone substitutes more osteointegrative. Mater. Sci. Eng., C 2008, 28, 129-140.

785. Kim, H.M.; Miyazaki, T.; Kokubo, T.; Nakamura, T. Revised simulated body fluid. In Bioceramics 13; Giannini, S., Moroni, A., Eds.; Trans Tech Publ.: Switzerland, 2001; Volume 192-195, pp. 47-50. 
786. Oyane, A.; Kim, H.M.; Furuya, T.; Kokubo, T.; Miyazaki, T.; Nakamura, T. Preparation and assessment of revised simulated body fluids. J. Biomed. Mater. Res. A 2003, 65A, 188-195.

787. Kokubo, T.; Takadama, H. How useful is SBF in predicting in vivo bone bioactivity? Biomaterials 2006, 27, 2907-2915.

788. Bohner, M.; Lemaitre, J. Can bioactivity be tested in vitro with SBF solution? Biomaterials 2009, 30, 2175-2179.

789. Kim, H.M. Ceramic bioactivity and related biomimetic strategy. Curr. Opin. Solid State Mater. Sci. 2003, 7, 289-299.

790. Marques, P.A.A.P.; Magalhães, M.C.F.; Correia, R.N. Inorganic plasma with physiological $\mathrm{CO}_{2} /$ $\mathrm{HCO}_{3}{ }^{-}$buffer. Biomaterials 2003, 24, 1541-1548.

791. Dorozhkina, E.I.; Dorozhkin, S.V. Surface mineralisation of hydroxyapatite in modified simulated body fluid (mSBF) with higher amounts of hydrogencarbonate ions. Colloids Surf., A 2002, 210, 41-48.

792. Miyaji, F.; Kim, H.M.; Handa, S.; Kokubo, T.; Nakamura, T. Bonelike apatite coating on organic polymers: novel nucleation process using sodium silicate solution. Biomaterials 1999, 20, 913-919.

793. Kim, H.M.; Kishimoto, K.; Miyaji, F.; Kokubo, T.; Yao, T.; Suetsugu, Y.; Tanaka, J.; Nakamura, T. Composition and structure of apatite formed on organic polymer in simulated body fluid with a high content of carbonate ion. J. Mater. Sci. Mater. Med. 2000, 11, 421-426.

794. Barrere, F.; van Blitterswijk, C.A.; de Groot, K.; Layrolle, P. Influence of ionic strength and carbonate on the Ca-P coating formation from $\mathrm{SBF} \times 5$ solution. Biomaterials 2002, 23, 1921-1930.

795. Barrere, F.; van Blitterswijk, C.A.; de Groot, K.; Layrolle, P. Nucleation of biomimetic Ca-P coatings on Ti6Al4V from a SBF $\times 5$ solution: influence of magnesium. Biomaterials 2002, 23, 2211-2220.

796. Tas, A.C.; Bhaduri, S.B. Rapid coating of Ti6Al4V at room temperature with a calcium phosphate solution similar to 10x simulated body fluid. J. Mater. Res. 2004, 19, 2742-2749.

797. Dorozhkina, E.I.; Dorozhkin, S.V. Structure and properties of the precipitates formed from condensed solutions of the revised simulated body fluid. J. Biomed. Mater. Res. A 2003, 67A, 578-581.

798. Pompe, W.; Lampenscherf, S.; Rößler, S.; Scharnweber, D.; Weis, K.; Worch, H.; Hofinger, J. Functionally graded bioceramics. Mater. Sci. Forum 1999, 308-311, 325-330.

799. Fan, Y.; Duan, K.; Wang, R. A composite coating by electrolysis-induced collagen self-assembly and calcium phosphate mineralization. Biomaterials 2005, 26, 1623-1632.

800. Yamauchi, K.; Goda, T.; Takeuchi, N.; Einaga, H.; Tanabe, T. Preparation of collagen / calcium phosphate multilayer sheet using enzymatic mineralization. Biomaterials 2004, 25, 5481-5489.

801. Zhang, W.; Huang, Z.L.; Liao, S.S.; Cui, F.Z. Nucleation sites of calcium phosphate crystals during collagen mineralization. J. Am. Ceram. Soc. 2003, 86, 1052-1054.

802. Wang, Y.; Yang, C.; Chen, X.; Zhao, N. Biomimetic formation of hydroxyapatite / collagen matrix composite. Adv. Eng. Mater. 2006, 8, 97-100. 
803. Lickorish, D.; Ramshaw, J.A.M.; Werkmeister, J.A.; Glattauer, V.; Howlett, C.R. Collagen hydroxyapatite composite prepared by biomimetic process. J. Biomed. Mater. Res. A 2004, 68A, 19-27.

804. Zhao, F.; Yin, Y.; Lu, W.W.; Leong, J.C.; Zhang, W.; Zhang, J.; Zhang, M.; Yao, K. Preparation and histological evaluation of biomimetic three-dimensional hydroxyapatite / chitosan-gelatin network composite scaffolds. Biomaterials 2002, 23, 3227-3234.

805. Kim, H.W.; Kim, H.E.; Salih, V. Stimulation of osteoblast responses to biomimetic nanocomposites of gelatin - hydroxyapatite for tissue engineering scaffolds. Biomaterials 2005, 26, 5221-5230.

806. Kim, H.W.; Knowles, J.C.; Kim, H.E. Porous scaffolds of gelatin-hydroxyapatite nanocomposites obtained by biomimetic approach: characterization and antibiotic drug release. $J$. Biomed. Mater. Res. B Appl. Biomater. 2005, 74B, 686-698.

807. Chen, Z.; Li, Q.L.; Zen, Q.; Li, G.; Jiang, H.; Liu, L.; Darvell, B.W. Biomimetic mineralization and bioactivity of phosphorylated chitosan. Key Eng. Mater. 2005, 288-289, 429-432.

808. Li, Q.L.; Chen, Z.; Ou, G.; Liu, L.; Jiang, H.; Zeng, Q.; Li, G.; He, G.; Mo, A.; Darvell, B.W. Biomimetic synthesis of apatite - polyelectrolyte complex (chitosan - phosphorylated chitosan) hydrogel as an osteoblast carrier. Key Eng. Mater. 2005, 288-289, 75-78.

809. Stupp, S.I.; Ciegler, G.W. Organoapatites: materials for artificial bone. I. Synthesis and microstructure. J. Biomed. Mater. Res. 1992, 26, 169-183.

810. Stupp, S.I.; Braun, P.V. Molecular manipulation of microstructures: biomaterials, ceramics, and semiconductors. Science 1997, 277, 1242-1248.

811. Stupp, S.I.; Mejicano, G.C.; Hanson, J.A. Organoapatites: materials for artificial bone. II. Hardening reactions and properties. J. Biomed. Mater. Res. 1993, 27, 289-299.

812. Stupp, S.I.; Hanson, J.A.; Eurell, J.A.; Ciegler, G.W.; Johnson, A. Organoapatites: materials for artificial bone. III. Biological testing. J. Biomed. Mater. Res. 1993, 27, 301-311.

813. Liu, Y.; Layrolle, P.; de Bruijn, J.; van Blitterswijk, C.A.; de Groot, K. Biomimetic coprecipitation of calcium phosphate and bovine serum albumin on titanium alloy. J. Biomed. Mater. Res. 2001, 57, 327-335.

814. Wang, J.; Layrolle, P.; Stigter, M.; de Groot, K. Biomimetic and electrolytic calcium phosphate coatings on titanium alloy: physicochemical characteristics and cell attachment. Biomaterials 2004, 25, 583-592.

815. Zhang, Q.; Leng, Y. Electrochemical activation of titanium for biomimetic coating of calcium phosphate. Biomaterials 2005, 26, 3853-3859.

816. Bigi, A.; Boanini, E.; Bracci, B.; Facchini, A.; Panzavolta, S.; Segatti, F.; Sturba, L. Nanocrystalline hydroxyapatite coatings on titanium: a new fast biomimetic method. Biomaterials 2005, 26, 4085-4089.

817. Kim, H.M.; Himeno, T.; Kawashita, M.; Lee, J.H.; Kokubo, T.; Nakamura, T. Surface potential change in bioactive titanium metal during the process of apatite formation in simulated body fluid. J. Biomed. Mater. Res. A 2003, 67A, 1305-1309.

818. Allegrini, S.; Rumpel, E.; Kauschke, E.; Fanghänel, J.; König, B. Hydroxyapatite grafting promotes new bone formation and osseointegration of smooth titanium implants. Ann. Anat. 2006, $188,143-151$. 
819. Arnould, C.; Delhalle, J.; Mekhalif, Z. Multifunctional hybrid coating on titanium towards hydroxyapatite growth: electrodeposition of tantalum and its molecular functionalization with organophosphonic acids films. Electrochim. Acta 2008, 53, 5632-5638.

820. Iwatsubo, T.; Kusumocahyo, S.P.; Kanamori, T.; Shinbo, T. Mineralization of hydroxyapatite on a polymer substrate in a solution supersaturated by polyelectrolyte. J. Appl. Polymer Sci. 2006, 100, 1465-1470.

821. Bodin, A.; Gustafsson, L.; Gatenholm, P. Surface-engineered bacterial cellulose as template for crystallization of calcium phosphate. J. Biomater. Sci. Polym. Ed. 2006, 17, 435-447.

822. Toworfe, G.K.; Composto, R.J.; Shapiro, I.M.; Ducheyne, P. Nucleation and growth of calcium phosphate on amine-, carboxyl- and hydroxyl-silane self-assembled monolayers. Biomaterials 2006, 27, 631-642.

823. Griffith, L.G.; Naughton, G. Tissue engineering - current challenges and expanding opportunities. Science 2002, 295, 1009-1014.

824. In 2003, the NSF published a report titled: "The emergence of tissue engineering as a research field", which provides a thorough description of the history of this field. See: http://www.nsf.gov/pubs/2004/nsf0450/start.htm, accessed in April 2009.

825. Langer, R.; Vacanti, J.P. Tissue engineering. Science 1993, 260, 920-926.

826. Schieker, M.; Seitz, H.; Drosse, I.; Seitz, S.; Mutschler, W. Biomaterials as scaffold for bone tissue engineering. Eur. J. Trauma 2006, 32, 114-124.

827. Fini, M.; Giardino, R.; Borsari, V.; Torricelli, P.; Rimondini, L.; Giavaresi, G.; Aldini, N.N. In vitro behaviour of osteoblasts cultured on orthopaedic biomaterials with different surface roughness, uncoated and fluorohydroxyapatite-coated, relative to the in vivo osteointegration rate. Int. J. Artif. Organs 2003, 26, 520-528.

828. Zimmerman, R.; Ila, D.; Muntele, C.; Rodrigues, M.; Poker, D.B.; Hensley, D. Enhanced tissue adhesion by increased porosity and surface roughness of carbon based biomaterials. Nucl. Instrum. Methods Phys. Res., Sect. B 2002, 191, 825-829.

829. Sato, M.; Webster, T.J. Designing orthopedic implant surfaces: harmonization of nanotopographical and chemical aspects. Nanomed. 2006, 1, 351-354.

830. Okamoto, M.; Dohi, Y.; Ohgushi, H.; Shimaoka, H.; Ikeuchi, M.; Matsushima, A.; Yonemasu, K.; Hosoi, H. Influence of the porosity of hydroxyapatite ceramics on in vitro and in vivo bone formation by cultured rat bone marrow stromal cells. J. Mater. Sci. Mater. Med. 2006, 17, 327-336.

831. Annaz, B.; Hing, K.A.; Kayser, M.; Buckland, T.; di Silvio, L. Porosity in phase-pure hydroxyapatite. J. Microscopy 2004, 216, 97-109.

832. Ebaretonbofa, E.; Evans, J.R. High porosity hydroxyapatite foam scaffolds for bone substitute. $J$. Porous Mater. 2002, 9, 257-263.

833. Specchia, N.; Pagnotta, A.; Cappella, M.; Tampieri, A.; Greco, F. Effect of hydroxyapatite porosity on growth and differentiation of human osteoblast-like cells. J. Mater. Sci. 2002, 37, 577-584.

834. Teixeira, C.C.; Nemelivsky, Y.; Karkia, C.; LeGeros, R.Z. Biphasic calcium phosphate: a scaffold for growth plate chondrocyte maturation. Tissue Eng. 2006, 12, 2283-2289. 
835. Artzi, Z.; Weinreb, M.; Givol, N.; Rohrer, M.D.; Nemcovsky, C.E.; Prasad, H.S.; Tal, H. Biomaterial resorbability and healing site morphology of inorganic bovine bone and beta tricalcium phosphate in the canine. A 24-month longitudinal histologic study and morphometric analysis. Int. J. Oral Max. Impl. 2004, 19, 357-368.

836. Dellinger, J.G.; Eurell, J.A.C.; Jamison, R.D. Bone response to 3D periodic hydroxyapatite scaffolds with and without tailored microporosity to deliver bone morphogenetic protein $2 . J$. Biomed. Mater. Res. A 2006, 76A, 366-376.

837. Pal, K.; Pal, S. Development of porous hydroxyapatite scaffolds. Mater. Manuf. Process. 2006, 21, 325-328.

838. Bae, C.J.; Kim, H.W.; Koh, Y.H.; Kim, H.E. Hydroxyapatite (HA) bone scaffolds with controlled macrochannel pores. J. Mater. Sci. Mater. Med. 2006, 17, 517-521.

839. Guo, H.; Wei, J.; Kong, H.; Liu, C.; Pan, K. Biocompatibility and osteogenesis of calcium phosphate cement scaffolds for bone tissue engineering. Adv. Mater. Res. 2008, 47-50 (Part 2), 1383-1386.

840. Guo, H.; Su, J.; Wei, J.; Kong, H.; Liu, C. Biocompatibility and osteogenicity of degradable Cadeficient hydroxyapatite scaffolds from calcium phosphate cement for bone tissue engineering. Acta Biomater. 2009, 5, 268-278.

841. Liu, H.; Webster, T.J. Nanomedicine for implants: a review of studies and necessary experimental tools. Biomaterials 2007, 28, 354-369.

842. Matsumoto, T.; Okazaki, M.; Nakahira, A.; Sasaki, J.; Egusa, H.; Sohmura, T. Modification of apatite materials for bone tissue engineering and drug delivery carriers. Curr. Med. Chem. 2007, 14, 2726-2733.

843. Kim, H.W.; Koh, Y.H.; Kong, Y.M.; Kang, J.G.; Kim, H.E. Strontium substituted calcium phosphate biphasic ceramics obtained by a powder precipitation method. J. Mater. Sci. Mater. Med. 2004, 15, 1129-1134.

844. Vallet-Regi, M.; Arcos, D. Silicon substituted hydroxyapatites. A method to upgrade calcium phosphate based implants. J. Mater. Chem. 2005, 15, 1509-1516.

845. Gbureck, U.; Thull, R.; Barralet, J.E. Alkali ion substituted calcium phosphate cement formation from mechanically activated reactants. J. Mater. Sci. Mater. Med. 2005, 16, 423-427.

846. Kannan, S.; Ventura, J.M.; Ferreira, J.M.F. In situ formation and characterization of flourinesubstituted biphasic calcium phosphate ceramics of varied F-HAP / $\beta$-TCP ratios. Chem. Mater. 2005, 17, 3065-3068.

847. Gbureck, U.; Knappe, O.; Grover, L.M.; Barralet, J.E. Antimicrobial potency of alkali ion substituted calcium phosphate cements. Biomaterials 2005, 26, 6880-6886.

848. Pietak, A.M.; Reid, J.W.; Stott, M.J.; Sayer, M. Silicon substitution in the calcium phosphate bioceramics. Biomaterials 2007, 28, 4023-4032.

849. Tadic, D.; Veresov, A.; Putlayev, V.I.; Epple, M. In vitro preparation of nanocrystalline calcium phosphates as bone substitution materials in surgery. Mat.-Wiss. u. Werkstofftech. 2003, 34, 1048-1051.

850. Lilley, K.J.; Gbureck, U.; Wright, A.J.; Farrar, D.F.; Barralet, J.E. Cement from nanocrystalline hydroxyapatite: effect of calcium phosphate ratio. J. Mater. Sci. Mater. Med. 2005, 16, 1185-1190. 
851. Meejoo, S.; Maneeprakorn, W.; Winotai, P. Phase and thermal stability of nanocrystalline hydroxyapatite prepared via microwave heating. Thermochim. Acta 2006, 447, 115-120.

852. Zhu, X.; Eibl, O.; Berthold, C.; Scheideler, L.; Geis-Gerstorfer, J. Structural characterization of nanocrystalline hydroxyapatite and adhesion of pre-osteoblast cells. Nanotechnology 2006, 17, 2711-2721.

853. Li, H.; Zhu, M.Y.; Li, L.H.; Zhou, C.R. Processing of nanocrystalline hydroxyapatite particles via reverse microemulsions. J. Mater. Sci. 2008, 43, 384-389.

854. Banerjee, A.; Bose, S. Effect of dopants on the properties of nanocrystalline hydroxyapatite. Ceram. Trans. 2005, 164, 91-99.

855. Feng, W.; Sen, L.M.; Peng, L.Y.; Song, G.S. Synthesis of nanocrystalline hydroxyapatite powders in stimulated body fluid. J. Mater. Sci. 2005, 40, 2073-2076.

856. Ito, H.; Oaki, Y.; Imai, H. Selective synthesis of various nanoscale morphologies of hydroxyapatite via an intermediate phase. Cryst. Growth Des. 2008, 8, 1055-1059.

857. Fathi, M.H.; Hanifi, A.; Mortazavi, V. Preparation and bioactivity evaluation of bone-like hydroxyapatite nanopowder. J. Mater. Process. Technol. 2008, 202, 536-542.

858. Li, J.; Chen, Y.; Yin, Y.; Yao, F.; Yao, K. Modulation of nano-hydroxyapatite size via formation on chitosan-gelatin network film in situ. Biomaterials 2007, 28, 781-790.

859. He, Q.; Huang, Z.; Liu, Y.; Chen, W.; Xu, T. Template-directed one-step synthesis of flowerlike porous carbonated hydroxyapatite spheres. Mater. Lett. 2007, 61, 141-143.

860. You, C.; Miyazaki, T.; Ishida, E.; Ashizuka, M.; Ohtsuki, C.; Tanihara, M. Fabrication of poly(vinyl alcohol) - apatite hybrids through biomimetic process. J. Eur. Ceram. Soc. 2007, 27, 1585-1588.

861. Aizawa, M.; Porter, A.E.; Best, S.M.; Bonfield, W. Ultrastructural observation of single-crystal apatite fibres. Biomaterials 2005, 26, 3427-3433.

862. Park, Y.M.; Ryu, S.C.; Yoon, S.Y.; Stevens, R.; Park, H.C. Preparation of whisker-shaped hydroxyapatite / $\beta$-tricalcium phosphate composite. Mater. Chem. Phys. 2008, 109, 440-447.

863. Morisue, H.; Matsumoto, M.; Chiba, K.; Matsumoto, H.; Toyama, Y.; Aizawa, M.; Kanzawa, N.; Fujimi, T.J.; Uchida, H.; Okada, I. A novel hydroxyapatite fiber mesh as a carrier for recombinant human bone morphogenetic protein-2 enhances bone union in rat posterolateral fusion model. Spine 2006, 31, 1194-1200.

864. Matsuda, A.; Ikoma, T.; Kobayashi, H.; Tanaka, J. Preparation and mechanical property of coreshell type chitosan / calcium phosphate composite fiber. Mater. Sci. Eng., C 2004, 24, 723-728.

865. Wu, Y.; Hench, L.L.; Du, J.; Choy, K.L.; Guo, J. Preparation of hydroxyapatite fibers by electrospinning technique. J. Am. Ceram. Soc. 2004, 87, 1988-1991.

866. Ramanan, S.R.; Venkatesh, R. A study of hydroxyapatite fibers prepared via sol-gel route. Mater. Lett. 2004, 58, 3320-3323.

867. Seo, D.S.; Lee, J.K. Synthesis of hydroxyapatite whiskers through dissolution-reprecipitation process using EDTA. J. Cryst. Growth 2008, 310, 2162-2167.

868. Neira, I.S.; Guitián, F.; Taniguchi, T.; Watanabe, T.; Yoshimura, M. Hydrothermal synthesis of hydroxyapatite whiskers with sharp faceted hexagonal morphology. J. Mater. Sci. 2008, 43, 2171-2178. 
869. Ribeiro, C.C.; Barrias, C.C.; Barbosa, M.A. Preparation and characterisation of calciumphosphate porous microspheres with a uniform size for biomedical applications. J. Mater. Sci. Mater. Med. 2006, 17, 455-463.

870. Ribeiro, C.C.; Barrias, C.C.; Barbosa, M.A. Calcium phosphate-alginate microspheres as enzyme delivery matrices. Biomaterials 2004, 25, 4363-4373.

871. Zhou, W.Y.; Wang, M.; Cheung, W.L.; Guo, B.C.; Jia, D.M. Synthesis of carbonated hydroxyapatite nanospheres through nanoemulsion. J. Mater. Sci. Mater. Med. 2008, 19, 103-110.

872. Kim, H.W.; Gu, H.J.; Lee, H.H. Microspheres of collagen-apatite nanocomposites with osteogenic potential for tissue engineering. Tissue Eng. 2007, 13, 965-973.

873. Deville, S.; Saiz, E.; Tomsia, A.P. Freeze casting of hydroxyapatite scaffolds for bone tissue engineering. Biomaterials 2006, 27, 5480-5489.

874. Min, S.H.; Jin, H.H.; Park, H.Y.; Park, I.M.; Park, H.C.; Yoon, S.Y. Preparation of porous hydroxyapatite scaffolds for bone tissue engineering. Mater. Sci. Forum 2006, 510-511, 754-757.

875. Leukers, B.; Gülkan, H.; Irsen, S.H.; Milz, S.; Tille, C.; Schieker, M.; Seitz, H. Hydroxyapatite scaffolds for bone tissue engineering made by 3D printing. J. Mater. Sci. Mater. Med. 2005, 16, 1121-1124.

876. Deville, S.; Saiz, E.; Nalla, R.K.; Tomsia, A.P. Strong biomimetic hydroxyapatite scaffolds. Adv. Sci. Technol. 2006, 49, 148-152.

877. Yang, W.; Zhou, D.; Yin, G.; Chen, H. Progress of biphasic calcium phosphate bioceramic as scaffold materials of bone tissue engineering. J. Chinese Ceram. Soc. 2004, 32, 1143-1149.

878. Tampieri, A.; Celotti, G.; Sprio, S.; Delcogliano, A.; Franzese, S. Porosity-graded hydroxyapatite ceramics to replace natural bone. Biomaterials 2001, 22, 1365-1370.

879. Furuichi, K.; Oaki, Y.; Ichimiya, H.; Komotori, J.; Imai, H. Preparation of hierarchically organized calcium phosphate-organic polymer composites by calcification of hydrogel. Sci. Technol. Adv. Mater. 2006, 7, 219-225.

880. Okamoto, M.; Dohi, Y.; Ohgushi, H.; Shimaoka, H.; Ikeuchi, M.; Matsushima, A.; Yonemasu, K. Hosoi, H. Influence of the porosity of hydroxyapatite ceramics on in vitro and in vivo bone formation by cultured rat bone marrow stromal cells. J. Mater. Sci. Mater. Med. 2006, 17, 327-336.

881. Hench, L.L.; Polak, J.M. Third-generation biomedical materials. Science 2002, 295, 1014-1017.

882. Blawas, A.S.; Reichert, W.M. Protein patterning. Biomaterials 1998, 19, 595-609.

883. Kim, S.S.; Park, M.S.; Jeon, O.; Choi, C.Y.; Kim, B.S. Poly(lactide-co-glycolide) / hydroxyapatite composite scaffolds for bone tissue engineering. Biomaterials 2006, 27, 1399-1409.

884. Pang, L.; Hu, Y.; Yan, Y.; Liu, L.; Xiong, Z.; Wei, Y.; Bai, J. Surface modification of PLGA / $\beta$ TCP scaffold for bone tissue engineering: hybridization with collagen and apatite. Surf. Coat. Technol. 2007, 201, 9549-9557.

885. Kim, S.S.; Ahn, K.M.; Park, M.S.; Lee, J.H.; Choi, C.Y.; Kim, B.S. A poly(lactide-co-glycolide) / hydroxyapatite composite scaffold with enhanced osteoconductivity. J. Biomed. Mater. Res. A 2007, 80A, 206-215. 
886. Li, J.; Beaussart, A.; Chen, Y.; Mak, A.F.T. Transfer of apatite coating from porogens to scaffolds: uniform apatite coating within porous poly(D,L-lactic-co-glycolic acid) scaffold in vitro. J. Biomed. Mater. Res. A 2007, 80A, 226-233.

887. Habraken, W.J.E.M.; Wolke, J.G.C.; Mikos, A.G.; Jansen, J.A. PLGA microsphere / calcium phosphate cement composites for tissue engineering: in vitro release and degradation characteristics. J. Biomater. Sci. Polym. Ed. 2008, 19, 1171-1188.

888. Charles-Harris, M.; Koch, M.A.; Navarro, M.; Lacroix, D.; Engel, E.; Planell, J.A. A PLA / calcium phosphate degradable composite material for bone tissue engineering: an in vitro study. J. Mater. Sci. Mater. Med. 2008, 19, 1503-1513.

889. Liu, X.; Smith, L.A.; Hu, J.; Ma, P.X. Biomimetic nanofibrous gelatin / apatite composite scaffolds for bone tissue engineering. Biomaterials 2009, 30, 2252-2258.

890. Sanchez-Salcedo, S.; Izquierdo-Barba, I.; Arcos, D.; Vallet-Regi, M. In vitro evaluation of potential calcium phosphate scaffolds for tissue engineering. Tissue Eng. 2006, 12, 279-290.

891. Meganck, J.A.; Baumann, M.J.; Case, E.D.; McCabe, L.R.; Allar, J.N. Biaxial flexure testing of calcium phosphate bioceramics for use in tissue engineering. J. Biomed. Mater. Res. A 2005, 72A, 115-126.

892. Case, E.D.; Smith, I.O.; Baumann, M.J. Microcracking and porosity in calcium phosphates and the implications for bone tissue engineering. Mater. Sci. Eng., A 2005, 390, 246-254.

893. Sibilla, P.; Sereni, A.; Aguiari, G.; Banzi, M.; Manzati, E.; Mischiati, C.; Trombelli, L.; del Senno, L. Effects of a hydroxyapatite-based biomaterial on gene expression in osteoblast-like cells. J. Dent. Res. 2006, 85, 354-358.

894. Sawyer, A.A.; Hennessy, K.M.; Bellis, S.L. The effect of adsorbed serum proteins, RGD and proteoglycan-binding peptides on the adhesion of mesenchymal stem cells to hydroxyapatite. Biomaterials 2007, 28, 383-392.

895. Mastrogiacomo, M.; Muraglia, A.; Komlev, V.; Peyrin, F.; Rustichelli, F.; Crovace, A.; Cancedda, R. Tissue engineering of bone: search for a better scaffold. Orthod. Craniofac. Res. 2005, 8, 277-284.

896. Schek, R.M.; Taboas, J.M.; Hollister, S.J.; Krebsbach, P.H. Tissue engineering osteochondral implants for temporomandibular joint repair. Orthod. Craniofac. Res. 2005, 8, 313-319.

897. Krylova, E.A.; Ivanov, A.A.; Krylov, S.E.; Plashchina, I.G.; Grigorjan, A.S.; Goldstein, D.V.; Pulin, A.A.; Fatkhudinov, T.H. Hydroxyapatite - alginate structure as living cells supporting system. Minerva Biotecnol. 2006, 18, 17-22.

898. Hench, L.L. Biomaterials: a forecast for the future. Biomaterials 1998, 19, 1419-1423.

899. Ratner, B.D.; Bryant, S.J. Biomaterials: where we have been and where we are going. Ann. Rev. Biomed. Eng. 2004, 6, 41-75.

900. Drouet, C.; Largeot, C.; Raimbeaux, G.; Estournès, C.; Dechambre, G.; Combes, C.; Rey, C. Bioceramics: spark plasma sintering (SPS) of calcium phosphates. Adv. Sci. Technol. 2006, 49, 45-50.

901. Anderson, J.M. The future of biomedical materials. J. Mater. Sci. Mater. Med. 2006, 17, 1025-1028.

902. White, A.A.; Best, S.M.; Kinloch, I.A. Hydroxyapatite - carbon nanotube composites for biomedical applications: A review. Int. J. Appl. Ceram. Technol. 2007, 4, 1-13. 
903. Kealley, C.; Elcombe, M.; van Riessen, A.; Ben-Nissan, B. Development of carbon nanotubereinforced hydroxyapatite bioceramics. Physica B 2006, 385-386, 496-498.

904. Balani, K.; Anderson, R.; Laha, T.; Andara, M.; Tercero, J.; Crumpler, E.; Agarwal, A. Plasmasprayed carbon nanotube reinforced hydroxyapatite coatings and their interaction with human osteoblasts in vitro. Biomaterials 2007, 28, 618-624.

905. Maitra, A. Calcium phosphate nanoparticles: second-generation nonviral vectors in gene therapy. Exp. Rev. Mol. Diag. 2005, 5, 893-905.

906. Li, Y.H.; Cao, L.Y.; Huang, J.F.; Zeng, X.R. Characteristics and preparation of nanometer hydroxyapatite in medical science. J. Clin. Rehabil. Tiss. Eng. Res. 2008, 12, 8143-8146.

907. For multiphase compositions of various calcium orthophosphates, the problem of accurate phase quantification often arises. The problem is usually solved by the Rietveld refinement and the readers are referred to a recent paper on this subject [908].

908. Reid, J.W.; Hendry, J.A. Rapid, accurate phase quantification of multiphase calcium phosphate materials using Rietveld refinement. J. Appl. Cryst. 2006, 39, 536-543.

909. Dorozhkin, S.V. Green chemical synthesis of calcium phosphate bioceramics. J. Appl. Biomater. Biomech. 2008, 6, 104-109.

910. Mizushima, Y.; Ikoma, T.; Tanaka, J.; Hoshi, K.; Ishihara, T.; Ogawa, Y.; Ueno, A. Injectable porous hydroxyapatite microparticles as a new carrier for protein and lipophilic drugs. $J$. Control. Release 2006, 110, 260-265.

911. Ginebra, M.P.; Traykova, T.; Planell, J.A. Calcium phosphate cements as bone drug delivery systems: a review. J. Control. Release 2006, 113, 102-110.

912. Ginebra, M.P.; Traykova, T.; Planell, J.A. Calcium phosphate cements: competitive drug carriers for the musculoskeletal system? Biomaterials 2006, 27, 2171-2177.

913. Fan, J.; Lei, J.; Yu, C.; Tu, B.; Zhao, D. Hard-templating synthesis of a novel rod-like nanoporous calcium phosphate bioceramics and their capacity as antibiotic carriers. Mater. Chem. Phys. 2007, 103, 489-493.

914. Barrère, F.; Mahmood, T.A.; de Groot, K.; van Blitterswijk, C.A. Advanced biomaterials for skeletal tissue regeneration: instructive and smart functions. Mater. Sci. Eng., $R$ 2008, 59, 38-71.

915. Sudo, A.; Hasegawa, M.; Fukuda, A.; Uchida, A. Treatment of infected hip arthroplasty with antibiotic-impregnated calcium hydroxyapatite. J. Arthroplasty 2008, 23, 145-150.

(C) 2009 by the authors; licensee Molecular Diversity Preservation International, Basel, Switzerland. This article is an open-access article distributed under the terms and conditions of the Creative Commons Attribution license (http://creativecommons.org/licenses/by/3.0/). 